\title{
Anticoagulants for acute ischaemic stroke (Review)
}

\author{
Sandercock PAG, Counsell C, Kane EJ
}

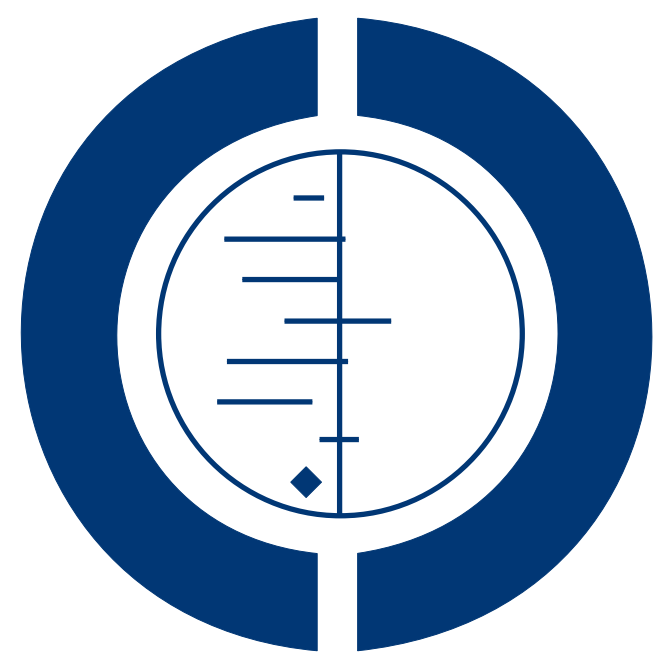

THE COCHRANE COLLABORATION $^{\circledR}$

This is a reprint of a Cochrane review, prepared and maintained by The Cochrane Collaboration and published in The Cochrane Library 2015, Issue 3

http://www.thecochranelibrary.com

\section{WILEY}


TABLE OF CONTENTS

HEADER

ABSTRACT

PLAIN LANGUAGE SUMMARY

BACKGROUND . . . . . . . . . . . . . . . . . . . . . . . . . . . . . . . . . . . . . 2

OBJECTIVES . . . . . . . . . . . . . . . . . . . . . . . . . . . . . . . . . . . . .

METHODS . . . . . . . . . . . . . . . . . . . . . . . . . . . . . . . . . . . . . . 3

RESULTS . . . . . . . . . . . . . . . . . . . . . . . . . . . . . . . . . . . . . . . 6

Figure 1. . . . . . . . . . . . . . . . . . . . . . . . . . . . . . . . . . . . . 7

Figure 2. . . . . . . . . . . . . . . . . . . . . . . . . . . . . . . . . . . . . .

Figure 3. . . . . . . . . . . . . . . . . . . . . . . . . . . . . . . . . . . . . . 14

Figure $4 . \quad$. . . . . . . . . . . . . . . . . . . . . . . . . . . . . . . . . . . . . 415

DISCUSSION . . . . . . . . . . . . . . . . . . . . . . . . . . . . . . . . . . . . .

AUTHORS' CONCLUSIONS . . . . . . . . . . . . . . . . . . . . . . . . . . . . . . . . . . . . . .

ACKNOWLEDGEMENTS . . . . . . . . . . . . . . . . . . . . . . . . . . . . . . . . . . . . . . .

REFERENCES . . . . . . . . . . . . . . . . . . . . . . . . . . . . . . . . . . . . . 18

CHARACTERISTICS OF STUDIES . . . . . . . . . . . . . . . . . . . . . . . . . . . . . . . . . . 23

DATA AND ANALYSES . . . . . . . . . . . . . . . . . . . . . . . . . . . . . . . . . . . . . . . . . . . . . . . 44

Analysis 1.1. Comparison 1 Anticoagulant versus control in acute presumed ischaemic stroke, Outcome 1 Dead or dependent at end of follow up (if $>1$ month). . . . . . . . . . . . . . . . . . . . . . . . . . 47

Analysis 1.2. Comparison 1 Anticoagulant versus control in acute presumed ischaemic stroke, Outcome 2 Death from all causes during treatment period.

Analysis 1.3. Comparison 1 Anticoagulant versus control in acute presumed ischaemic stroke, Outcome 3 Death from all causes at final follow up (if $>1$ month).

Analysis 1.4. Comparison 1 Anticoagulant versus control in acute presumed ischaemic stroke, Outcome 4 Deep vein thrombosis during treatment period.

Analysis 1.5. Comparison 1 Anticoagulant versus control in acute presumed ischaemic stroke, Outcome 5 Symptomatic pulmonary embolism during treatment period.

Analysis 1.6. Comparison 1 Anticoagulant versus control in acute presumed ischaemic stroke, Outcome 6 Recurrent ischaemic or unknown stroke during treatment period.

Analysis 1.7. Comparison 1 Anticoagulant versus control in acute presumed ischaemic stroke, Outcome 7 Symptomatic intracranial haemorrhage during treatment period.

Analysis 1.8. Comparison 1 Anticoagulant versus control in acute presumed ischaemic stroke, Outcome 8 Any recurrent stroke or symptomatic intracranial haemorrhage during treatment period or follow up ( $>1$ month).

Analysis 1.9. Comparison 1 Anticoagulant versus control in acute presumed ischaemic stroke, Outcome 9 Major extracranial haemorrhage during treatment period.

Analysis 1.10. Comparison 1 Anticoagulant versus control in acute presumed ischaemic stroke, Outcome 10 Subgroup analysis by anticoagulant dose: effect on death or dependency. 


\title{
[Intervention Review]
}

\section{Anticoagulants for acute ischaemic stroke}

\author{
Peter AG Sandercock ${ }^{1}$, Carl Counsell ${ }^{2}$, Edward J Kane ${ }^{3}$ \\ ${ }^{1}$ Centre for Clinical Brain Sciences (CCBS), University of Edinburgh, Edinburgh, UK. ${ }^{2}$ Division of Applied Health Sciences, University \\ of Aberdeen, Aberdeen, UK. ${ }^{3}$ University of Edinburgh, Edinburgh, UK \\ Contact address: Peter AG Sandercock, Centre for Clinical Brain Sciences (CCBS), University of Edinburgh, The Chancellor's Building, \\ 49 Little France Crescent, Edinburgh, EH16 4SB, UK. peter.sandercock@ed.ac.uk.
}

Editorial group: Cochrane Stroke Group.

Publication status and date: New search for studies and content updated (no change to conclusions), published in Issue 3, 2015.

Review content assessed as up-to-date: 10 November 2014.

Citation: Sandercock PAG, Counsell C, Kane EJ. Anticoagulants for acute ischaemic stroke. Cochrane Database of Systematic Reviews 2015, Issue 3. Art. No.: CD000024. DOI: 10.1002/14651858.CD000024.pub4.

Copyright (C) 2015 The Cochrane Collaboration. Published by John Wiley \& Sons, Ltd.

\begin{abstract}
A B S T R A C T
Background

Most ischaemic strokes are caused by a blood clot blocking an artery in the brain. Clot prevention with anticoagulants might improve outcomes if bleeding risks are low. This is an update of a Cochrane review first published in 1995, with recent updates in 2004 and 2008.
\end{abstract}

\section{Objectives}

To assess the effectiveness and safety of early anticoagulation (within the first 14 days of onset) in people with acute presumed or confirmed ischaemic stroke.

\section{Search methods}

We searched the Cochrane Stroke Group Trials Register (June 2014), the Cochrane Central Register of Controlled Trials (CENTRAL), the Cochrane Database of Systematic Reviews (CDSR), the Database of Reviews of Effects (DARE) and the Health Technology Assessment Database (HTA) (The Cochrane Library 2014 Issue 6), MEDLINE (2008 to June 2014) and EMBASE (2008 to June 2014). In addition, we searched ongoing trials registries and reference lists of relevant papers. For previous versions of this review, we searched the register of the Antithrombotic Trialists' (ATT) Collaboration, consulted MedStrategy (1995), and contacted relevant drug companies.

\section{Selection criteria}

Randomised trials comparing early anticoagulant therapy (started within two weeks of stroke onset) with control in people with acute presumed or confirmed ischaemic stroke.

\section{Data collection and analysis}

Two review authors independently selected trials for inclusion, assessed trial quality, and extracted the data.

\section{Main results}

We included 24 trials involving 23,748 participants. The quality of the trials varied considerably. The anticoagulants tested were standard unfractionated heparin, low-molecular-weight heparins, heparinoids, oral anticoagulants, and thrombin inhibitors. Over $90 \%$ of the evidence relates to the effects of anticoagulant therapy initiated within the first 48 hours of onset. Based on 11 trials (22,776 participants) there was no evidence that anticoagulant therapy started within the first 14 days of stroke onset reduced the odds of death 
from all causes (odds ratio (OR) 1.05; 95\% confidence interval (CI) 0.98 to 1.12) at the end of follow-up. Similarly, based on eight trials (22,125 participants), there was no evidence that early anticoagulation reduced the odds of being dead or dependent at the end of follow-up (OR 0.99; 95\% CI 0.93 to 1.04). Although early anticoagulant therapy was associated with fewer recurrent ischaemic strokes (OR 0.76; 95\% CI 0.65 to 0.88 ), it was also associated with an increase in symptomatic intracranial haemorrhages (OR 2.55; $95 \%$ CI 1.95 to 3.33 ). Similarly, early anticoagulation reduced the frequency of symptomatic pulmonary emboli (OR $0.60 ; 95 \%$ CI 0.44 to 0.81 ), but this benefit was offset by an increase in extracranial haemorrhages (OR 2.99; 95\% CI 2.24 to 3.99).

\section{Authors' conclusions}

Since the last version of the review, no new relevant studies have been published and so there is no additional information to change the conclusions. Early anticoagulant therapy is not associated with net short- or long-term benefit in people with acute ischaemic stroke. Treatment with anticoagulants reduced recurrent stroke, deep vein thrombosis and pulmonary embolism, but increased bleeding risk. The data do not support the routine use of any of the currently available anticoagulants in acute ischaemic stroke.

\section{PLAIN LANGUAGE SUMMARY}

\section{Anticoagulants for acute ischaemic stroke}

Millions of people around the world have strokes every year. Most strokes take place when a blood clot blocks a blood vessel leading to the brain. Without a proper blood supply, the brain quickly suffers damage, which can be permanent. The damage from a stroke can cause arm or leg weakness, or difficulties with language or vision. Strokes are sometimes fatal, but will more often leave the survivor unable to do the things that they used to do. Because strokes are common and cause such damage, researchers are trying to find ways to get rid of the blood clot soon after the stroke happens. One way to do this is with blood thinning drugs called anticoagulants. If anticoagulants work, the bad effects of the stroke might be avoided. The main problem with anticoagulants is that they can cause bleeding, which can sometimes be very serious. This systematic review was designed to find out whether people treated with anticoagulants soon after having a stroke got better or not, and whether they had problems with bleeding. There is a lot of information in this systematic review - 23,748 people with stroke have been involved in 24 included randomised trials to answer this question. People treated with anticoagulants did not have less long-term disability, and experienced more bleeding. Anticoagulant treated patients had less chance of developing blood clots in their legs and in their lungs following their stroke, but these benefits were offset by the increased number of bleeds. This review did not provide any evidence that the early use of anticoagulants is of overall benefit to people with strokes caused by blood clots. More research is needed to find out if there are ways to select the people with stroke who will benefit from anticoagulants without suffering the bleeding complications.

\section{B A C K G R O U N D}

\section{Description of the condition}

Ischaemic stroke is usually caused by a blood clot blocking flow in an artery supplying parts of the brain and, in Western countries, is approximately 10 times more frequent than haemorrhagic stroke (Andersen 2009). Stroke is the second most common cause of death in the world (Lozano 2012) and the third most common cause of disability (Murray 2012). Globally, death and disability that result from stroke have been increasing in absolute numbers, with the greatest burden being in low and middle income countries (Feigin 2014).

\section{Description of the intervention}

Anticoagulants are agents acting on the coagulation cascade to reduce fibrin polymerisation and thrombus formation and are distinct from thrombolytic and defibrinogenating agents. Agents included in this review include unfractionated heparin, low-molecular-weight heparins, heparinoids, oral vitamin $\mathrm{K}$ antagonists and specific thrombin inhibitors. The control was an inactive intervention, either placebo or no treatment, delivered along with the standard interventions of the respective healthcare systems.

Heparins are administered parenterally (intravenously or subcutaneously) and so have a sufficiently rapid onset to be used in the acute phase of ischaemic stroke whereas oral anticoagulants, such as vitamin $\mathrm{K}$ antagonists and direct thrombin inhibitors, have a

Anticoagulants for acute ischaemic stroke (Review)

Copyright $\odot 2015$ The Cochrane Collaboration. Published by John Wiley \& Sons, Ltd. 
slower onset of effect and may be of less use. Unfractionated heparin, a sulphated polysaccharide, acts by binding to antithrombin to inhibit factor $\mathrm{Xa}$ and deactivate thrombin. Important sideeffects include thrombocytopenia and osteopenia. Low molecular weight heparins are depolymerised heparin fragments approximately one third the size of unfractionated heparin and act primarily to inhibit factor Xa. They have a longer half-life, greater bio-availability and more predictable anticoagulant effect than unfractionated heparin. Heparinoids are glycosaminoglycans whose components catalyse the effect of heparin co-factor 2 to inhibit thrombin. All heparins ultimately prevent fibrin formation and subsequent thrombosis.

\section{How the intervention might work}

Theoretically, early use of anticoagulants may, by reducing the propagation of a thrombus in an intracerebral artery, decrease the volume of infarcted cerebral tissue and so decrease the neurological deficit, risk of disability and death. Additionally, anticoagulants might inhibit the formation of new arterial and venous thromboses and so reduce the risk of early recurrent thromboembolic stroke, deep vein thrombosis and pulmonary embolism. However, these benefits could be offset by the possibility that anticoagulant therapy increases risk of intracranial and extracranial haemorrhage.

\section{Why it is important to do this review}

This is an update of a Cochrane review first published in 1995, and most recently updated in 2008, encompassing all of the randomised trials of anticoagulants versus control in people with acute presumed or confirmed ischaemic stroke. The aim is to establish the balance of risk and benefit of early anticoagulation for acute ischaemic stroke.

\section{O B J E C T I VES}

To assess the effectiveness and safety of early anticoagulation (within the first 14 days of onset) in people with acute presumed or confirmed ischaemic stroke. Our hypotheses were that, compared with a policy of avoiding their use, early anticoagulation would be associated with:

1. a reduced risk of being dead or dependent in activities of daily living a few months after stroke onset;

2. a reduced risk of early recurrent ischaemic stroke;

3. an increased risk of symptomatic intracranial and extracranial haemorrhage; and

4. a reduced risk of deep vein thrombosis and pulmonary embolism.

\section{METHODS}

\section{Criteria for considering studies for this review}

\section{Types of studies}

We sought all unconfounded, truly randomised trials in which early treatment with anticoagulants was compared with control in people with acute presumed or confirmed ischaemic stroke. People with ischaemic stroke due to cerebral venous thrombosis were not specifically included in these trials, and so are not represented in this review. People with transient ischaemic attacks (TIAs) are also not included in this review. We did not include trials in which allocation to treatment or control group was not truly random or where allocation was not adequately concealed (e.g. allocation by alternation, date of birth, hospital number, day of the week, or open random number list), since foreknowledge of treatment allocation could lead to biased treatment allocation, and thereby overestimate the treatment effect by up to $30 \%$ (Odgaard-Jensen 2011). We included trials if it was unclear whether the method of randomisation provided adequate concealment of allocation.

\section{Types of participants}

This review was confined to the early treatment of acute ischaemic stroke, and therefore we excluded the following types of trial: those that randomised participants more than 14 days after stroke onset, those that included only people with TIAs, and those that only included people with intracerebral haemorrhage, confirmed by appropriate brain imaging before entry. We included trials in which the pathological type of stroke was not confirmed by scanning before entry, as the majority of such strokes are ischaemic, at least in the white population (Bamford 1990).

\section{Types of interventions}

Anticoagulants are broadly defined as agents that act on the coagulation cascade to exert an anticoagulant effect, excluding thrombolytic agents (such as alteplase) and defibrinogenating agents (such as ancrod). The use of thrombolytic agents in acute ischaemic stroke is the subject of a separate Cochrane review (Wardlaw 2014), as is the use of fibrinogen depleting agents (Hao 2012). We included the following anticoagulants in this review: subcutaneous and intravenous standard unfractionated heparin, low-molecularweight heparins, subcutaneous and intravenous heparinoids, oral vitamin $\mathrm{K}$ antagonists, factor $\mathrm{Xa}$ inhibitors and specific thrombin inhibitors. 


\section{Types of outcome measures}

For each trial, we identified the number of participants originally randomly allocated to each treatment and control group. In both groups, we sought outcome information regarding the number of participants who met the following outcomes.

\section{Primary outcomes}

1. Death or dependency (i.e. people who were either dead, or dependent on help from other people for their activities of daily living), at least one month after their stroke. This minimum interval was used to allow time for recovery from the initial stroke. Comparable definitions of dependency were used in all of the trials assessed in this review.

\section{Secondary outcomes}

1. Participants who died from any cause during the scheduled treatment period (generally shorter than the scheduled follow-up period).

2. Participants who died from any cause during the scheduled follow-up period (greater than one month after their stroke).

3. Participants with objective evidence of deep vein thrombosis detected by the systematic use of imaging techniques such as iodine 125 fibrinogen scanning (I-125 scan), ultrasound of the leg, plethysmography, or X-ray contrast venography in all participants during the scheduled treatment period and during scheduled follow up. These methods therefore detected clinically silent deep vein thrombosis as well as confirming or refuting the diagnosis in participants with clinical features suggestive of deep vein thrombosis. The outcome was therefore 'symptomatic or asymptomatic deep vein thrombosis.' Screening of participants by clinical observation alone was not considered adequate.

4. Participants with at least one confirmed symptomatic pulmonary embolus diagnosed during life, or at autopsy (symptomatic or not) within the scheduled treatment period and during scheduled follow-up.

5. Particpants with recurrent stroke during the treatment period and during follow-up, which was either definitely ischaemic (haemorrhage excluded by brain imaging or autopsy), or of unknown type (no brain imaging or autopsy performed).

6. Participants with symptomatic intracranial (intra or extracerebral) haemorrhage, including symptomatic haemorrhagic transformation of the cerebral infarct, during the scheduled treatment period and during follow-up. The haemorrhage must have been confirmed by appropriate brain imaging after clinical deterioration, or by autopsy.

7. Participants with any recurrent stroke or symptomatic intracranial haemorrhage during the treatment period or during long-term follow up (as previously defined).

8. Participants with any major extracranial haemorrhage during the scheduled treatment period. The definition of major haemorrhage was usually taken from the original article but if none was given it was defined as any fatal bleed, or bleeding severe enough to require transfusion or operation.

Although we sought trials that reported the primary outcome (dead or dependent at least one month after stroke), we also included data from trials that only reported data on our secondary outcomes.

\section{Search methods for identification of studies}

See the 'Specialized register' section in the Cochrane Stroke Group module. We searched for trials in all languages and arranged translation of relevant papers published in languages other than English

\section{Electronic searches}

We searched the Cochrane Stroke Group Trials Register (last searched June 2014) and the following bibliographic databases and trials registers:

- Cochrane Central Register of Controlled Trials

(CENTRAL) (The Cochrane Library 2014 Issue 6) (Appendix 1);

- Cochrane Database of Systematic Reviews (CDSR) (The

Cochrane Library 2014 Issue 6) (Appendix 1);

- Database of Reviews of Effects (DARE) (The Cochrane Library 2014 Issue 6) (Appendix 1);

- Health Technology Assessment Database (HTA) (The Cochrane Library 2014 Issue 6) (Appendix 1);

- MEDLINE (Ovid; 2008 to June 2014) (Appendix 2);

- EMBASE (Ovid; 2008 to June 2014) (Appendix 3);

- ClinicalTrials.gov (https://clinicaltrials.gov; searched June 2014) (Appendix 4);

- Internet Stroke Center Stroke Trials Registry (http:// www.strokecenter.org/trials/; searched June 2014) (Appendix 4);

- ISRCTN Registry (http://www.isrctn.com/; searched June 2014) (Appendix 4).

Using a comprehensive search strategy the Cochrane Stroke Group Trials Search Co-ordinator has already completed a retrospective search of MEDLINE and EMBASE for all stroke trials to January 2008 and added all relevant trials to the Cochrane Stroke Group Trials Register. To avoid duplication of effort we have limited the search of these two databases from January 2008 onwards.

\section{Searching other resources}

1. We scanned the reference lists of all relevant papers.

2. For previous versions of this review:

i) we contacted the following anticoagulant manufacturers in an effort to identify unpublished trials (last contact 1999): Alfa Wasserman (parnaparin and dermatan sulphate), Kabi (dalteparin), Knoll (reviparin), Leo (tinzaparin), 
Mediolanum (dermatan sulphate), Mitsubishi Chemical (argatroban/MD-805), Novo (tinzaparin), Organon (danaparoid), Rhone-Poulenc Rorer (enoxaparin), Sandoz (Sandoz LMWH), Sanofi Winthrop (nadroparin and CY 222);

ii) we consulted a comprehensive guide to pharmaceutical development in the field of stroke (MedStrategy 1995) but have not updated the search, as relevant trials contained within it are in the Cochrane Stroke Group Trials Register;

iii) we searched the trials register held by the Antithrombotic Trialists' (ATT) Collaboration in August 1998, but this is no longer available and relevant trials from the register are now in the Cochrane Stroke Group Trials Register.

\section{Data collection and analysis}

For this update EK performed the searches following advice from Brenda Thomas (Cochrane Stroke Group Trials Search Co-ordinator). EK and PS then independently screened all the titles and abstracts of the identified references and excluded obviously irrelevant studies. EK obtained the full-text articles of the remaining studies and both EK and PS independently assessed these for inclusion or exclusion. We resolved any disagreements by discussion.

\section{Selection of studies}

Two review authors (PS \& CC, for the trials included in the first version of this review; PS \& Gordon Gubitz for the proceeding two updates following the original review, Ayeesha Kamal \& PS for the most recent update and PS \& EK for this review) independently selected trials for inclusion in the review. We resolved disagreements through discussion. The same two review authors assessed the methodological quality of each trial.

\section{Data extraction and management}

Two review authors independently extracted and cross-checked the data. We sought data on the number of participants with each outcome event, by allocated treatment group, irrespective of compliance, and whether or not the participant was subsequently deemed ineligible or otherwise excluded from treatment or follow-up, to allow an intention-to-treat (ITT) analysis. We also sought data on the use of brain imaging prior to randomisation, the delay from stroke onset to trial entry, the type of patients included, and the type of anticoagulant regimen used. If any of the above data were not available in the publications, we sought further information by correspondence with the trialists.

\section{Assessment of risk of bias in included studies}

For the previous versions of this review, two authors assessed the methodological quality of each trial. We did not use a scoring system to assess trial quality, but simply recorded details of randomisation and concealment methods, blinding, if ITT analyses were possible from the published data (that is, if there were any exclusions from the trial after randomisation) and if any participants were lost to follow-up. We sought data on the number of participants with each outcome event, by allocated treatment group, irrespective of compliance, and whether or not the participant was subsequently deemed ineligible or otherwise excluded from treatment or follow-up, to allow an ITT analysis.

\section{Measures of treatment effect}

The results reported in the text are odds ratios (OR: that is, the ratio of the odds of an unfavourable outcome among treatmentallocated participants to the corresponding odds amongst controls), which we calculated using the Peto fixed-effect method (APT 1994). We calculated the significance of any differences between ORs (in relation to subgroup analyses) using a standard method (Altman 1996). Where relevant, the absolute effects of treatment on each outcome are expressed as the number needed to treat to benefit (NNTB) i.e. to avoid one bad outcome event. For events that are adverse (such as intracranial haemorrhage), this is calculated as the number needed to treat to harm (NNTH). To calculate NNTBs or NNTHs, we used the NNT calculator at http://www.dcn.ed.ac.uk/csrg/entity/entity_NNT2.asp. This applies the point estimate of relative effect and its $95 \%$ confidence interval (CI), and then calculates the NNTB or NNTH for a specified control event rate.

\section{Unit of analysis issues}

All the included studies were trials in which individuals were randomised, and follow-up was generally to a prespecified and fixed time point, and all analyses were by ITT where possible (see Dealing with missing data). For outcomes where more than one event could occur during follow-up, such as non-fatal recurrent stroke, we counted only the first event.

\section{Dealing with missing data}

For some outcomes (such as deep vein thrombosis and any intracranial haemorrhage), ITT analyses were not possible because all participants did not have the relevant investigation performed to detect the event. In these analyses, we used the number of participants in each group who had the appropriate investigation as the denominator for the main analyses. However, if we found statistically significant results we also analysed best and worst case scenarios: the best-case scenario (with regards to treatment) assumed that none of the participants excluded from the analysis in the treatment group had an adverse outcome, whilst all those excluded from the control group did, and vice versa for the worstcase analysis. 


\section{Assessment of heterogeneity}

We tested for heterogeneity between trial results with the $\mathrm{I}^{2}$ test. We used the method described in Bland 2003 to test for interaction between the effect in a specified subgroup and the overall effect.

\section{Assessment of reporting biases}

We sought evidence of publication bias with funnel plots for three outcomes: deep vein thrombosis, death from all causes within the scheduled treatment period and death from all causes by the end of follow-up.

\section{Data synthesis}

We used RevMan 2014 for the analyses, in which we grouped together trials of each type of anticoagulant (e.g. unfractionated heparin, low-molecular-weight heparins, heparinoids, oral vitamin $\mathrm{K}$ antagonists, thrombin inhibitors) to assess whether there were any significant differences between classes of anticoagulant agent. It should be noted that this was an indirect rather than a direct randomised comparison.

We also specified the following classification of anticoagulant dosing regimens.

1. Low fixed-dose anticoagulant, that is a dose intended to be sufficient for the prevention of deep vein thrombosis and pulmonary embolism.

2. Medium fixed-dose anticoagulant, that is a dose intended to have effects on the arterial circulation, but not enough to require monitoring.

3. Adjusted-dose anticoagulant, that is a dose adjusted by blood testing or body weight to meet a specific target.

\section{Subgroup analysis and investigation of heterogeneity}

For this update, we performed subgroup analyses of:

- the type of anticoagulant agent used; and

- the dose of anticoagulant used, applying the classification above.

\section{Sensitivity analysis}

For this update, we performed the following sensitivity analyses, restricting analyses to:

- trials in which the method of randomisation ensured adequate concealment of treatment allocation;

- trials in which all participants were recruited within 48 hours of stroke onset; and

- trials except IST 1997, as this trial contained most of the data for the review.

In the previous version of this review we performed numerous sensitivity analyses to investigate whether the exclusion or inclusion of trials with particular characteristics would alter the overall conclusions. These characteristics included: trials that had intracerebral haemorrhages excluded by neuroimaging prior to trial entry, time from stroke onset (less than 48 hours versus more than 48 hours) to randomisation, concomitant unconfounded treatment with antiplatelet agents, trials in which stroke was of suspected cardioembolic origin versus non-cardioembolic origin, and trials that evaluated different anticoagulant doses. These analyses were not informative and we have excluded them from this updated review for brevity and clarity. In future updates of the review, we do not plan to repeat these analyses unless substantial new trial data had been added.

\section{R E S U L T S}

\section{Description of studies}

\section{Results of the search}

For this update we searched the Cochrane Stroke Group Trials Register and performed additional new comprehensive searches of The Cochrane Library databases, MEDLINE and EMBASE. After removal of duplicate records we screened the titles and abstracts of 8913 records from these electronic bibliographic databases and obtained the full text of six studies, all of which we excluded leaving no new trials for inclusion. The total number of included studies remains unchanged from the last update at 24 trials. See Figure 1. 
Figure I. Study flow diagram for 2014 update

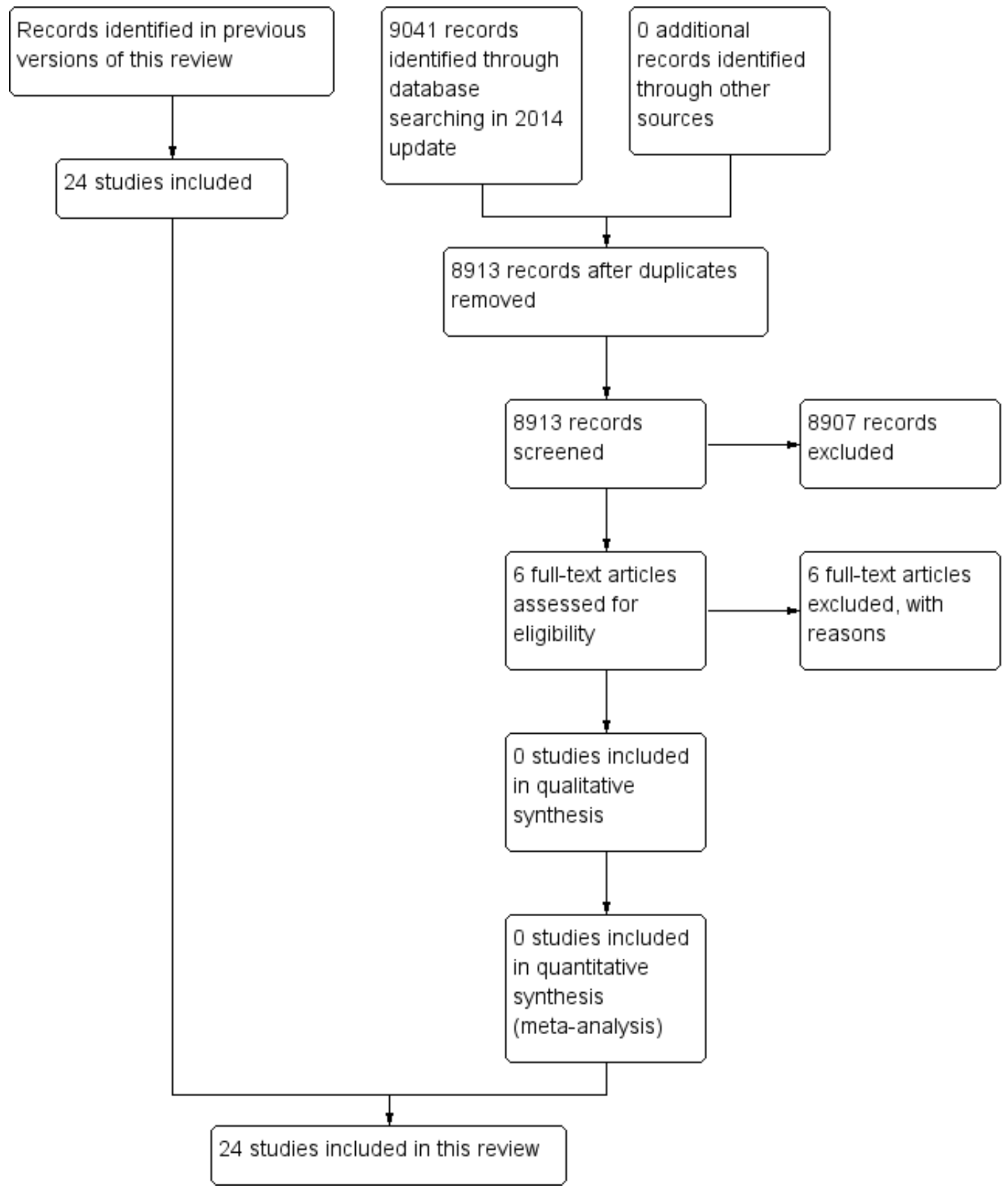


We identified one new ongoing trial from searches of the trials registers (see Characteristics of ongoing studies).

\section{Included studies}

We included 24 trials with a total of 23,748 participants in this review. Summary details of the trials are given in the 'Characteristics of included studies' table. Of the 24 included studies, one enrolled participants within 12 hours of stroke onset (ARGIS-1 2004), two enrolled participants within 24 hours of stroke onset (FISS-bis 1998; TOAST 1998), 10 enrolled participants within 48 hours of stroke onset (Cazzato 1989; CESG 1983; Duke 1983; Duke 1986; Elias 1990; FISS 1995; IST 1997; Kwiecinski 1995; McCarthy 1977; McCarthy 1986), and the rest enrolled participants within 14 days. The age of participants in the included studies ranged from 28 to 92 years. A significant proportion of participants were over 70 years old. For example, $61 \%$ of participants enrolled in IST 1997 were aged 70 or older. Most trials included slightly more males than females. Most trials excluded people thought to be at high risk of bleeding (e.g. clotting disorders, hepatic or renal failure). In addition, 10 trials excluded people with significant degrees of hypertension (generally diastolic pressures greater than $120 \mathrm{mmHg}$ or systolic pressures greater than $180 \mathrm{mmHg}$ ), and nine trials excluded comatose people.

The scheduled period of anticoagulant treatment in the included trials was one to two weeks in 20 trials and one month in four trials. The anticoagulants used were:

- standard unfractionated subcutaneous heparin (six trials);

- standard unfractionated intravenous heparin (two trials);

- low-molecular-weight heparins (eight trials: two dalteparin, two nadroparin, one tinzaparin, one fraxiparin, one parnaparin, and one CY 222);

- subcutaneous heparinoid (two trials: one danaparoid and one mesoglycan);

- intravenous heparinoid (one danaparoid trial);

- oral vitamin K antagonists (two trials); and

- thrombin inhibitors (three trials: two MD805 trials, one argatroban).

In the trials using oral vitamin $\mathrm{K}$ antagonists, heparin was given intravenously for the first few days to provide rapid anticoagulation (Marshall 1960; NAT-COOP 1962). Three trials randomised between two doses of anticoagulant as well as control (FISS 1995; FISS-bis 1998; IST 1997); for the main analyses in this review we combined the two anticoagulant groups for these trials.

Fifteen trials routinely performed a CT head scan in all patients to rule out haemorrhage before randomisation (ARGIS-1 2004; Cazzato 1989; CESG 1983; Duke 1986; Elias 1990; FISS 1995; FISS-bis 1998; Kwiecinski 1995; Pambianco 1995; Prins 1989; Sandset 1990; Tazaki 1986; Tazaki 1992; TOAST 1998; Turpie 1987). Three trials performed CT in most patients (Duke 1983;
IST 1997; Vissinger 1995): eighty-one per cent of participants in Duke 1983 were scanned; in IST 1997, 67\% were scanned before randomisation, and $29 \%$ after randomisation, so that overall, $96 \%$ of participants were scanned; in Vissinger 1995, 66\% of participants were scanned, and the remainder had cerebral scintigraphy to exclude haemorrhage. Three trials performed almost no CT scans (McCarthy 1977; McCarthy 1986; Pince 1981), and two trials were undertaken before CT scanning was introduced (Marshall 1960; NAT-COOP 1962). It is therefore likely that some people with intracerebral haemorrhage were inadvertently included in the main analyses of this review. This may have biased the results against anticoagulation if the risks of anticoagulation are greater in those with intracerebral haemorrhage, although such a bias is unlikely given the relatively small numbers of people with intracerebral haemorrhage involved in these trials, and because IST 1997 provided well over $80 \%$ of the overall data.

Two trials included only participants with presumed cardioembolic stroke (CESG 1983; NAT-COOP 1962). One trial enrolled a subset of people with atrial fibrillation (IST 1997) and detailed information on the effect of heparin in this subgroup was reported in a paper published in 2001 (Saxena 2001).

The duration of follow-up in the trials was generally short, although this was mainly a characteristic of the smaller trials, which contributed less to the overall analysis. Four trials in which the primary outcome of interest was deep vein thrombosis did not follow the participants beyond 14 days (Elias 1990; McCarthy 1977; Pince 1981; Prins 1989), and only 11 trials followed participants for longer than one month (ARGIS-1 2004; Chaudhary 2002; Duke 1986; FISS 1995; FISS-bis 1998; IST 1997; Kwiecinski 1995; Marshall 1960; McCarthy 1986; TOAST 1998; Turpie 1987). This lack of long-term follow-up is a weakness of many of the smaller studies, as a significant proportion of deaths after one month could have been due to stroke-related thromboembolic events and might therefore have been prevented by early anticoagulation. Similarly, disability is best assessed when most of the recovery has taken place (that is between three to six months), rather than in the first week or so.

Relatively few trials assessed the clinically most important outcome of long-term functional status. Treatments that prevent death from stroke may lead to survival in a disabled state - an outcome considered by many to be worse than death. The composite outcome of 'dead or dependent at follow-up' is therefore the most important outcome in acute stroke trials. Eight trials assessed this composite outcome. These trials contain data from well over $90 \%$ of the participants included in this review, and evaluated the outcomes of death and dependency adequately (ARGIS-1 2004; Cazzato 1989; Chaudhary 2002; FISS 1995; FISS-bis 1998; IST 1997; Kwiecinski 1995; TOAST 1998). Other important outcomes, including recurrent stroke or intracranial haemorrhage, were assessed 
but, once again, only by the more recent trials that included large numbers of participants. Quality of life assessments were not undertaken in any of these trials.

\section{Excluded studies}

We excluded 31 studies for a variety of reasons (see Characteristics of excluded studies).

\section{Risk of bias in included studies}

\section{Randomisation}

There was marked variation in the quality of the trials. In 14 trials, the method of randomisation adequately prevented foreknowledge of treatment allocation. IST 1997 used a central telephone randomisation service. TOAST 1998 used permuted blocks to generate a randomisation list controlled by the hospital pharmacy. Eight trials utilised numbered or coded containers administered sequentially to enrolled participants (FISS 1995; FISS-bis 1998; Prins 1989; Sandset 1990; Tazaki 1986; Tazaki 1992; Turpie 1987; Vissinger 1995). Three trials used random-number tables controlled by an independent party (Cazzato 1989; Duke 1983; Duke 1986). The 2:1 treatment-to-control allocation ratio in Turpie 1987, Tazaki 1986, FISS 1995, and FISS-bis 1998 was deliberate. CESG 1983 used opaque sequentially-numbered envelopes. The method of randomisation was unclear in nine trials. Six trials stated that sealed envelopes were used but in five of these it was not clear whether or not the envelopes were opaque and sequentially numbered (Elias 1990; McCarthy 1977; McCarthy 1986; NAT-COOP 1962; Pince 1981). In Pambianco 1995 the envelopes were not numbered. The exact method of randomisation was unknown in ARGIS-1 2004, Chaudhary 2002, Kwiecinski 1995, and Marshall 1960.

\section{Allocation}

Allocation concealment for the following small trials was unclear: ARGIS-1 2004, Chaudhary 2002, Elias 1990, Kwiecinski 1995, Marshall 1960, McCarthy 1977, McCarthy 1986, Pambianco 1995, and Pince 1981. In the remainder we deemed allocation concealment adequate, with low risk of bias.

\section{Blinding}

Adequate blinding may be important to reduce bias in the detection of deep vein thrombosis, pulmonary embolism, symptomatic intracranial haemorrhage, recurrent stroke and functional outcome. Twelve trials were double-blind, that is treatment allocation was concealed from participants, physicians and outcome assessors (ARGIS-1 2004; Duke 1983; Duke 1986; FISS 1995; FISS-bis 1998; Prins 1989; Sandset 1990; Tazaki 1986; Tazaki
1992; TOAST 1998; Turpie 1987; Vissinger 1995), and in two other trials the assessment of deep vein thrombosis was made by radiologists blinded to treatment allocation (McCarthy 1977; McCarthy 1986). Cazzato 1989 had a blinded outcome assessor only. IST 1997 was not designed as a blinded study. However, an analysis of 207 participants from the UK enrolled in the IST pilot study showed that, at the six-month follow-up, the majority of participants could not remember whether or not they had been treated, and so these participants were effectively 'blinded' (Lindley 1993). In IST 1997, follow-up data were collected by self-completed questionnaire mailed to the participant six months after randomisation, or by telephone interview by a person blinded to treatment allocation. The remainder of the trials did not appear to use any form of blinded assessment.

\section{Incomplete outcome data}

In total, only 218 participants ( $0.9 \%$ overall) were reported to be excluded from analysis after randomisation or were lost to followup, with the vast majority of participants enrolled in studies in which an ITT analysis was performed. However, a number of participants in the smaller trials that did not report an ITT analysis may have been omitted from the analysis.

\section{Selective reporting}

We were only able to assess this for IST 1997 and did not have access to the original protocols of the remaining studies. There was no evidence of reporting bias for IST 1997.

\section{Other potential sources of bias}

\section{Long-term use of antiplatelet agents}

In trials with follow-up, differences in the long-term use of antiplatelet treatment between the anticoagulant and control groups after hospital discharge may have biased the results, as antiplatelet treatment has been shown to reduce the risk of further vascular events by about 25\% (ATC 2002). Aspirin was given to all survivors in FISS 1995. Long-term treatment with aspirin was encouraged, but optional in several other trials, including IST 1997, FISS-bis 1998 and TOAST 1998. Aspirin ( $81 \mathrm{mg}$ to $325 \mathrm{mg}$ ) was also used in both arms of the ARGIS-1 2004 trial of the direct thrombin inhibitor argatroban.

\section{Imbalance at baseline}

None of the trials reported significant imbalances in important baseline prognostic variables, although the small size of many suggests that they might only be ruling out substantial differences. 


\section{Effects of interventions}

\section{Outcome I.I: Dead or dependent at end of follow up more than one month after randomisation}

Eight trials including randomised data from 22,125 participants (93.2\% of participants included in the overall review) evaluated death and long-term disability. The degree of dependence was determined by noting whether the participants required help from other people for their activities of daily living at the time of final follow-up. Treatment with early anticoagulation was not associated with a significant reduction in the odds of being dead or dependent at final follow up (odds ratio (OR) 0.99; 95\% confidence interval (CI) 0.93 to 1.04, Analysis 1.1). There was, however, substantial heterogeneity of treatment effect $\left(\mathrm{I}^{2}=47.7 \%\right)$ between the different regimens included.

\section{Subgroup analyses}

\section{By the type of anticoagulant agent used}

The heterogeneity in the overall estimate was attributable to the non-significant trends to benefit associated with low-molecularweight heparins and subcutaneous heparinoid regimens, and trend to harm associated with direct thrombin inhibitor (OR 1.28; $95 \%$ CI 0.62 to 2.62 ).

\section{By the dose of anticoagulant agent}

There was no statistically significant difference in death or dependence at final follow-up between trials in which low fixed-dose anticoagulants were compared with control (OR 1.00; 95\% CI 0.92 to 1.08 ), or in which medium fixed-dose anticoagulants (OR 0.98 ; $95 \%$ CI 0.91 to 1.06 ) or adjusted-dose anticoagulants were compared with control (OR 0.95; 95\% CI 0.75 to 1.20 ).

\section{Sensitivity analyses}

Sensitivity analyses restricted to:

- trials in which the method of randomisation ensured adequate concealment of treatment allocation showed that all of the trials evaluating death and dependence at final follow-up had adequate concealment of the randomisation process;

- trials that restricted entry to the study to less than 48 hours of stroke onset showed that all trials evaluating death or dependence at final follow-up enrolled participants within 48 hours of stroke onset. Within IST 1997 there was no evidence that the effect of treatment increased or decreased with increasing delay to randomisation up to 48 hours;

- trials other than IST 1997 (since it contained most of the data for the review) showed no apparent difference in the effect of treatment on death or dependence at final follow-up if data from IST were included (OR 0.99; 95\% CI 0.94 to 1.05 ) or excluded (OR $0.92 ; 95 \%$ CI .78 to 1.09 ).

In a post-hoc sensitivity analysis to assess the impact of duration of follow-up on the estimate of effect for the primary outcome, exclusion of the trial with assessment of the primary outcome after only one month (Cazzato 1989) had no impact on the overall estimate of effect (OR 0.99; 95\% CI 0.94, 1.04) or the degree of heterogeneity $\left(\mathrm{I}^{2}=55 \%\right)$.

\section{Outcome I.2: Death from all causes during the scheduled treatment period}

Data from 21 trials, which included randomised data from 22,562 participants ( $95 \%$ of participants included in the review) were available for this outcome. Anticoagulants were not associated with a significant reduction in death at the end of the treatment period (OR 0.99; $95 \%$ CI 0.90 to 1.09 , Analysis 1.2 ). There was no significant heterogeneity $\left(\mathrm{I}^{2}=15.8 \%\right)$.

Outcome I.3: Death from all causes at final follow-up more than one month after randomisation

Data were available for 11 trials, which included 22,776 participants ( $95.9 \%$ of participants included in the overall review). Anticoagulants were not associated with any significant reduction in the odds of death at final follow-up of greater than one month (OR 1.05; 95\% CI 0.98 to $1.12, \mathrm{I}^{2}=28.5 \%$, Analysis 1.3 ).

\section{Outcome I.4: Deep vein thrombosis during the treatment period}

Ten trials, which included randomised data from 916 participants (only $3.9 \%$ of participants included in the overall review), sought to systematically determine the effect of anticoagulants on the occurrence of 'symptomatic or asymptomatic deep vein thrombosis' at the end of the treatment period, as detected by:

- I-125 fibrinogen scanning (Duke 1983; Elias 1990; McCarthy 1977; McCarthy 1986; Pince 1981; Prins 1989; Turpie 1987);

- B-mode and Doppler ultrasound (Pambianco 1995); or

- X-ray contrast venography (Sandset 1990; Vissinger 1995).

Despite the small numbers of participants studied, anticoagulation was associated with a highly significant reduction in the odds of deep vein thrombosis (OR $0.21 ; 95 \%$ CI 0.15 to 0.29 , Analysis $1.4)$, although the majority of deep vein thromboses detected were subclinical and asymptomatic. Assuming a control event rate of $15 \%$, this would be equivalent to an NNTB of $9(95 \%$ CI 9 to 10). To calculate NNTBs for different control event rates, we used the NNT calculator at http://www.dcn.ed.ac.uk/csrg/entity/ entity NNT2.asp. Fifteen participants (10 in the treatment group, five in the control group) did not have an adequate assessment of 
deep vein thrombosis and therefore we excluded them from this analysis, however even if we included these participants under a worst-case scenario the results did not change significantly (OR $0.23)$.

There was significant heterogeneity between the trial results $\left(\mathrm{I}^{2}=\right.$ $71.5 \%$ ), which appeared to be due to three trials that did not show any clear effect of anticoagulation on the odds of deep vein thrombosis (Pambianco 1995; Sandset 1990; Vissinger 1995) and two trials that did (Elias 1990; McCarthy 1986). The three negative trials were the only ones that did not use I-125 fibrinogen scanning. One used ultrasound assessment (Pambianco 1995) while the other two used venography (Sandset 1990; Vissinger 1995). In addition, in one of these trials, participants were randomised up to 14 days after their initial stroke (Pambianco 1995) whereas the other trials all randomised participants within seven days. The two most positive trials had very small numbers of participants, with the resultant possibility that the results may have been due to chance. In addition, McCarthy 1986 (the most positive trial) was poorly concealed, introducing another potential source of bias. Sensitivity analyses showed that there was no significant difference in the reduction in deep vein thrombosis from the above result if the analysis was restricted to trials where the concealment of allocation was secure (OR $0.45 ; 95 \%$ CI 0.26 to 0.78 ) or to trials in which radiographic assessment was blinded (OR 0.21; 95\% CI 0.15 to 0.29 ). One of the trials excluded from this review did provide data on the numbers of deep vein thromboses in the participants by allocated treatment group (1/19 heparin, 3/27 placebo), but inclusion of these results did not significantly alter the analysis (Dahan 1986). No trials systematically sought to assess deep vein thrombosis after the end of the treatment period.

\section{Outcome I.5: Symptomatic pulmonary embolism during the treatment period}

Fourteen trials, which included data from 22,544 participants (95.7\% of participants included in the overall review), assessed reported fatal and non-fatal symptomatic pulmonary embolism, but no trial had systematically sought asymptomatic pulmonary embolism by performing ventilation-perfusion scans in all participants at the end of the treatment period. Anticoagulation was associated with a significant reduction in the odds of pulmonary embolism (OR 0.60; 95\% CI 0.44 to $0.81, \mathrm{I}^{2}=13.7 \%$, Analysis $1.5)$.

In the trials described, the frequency of pulmonary embolism during the treatment period was variable, but quite low (1\% in IST 1997 versus 7\% in Elias 1990 and Prins 1989). Although not reported systematically, and thereby potentially under-reported, the rate of pulmonary embolism in IST 1997 in participants not receiving heparin was only $0.8 \%$. This observation is supported by data from prospective hospital-based studies that have reported symptomatic pulmonary embolism as a complication in between $1 \%$ and $3 \%$ of patients with acute stroke (Davenport 1996). Ap- plying the observed odds reduction in pulmonary embolism and assuming a control event rate of $2 \%$, this effect translated into an NNTB of 127 (95\% CI 91 to 268), although this may be an underestimate of the reduction in risk due to incomplete ascertainment.

Patients may continue to be at risk of pulmonary embolism after the early treatment period. This was suggested by data from three trials that continued to seek events systematically during the follow-up period (FISS 1995; TOAST 1998; Turpie 1987). Eight further pulmonary emboli were recorded, six of which were in the control group. The potential use of antiplatelet or anticoagulant agents after the trial period may have influenced the results of several trials (FISS 1995; TOAST 1998; Turpie 1987). One trial, with an $80 \%$ autopsy rate, did show a significant reduction in the risk of symptomatic and asymptomatic pulmonary embolism detected at autopsy in the anticoagulation group (7/24 versus 33/ 47, OR 0.19; 95\% CI 0.07 to 0.52) (McCarthy 1986).

\section{Outcome 1.6: Recurrent ischaemic stroke or recurrent stroke of unknown pathological type during the treatment period}

Eleven trials, which included 21,605 participants (90.9\% of participants included in the overall review) systematically sought to record early recurrent strokes that were definitely ischaemic (CT scan excluded haemorrhage) or probably ischaemic, that is in which the cerebral pathology was unknown because a CT scan had not been performed. Anticoagulation was associated with a statistically significant reduction in recurrent ischaemic stroke (OR 0.76 ; $95 \%$ CI 0.65 to $0.88, \mathrm{I}^{2}=0$, Analysis 1.6 ) which, assuming a control event rate of $4 \%$, translated into an NNTB of $108(95 \%$ CI 74 to 266). The majority of the data (95\%) were obtained from one trial (IST 1997).

\section{Outcome I.7: Symptomatic intracranial haemorrhage during the treatment period}

Sixteen trials, which included randomised data from 22,943 participants $(96.6 \%$ of participants included in the overall review) reported data on symptomatic (fatal and non-fatal) intracranial haemorrhage confirmed by CT scanning or autopsy. Early anticoagulation significantly increased symptomatic intracranial haemorrhages by more than twofold (OR 2.55; 95\% CI 1.95 to 3.33 , $\mathrm{I}^{2}=0$, Analysis 1.7 ). Assuming a control event rate of $0.5 \%$, this is equivalent to a NNTH of 131 (95\% CI 88 to 213$)$. The majority of data $(76 \%)$ were contributed by one trial (IST 1997).

There was no significant heterogeneity in the excess of haemorrhages with different types of heparin. However, within IST 1997, intracranial haemorrhage significantly increased with increasing heparin dose. Participants allocated to avoid heparin, low-dose heparin, and medium-dose heparin had rates of intracranial haemorrhage of $0.3 \%, 0.7 \%$ and $1.8 \%$ respectively. 
There is the possibility of some bias within these data, as there may have been a lower threshold for rescanning participants who had deteriorated clinically if they were known to be receiving anticoagulants (for example in IST 1997, which was not blinded). In addition, even in blinded trials, a physician is likely to be unblinded if bruising is observed at heparin injection sites. An unbiased assessment of the effect of anticoagulants on the occurrence of intracranial haemorrhage would come from systematic studies, in which all participants undergo a CT scan before the beginning of treatment to exclude haemorrhage, and all survivors have a repeat CT scan at the end of the scheduled treatment period, regardless of their clinical status. In such an unbiased assessment, all participants who died during the study would also have to undergo an autopsy. Unfortunately, it is rarely possible to achieve repeat CT scans in all survivors, or autopsies in all deaths. Five trials in this review made a systematic attempt to detect both symptomatic and asymptomatic intracranial haemorrhage in this way (ARGIS-1 2004; CESG 1983; FISS 1995; Prins 1989; Sandset 1990). All of the confirmed intracranial haemorrhages were intracerebral. In FISS 1995 the use of systematic CT scanning was introduced during the trial and so not all participants were eligible for this analysis. However, the numbers of participants and events in this analysis were small (symptomatic plus asymptomatic haemorrhages occurring in 20/266 participants (7.5\%) allocated anticoagulant versus $27 / 264$ control participants $(10.2 \%)$ ) so the estimate of risk of 'symptomatic plus asymptomatic' haemorrhage is imprecise (OR 0.76 ; $95 \%$ CI 0.38 to 1.52$)$. In these trials, 25 participants $(5 \%$ overall, 15 treated versus 10 control) did not have a repeat CT scan or autopsy. Including these 25 participants in hypothetical best and worst-case analyses changed the odds ratio significantly (OR 0.44 and 1.44 respectively), which suggests that the results are compatible with either substantial reductions or increases in the risk of 'symptomatic plus asymptomatic' intracranial haemorrhages with treatment.

\section{Outcome 1.8: Any recurrent stroke or symptomatic intracranial haemorrhage during the treatment period and during long-term follow-up}

Early anticoagulation reduces the odds of ischaemic stroke but also increases the odds of symptomatic intracranial haemorrhage. An outcome that combines these two (without double counting - that is, each participant is counted only once, even if both events occurred, with the first event being the one which is included) is useful for assessing the net short-term effects of anticoagulants. Eleven trials, which included randomised data from 21,605 participants ( $96.0 \%$ of participants included in the overall review), evaluated the occurrence of 'any recurrent stroke or symptomatic intracranial haemorrhage' during the treatment period. Anticoagulation was not associated with a net reduction in the odds of this outcome (OR 0.97; 95\% CI 0.85 to $1.11, \mathrm{I}^{2}=31.3 \%$, Analysis 1.8 ). The majority of the data (93.6\%) were obtained from IST 1997. An analysis of the recurrent strokes or intracranial haemorrhages during the follow-up period could only include data from three small studies (FISS 1995; Marshall 1960; Turpie 1987). There were far too few events for a reliable analysis.

\section{Outcome I.9: Major extracranial haemorrhage during the treatment period}

Eighteen trials, which included randomised data from 22,255 participants $(93.7 \%$ of participants included in the overall review), reported data on major extracranial haemorrhage (defined as bleeding serious enough to cause death or require hospitalisation or transfusion). Anticoagulation was associated with a significant three-fold increase in major extracranial haemorrhage (OR 2.99; $95 \%$ CI 2.24 to $3.99, \mathrm{I}^{2}=4 \%$, Analysis 1.9$)$. Assuming a control event rate of $0.4 \%$, this is equivalent to an NNTH of $128(95 \%$ CI 85 to 204).

\section{Publication bias}

To determine whether or not we might have missed an important number of small negative trials (these are the trials most likely to remain unpublished) we undertook a funnel plot analysis (Egger 1997). The analyses with the most number of trials included (and hence the greatest statistical power) were the effects of treatment on death during the treatment period (Figure 2), death from all causes at final follow-up (Figure 3) and deep vein thrombosis ( Figure 4). For these outcomes, a plot of the sample size for each trial versus the odds ratio for that trial showed an approximate 'funnel distribution' with 'tails' in both the positive and negative treatment effect directions (except in the outcome of deep vein thrombosis) indicating that we were unlikely to have missed a substantial number of negative trials. 
Figure 2. Death from all causes during the treatment period

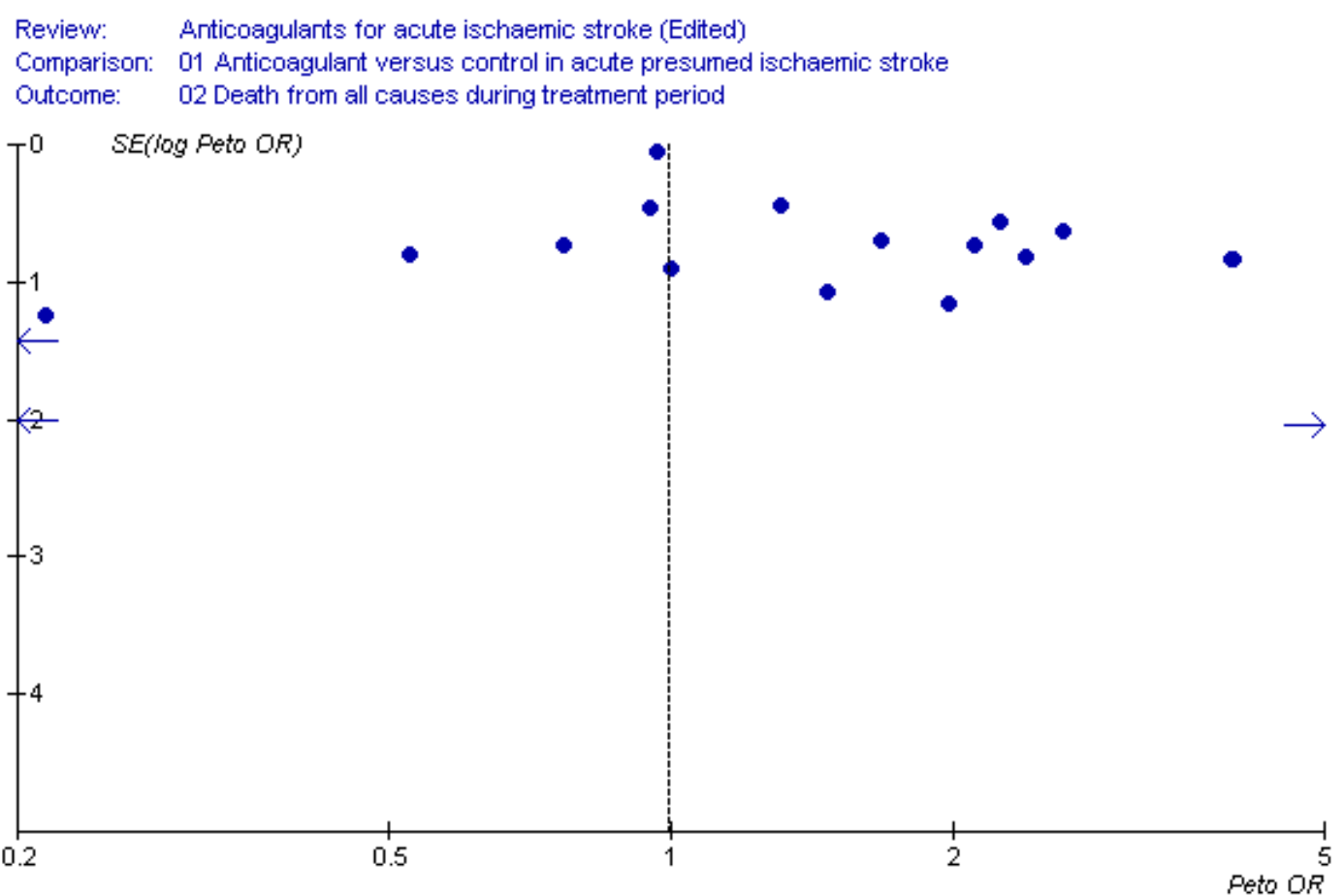


Figure 3. Death from all causes during final follow up

Review: Anticoagulants for acute ischaemic stroke (Edited)

Comparison: 01 Anticoagulant versus control in acute presumed ischaemic stroke

Outcome: $\quad 03$ Death from all causes at final follow up (if $>1$ month)

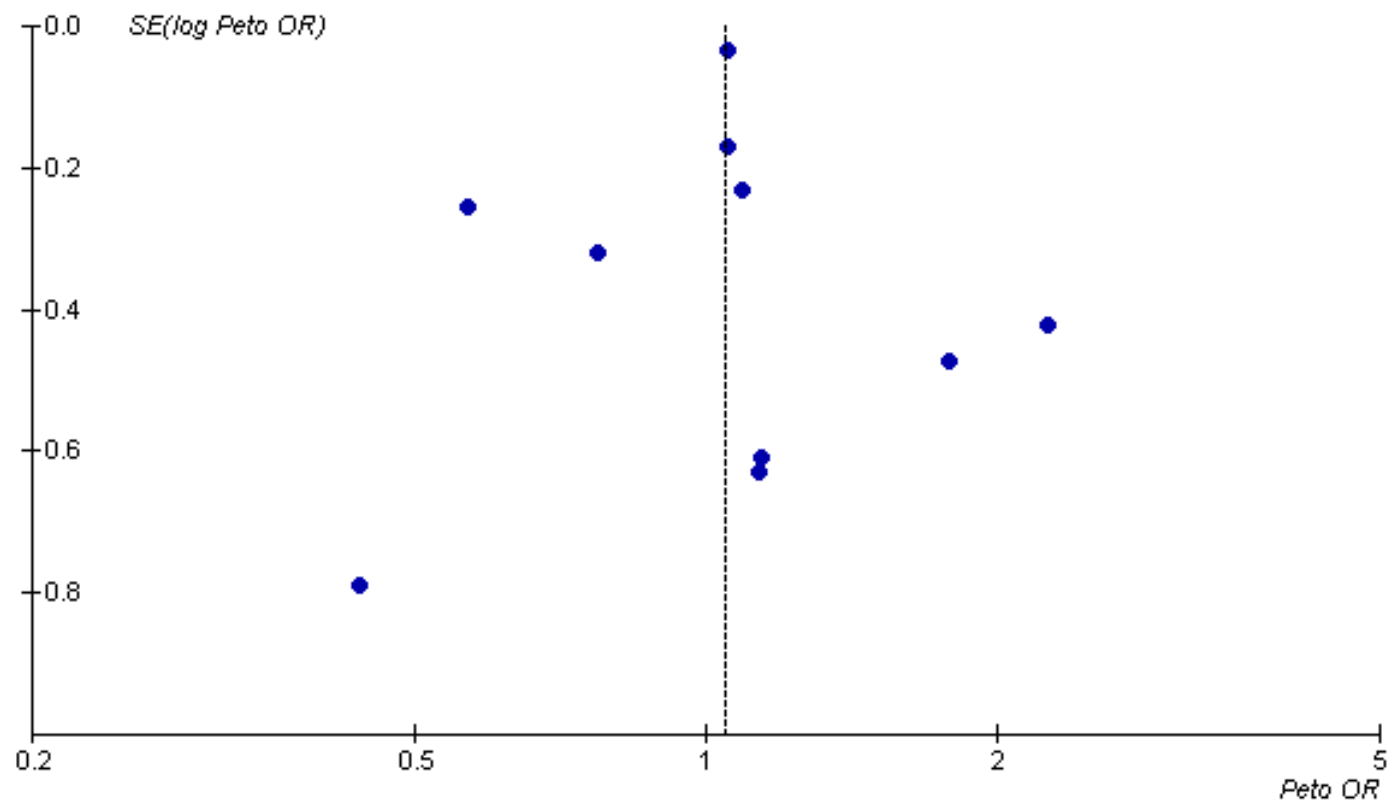




\section{Figure 4. Funnel plot of deep vein thrombosis during follow-up showing asymmetry}

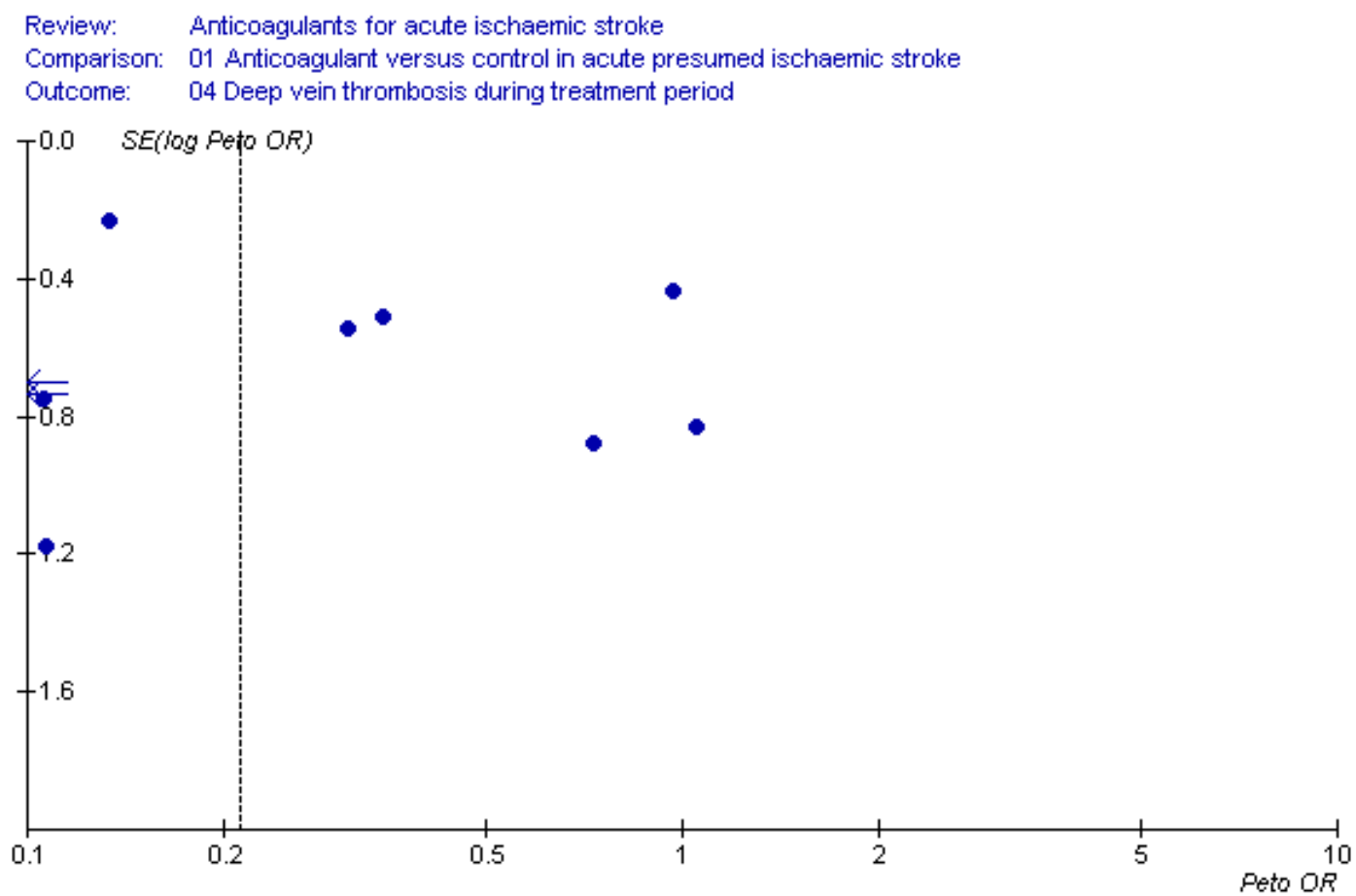

\section{DISCUSSIO N}

The evidence provided in this updated systematic review has not changed any of the conclusions of the previous review published in 2008 , and can be summarised as follows.

\section{Summary of main results}

\section{Net effect of early anticoagulants in acute ischaemic stroke}

Acute stroke treatments should aim to prevent disability as well as death, lest patients survive their acute stroke only to remain severely disabled. The currently available evidence from randomised trials indicates that routine early anticoagulation does not provide any significant net short or long-term reduction in death or disability. Although early anticoagulation leads to fewer recurrent ischaemic strokes (NNTB 108), this benefit is entirely offset by a similar-sized increase in intracranial haemorrhages (NNTH 131). The net result is no short or long-term benefit.

\section{Hazards of early anticoagulants in acute ischaemic stroke}

In order to be useful, a medical therapy must be safe. The current evidence from randomised trials demonstrates a clinically and statistically significant risk of major intra and extracranial haemorrhage with the early use of anticoagulants in people with acute ischaemic stroke.

\section{Different anticoagulant agents, doses and routes of administration}

The present evidence from randomised trials does not suggest that any one anticoagulant regimen is superior to any other. Indirect comparisons of unfractionated heparin, low-molecular-weight heparin, heparinoids and specific thrombin inhibitors have shown no significant net benefit in terms of reducing death during the treatment period, or death or dependency after follow-up greater than one month. Direct comparisons of different anticoagulants show no clear benefit of heparinoids versus unfractionated heparin (Sandercock 2008). The available evidence does not support the routine use of adjusted-dose intravenous heparin (or heparinoid) regimens, or of more intensive fixed-dose regimens. 


\section{Prevention of deep vein thrombosis and pulmonary embolism in acute ischaemic stroke with anticoagulants}

In participants with presumed or confirmed ischaemic stroke, allocation to early anticoagulation was associated with a highly significant $79 \%$ reduction in the odds of deep vein thrombosis during the treatment period, similar to that seen with the use of prophylactic heparin in people undergoing different types of surgery (Collins 1988). In this review, the reductions in deep vein thrombosis with acute anticoagulation were statistically significant, though this estimate is based on relatively small numbers of participants, and most of the deep vein thromboses detected were asymptomatic. There was also significant heterogeneity in the effects of treatment, which renders the overall estimate less reliable.

The clinical significance of this reduction depends critically on the control event rate. In the included studies, there was substantial variation in the control event rate from 13\% in Vissinger 1995 to $73 \%$ in McCarthy 1986. The rate will depend on many factors such as the severity of the stroke, the presence of leg paralysis and a history of previous deep vein thrombosis (Warlow 2008). The odds of pulmonary embolism were reduced significantly with the use of anticoagulants by $40 \%$. In the included trials, pulmonary embolism was uncommon, so assuming the $0.8 \%$ control rate seen in the largest trial with the most representative sample of participants (IST 1997), the NNTB was 315, though with a perhaps more realistic control event rate of $2 \%$ it would be 127 . The overall risk of pulmonary embolism appeared to be low, and the absolute benefit was small, and so the apparent reduction in deep vein thrombosis may have little clinical relevance if there is not a correspondingly large reduction in pulmonary embolism. However, there may well have been under-ascertainment of pulmonary embolism in all of the trials, since data on pulmonary emboli were not sought systematically. In addition, deep vein thrombosis can lead to morbidity (such as post-phlebitic leg and varicose ulcers), but data on these outcomes were not available from the trials. Finally, it is possible that once anticoagulants are stopped, rebound thrombosis could occur, and deep vein thromboses may begin to develop. We were unable to exclude this possibility because no trials sought data on deep vein thrombosis systematically after the treatment period.

If anticoagulants result in no net increase or decrease in longterm death or disability, but do lead to a reduction in the number of deep vein thromboses and pulmonary emboli (albeit in immobile patients at higher risk), then the benefit of fixed heparin regimens associated with a low risk of bleeding (for example low fixed-dose unfractionated or low-molecular weight heparin) may yet outweigh the increased risk of haemorrhage. A low deep vein thrombosis risk reduces the justification for unselective thromboprophylaxis with heparin. In IST 1997 the frequency of fatal and non-fatal symptomatic pulmonary embolism (perhaps a surrogate for the occurrence of deep vein thrombosis) was very similar among participants allocated low-dose subcutaneous heparin alone $(0.8 \%)$ and aspirin alone $(0.7 \%)$. Aspirin alone may therefore be an adequate antithrombotic agent to be used for routine deep vein thrombosis prophylaxis in some people with acute ischaemic stroke, as antiplatelet drugs, when used for prophylaxis of deep vein thrombosis and pulmonary embolism prophylaxis in other categories of high-risk patients are of modest benefit (ATC 2002). The recent CLOTS-3 2013 study has demonstrated that for people with ischaemic and haemorrhagic stroke, intermittent pneumatic compression reduces the risk of deep vein thrombosis after stroke, without any increased bleeding risk, and is effective both in the presence and absence of background heparin therapy. The effects observed on deep vein thrombosis and pulmonary embolism in the present review indicate there might be a net benefit of low-dose heparin regimens among patients who are at high risk of venous thromboembolism, but at relatively low risk of intracranial or major extracranial bleeding. PREVAIL 2007 illustrates some of the difficulty in identifying subgroups who might have a favourable balance of risk and benefit. In that study, although the risk of venous thromboembolism (VTE) (symptomatic plus asymptomatic) was significantly lower among participants allocated enoxaparin, the study could not exclude a $69 \%$ increase in the risk of death up to day 14 and a $134 \%$ increase in the risk of intracranial haemorrhage with enoxaparin. This was because the event rates for the more major clinical outcomes were low: among the participants allocated unfractionated heparin, pulmonary embolism occurred in $1 \%$ and intracerebral haemorrhage in $1 \%$. With such low event rates, conducting randomised trials large enough to reliably determine the balance of risk and benefit on these major clinical outcomes is challenging. In conclusion, the data from the present review were insufficient to reliably identify a subgroup that might benefit from heparin for thromboprophylaxis.

\section{Overall completeness and applicability of evidence}

This systematic review provides information about the use of anticoagulants in unselected people with ischaemic stroke as well as limited information about various subgroups. Given that many of the trials were conducted more than 20 years ago, are these results still relevant to clinical practice in the 21 st century? In the sense that they represent the totality of evidence comparing treatment with control, they remain relevant to current practice in many parts of the world and continue to be cited in stroke treatment guidelines. The pattern of background treatment has changed, with many patients now being treated within organised stroke units (in the developed world at least). This might have an impact on the absolute risks and benefit of anticoagulation, but is less likely to influence the estimates of relative effect, and hence in our view - the results remain relevant. Anticoagulants are also sometimes advocated for the treatment of acute carotid dissection and cerebral venous thrombosis. Separate Cochrane reviews have been prepared for these topics (Lyrer 2010; Coutinho 2011). We 
were reluctant to pursue further subgroup analysis, since it is hazardous to explore subgroup effects when there is no significant overall effect of an intervention on major outcomes and we only had access to major outcomes. A more detailed assessment of the effects of anticoagulants in other categories of patient (for example patients treated within three hours, patients with large-artery strokes, patients with carotid stenosis) would however, be possible with an individual patient data meta-analysis.

The stroke patients included in the trials of anticoagulants to prevent deep vein thrombosis generally had quite severe strokes, and paralysis of one leg (with the attendant high risk of deep vein thrombosis) was almost invariably present at randomisation. If, however, one accepts the estimate of treatment effect from these trials in the 1980s and 1990s, it is then difficult to assess the extent to which it may be generalisable to clinical practice from 2000 onwards. In current practice, the risk of deep vein thrombosis may well be low, since many patients are admitted to stroke units, receive aspirin, maintain good hydration, and are generally mobilised early.

With that qualification in mind, the small amounts of (randomised) subgroup data evaluated here do not provide any evidence to support the routine use of anticoagulants in any specific category of stroke patient.

\section{Quality of the evidence}

The bulk of the evidence in this review comes from trials with adequate allocation concealment, which is a strength. However, IST 1997 - by far the largest trial - was unblinded - which may well have led to ascertainment bias especially for the early outcomes. The final outcome, however, was assessed at a time when patients could not accurately recall their treatment allocation, so in all likelihood the assessment of the primary outcome was probably not materially biased.

\section{Potential biases in the review process}

This review is based on an analysis of tabular data, which limits the extent to which effects in subgroups can be explored. However, an individual patient data meta-analysis has been performed. The included trials measured the primary outcome at differing times after randomisation, ranging from one to six months after randomisation, as we did not have access to individual patient level data to calculate person-days or hazard ratios. In considering the impact of differing lengths of follow-up on the primary outcome, a post hoc-sensitivity analysis excluding the study with less than three months follow-up did not alter the overall estimate of effect or reduce the heterogeneity.

\section{Agreements and disagreements with other studies or reviews}

Lederle 2011 is a systematic review of venous thromboembolism prophylaxis in hospitalised medical patients and those with stroke, and concluded "Heparin prophylaxis had no significant effect on mortality, may have reduced PE (pulmonary embolism) in medical patients and all patients combined, and led to more bleeding and major bleeding events, thus resulting in little or no net benefit. No differences in benefits or harms were found according to type of heparin used." Similarly, there was no clear difference in effects between people with stroke and with other non-surgical causes for hospital admission. A number of guideline statements have since been developed; the most recent American Stroke Association Guidelines (AHA Guidelines 2012) include two specific recommendations that are supported by the evidence provided in this systematic review. These are as follows.

- Urgent anticoagulation, with the goal of preventing early recurrent stroke, halting neurological worsening, or improving outcomes after acute ischaemic stroke, is not recommended for treatment of patients with acute ischaemic stroke.

- At present, the usefulness of argatroban or other thrombin inhibitors for treatment of patients with acute ischaemic stroke is not well established.

An individual patient data meta-analysis of the large trials of heparin in acute ischaemic stroke was recently able to explore subgroup effects in greater detail, with the aim of identifying the subgroup of patients most likely to derive net benefit from heparin. However, the authors concluded: "There was no evidence that patients with ischaemic stroke who were at higher risk of thrombotic events or lower risk of haemorrhagic events benefited from heparins. We were, therefore, unable to define a targeted approach to select the patients who would benefit from treatment with early anticoagulant therapy." (Whiteley 2013).

\section{A U THORS'CONCLUSIONS}

\section{Implications for practice}

Evidence from this systematic review indicates that, compared with control, the types of anticoagulants tested in people with acute ischaemic stroke have no effect in terms of death in the short term, or death or dependency after follow-up of at least one month. A reduction in recurrent ischaemic stroke during the treatment period is exactly offset by an increase in intracranial haemorrhage. Although anticoagulants decrease deep vein thrombosis and pulmonary embolus, these benefits are once again offset by similarsized increases in extracranial haemorrhage.

The data do not support the routine use of early high-dose intravenous or subcutaneous anticoagulants in any form for peo- 
ple with acute ischaemic stroke. Low-dose subcutaneous regimens will prevent deep vein thrombosis, but with a small but definite increased risk of major haemorrhage. It may therefore be advisable to consider safer alternatives in immobile patients (such as aspirin, compression stockings, or early mobilisation).

The data reviewed from trials comparing these agents with control do not support the use of low-molecular-weight heparins, heparinoids or thrombin inhibitors in the treatment of acute ischaemic stroke.

The analysis performed did not identify any category of patient where there was clear net benefit. Clinicians who feel compelled to use early anticoagulants for specific categories of patients following acute ischaemic stroke should weigh any potential theoretical benefits with the known risk of bleeding. Aspirin is an effective antithrombotic alternative to anticoagulation that is safe when used in the acute phase of ischaemic stroke.

\section{Implications for research}

This review has not provided reliable evidence on a number of important categories of patient with acute cerebrovascular disease who might plausibly derive net benefit from early anticoagulation (very recent transient ischaemic attacks (within hours or days of onset), crescendo transient ischaemic attacks and progressing ischaemic stroke are a few examples) and further trials targeted at these groups (perhaps with new agents) may be warranted. The choice of comparator agent against which to test any anticoagulant will depend on a number of factors, but further trials comparing anticoagulants against control seem unlikely.

Those clinicians who wish to continue to use intensive intravenous dose-adjusted heparin regimens routinely to treat specific categories of stroke patient should provide convincing evidence from new randomised controlled trials to support such practices.

This review has not provided clear evidence about the optimum antithrombotic regimen for the prevention of deep vein thrombosis and pulmonary embolism in stroke patients. Aspirin alone, low- dose subcutaneous heparin, and the use of graded compression stockings are all promising possibilities, but a very large scale randomised trial with several tens of thousands of participants would be required to determine which (or which combination) has the most favourable balance of risk and benefit on overall clinical outcome.

\section{ACKNOW LEDGEMENTS}

We would like to thank individual trialists for supplying additional information: Professor B Boneu for providing us with a copy of Dr Pince's thesis; Dr Duke and Dr R Kay (FISS 1995); Dr G Pambianco and Dr H Magnani from Organon International for supplying additional information on the trial using danaparoid (Turpie 1987); Dr L Antonutti and Dr M Zorzon (Cazzato 1989); Dr Ewa Lindenstrom from Leo Pharmaceuticals for data on tinzaparin (Vissinger 1995); Dr M Lamonte who provided additional data on the ARGIS study (ARGIS-1 2004); H Willems who helped identify many of the early trials; Dr E Dick for supplying us with a copy of the MedStrategy document 'Stroke: A focus on opportunity'; Dr AGM van den Belt and Dr RI Lindley who helped produce the previously published version of this review (Sandercock 1993); and Hazel Fraser for supplying regular lists of trials identified by the Cochrane Stroke Group's search strategy. David Signorini was a co-author of an earlier version of the review. Dr Gord Gubitz contributed to earlier versions of this review. We also acknowledge the help given by the secretariat of the Antithrombotic Trialists' Collaboration (Dr C Baigent, Dr C Sudlow). We would like to acknowledge Brenda Thomas, Steff Lewis and Hazel Fraser of the Cochrane Stroke Group for their input and expertise in completing the update of this review.

\section{Ongoing trials}

Anyone who knows of additional trials that we have omitted, please write to Dr Peter Sandercock.

\section{RE F E R E N C E S}

\section{References to studies included in this review}

ARGIS-1 2004 \{published and unpublished data\} LaMonte MP, Nash ML, Wang DZ, Woolfenden AR, Schulz J, Hursting MJ, et al. Argatroban anticoagulation in patients with acute ischemic stroke (ARGIS-1). Stroke 2004;35:1677-82.

Cazzato 1989 \{published and unpublished data\} Cazzato G, Zorzon M, Mase G, Antonutto L, Iona LG. Mesoglycan in the treatment of acute cerebral infarction
[Il mesoglicano nelle ischemie cerebrali acute a focolaio]. Rivista di Neurologia 1989;59:121-6.

CESG 1983 \{published and unpublished data\}

* Hakim AM, Furlan AJ, Hart RG. Immediate anticoagulation of embolic stroke: a randomized trial. The Cerebral Embolism Study Group. Stroke 1983;14:668-76. Hakim AM, Ryder-Cooke A, Melanson D. Sequential computerized tomographic appearances of strokes. Stroke 1983;14:893-7. 
Chaudhary 2002 \{published data only\}

Chaudhry HR, Arora H, Yadav K, Dubey S, Gupta R, Jain R. Low molecular weight heparin In acute ischemic stroke. The Antiseptic 2002;99:31-2.

Duke 1983 \{published and unpublished data\}

Duke RJ, Turpie AGG, Bloch RF, Derby IR, Kronby $\mathrm{MH}$, Bayer NH. Clinical trial of low-dose heparin for the prevention of stroke progression. Circulation 1980;Suppl III: 21 .

* Duke RJ, Turpie AGG, Bloch RF, Trebilcock RG. Clinical trial of low-dose subcutaneous heparin for the prevention of stroke progression: natural history of acute partial stroke and stroke-in-evolution. In: Reivich M, Hurtig HI editor (s). Cerebrovascular Disease. New York: Raven Press, 1983: 399-405.

Duke 1986 \{published and unpublished data\} Duke RJ, Bloch RF, Turpie AGG. Heparin in acute partial stable stroke. Annals of Internal Medicine 1987;106:782.

* Duke RJ, Bloch RF, Turpie AGG, Trebilcock RG, Bayer N. Intravenous heparin for the prevention of stroke progression in acute partial stable stroke. Annals of Internal Medicine 1986;105:825-8.

Easton JD, Sherman DG, Hart RG. Heparin in acute partial stable stroke. Annals of Internal Medicine 1987;106:781.

Loeliger EA. Heparin in acute partial stable stroke. Annals of Internal Medicine 1987;106:781-2.

Elias 1990 \{published and unpublished data\}

Elias A, Milandre L, Lagrange G, Aillaud MF, Alonzo B, Toulemonde F, et al. Prevention of deep venous thrombosis of the leg by a very low molecular weight heparin fraction (CY 222) in patients with hemiplegia following cerebral infarction: a randomized pilot study (30 patients). Revue de Medecine Interne 1990;11:95-8.

FISS 1995 \{published and unpublished data\}

Kay R. Fraxiparin in stroke study. Stroke 1994;25:253.

* Kay R, Wong KS, Lu YL, Chan YW, Tsoi TH, Ahuja AT, et al. Low-molecular-weight heparin for the treatment of acute ischemic stroke. New England Journal of Medicine 1995;333:1588-93.

FISS-bis 1998 \{published data only\}

Hommel M, for the FISS-bis Investigators Group.

Fraxiparine in Ischaemic Stroke Study (FISS bis).

Cerebrovascular Diseases 1998;8 Suppl 4:19.

IST 1997 \{published data only\}

* International Stroke Trial Collaborative Group. The International Stroke Trial (IST): a randomised trial of aspirin, subcutaneous heparin, both, or neither among 19435 patients with acute ischaemic stroke. Lancet 1997; 349:1569-81.

International Stroke Trial Pilot Study Collaborative Group. Study design of the International Stroke Trial (IST), baseline data, and outcome in 984 randomised patients in the pilot study. Journal of Neurology Neurosurgery and Psychiatry 1996;60:371-6.

Saxena R, Lewis S, Berge E, Sandercock P, Koudstaal P, for the International Stroke Trial Collaborative Group. Risk of early death and recurrent stroke and effect of heparin in 3169 patients with acute ischaemic stroke and atrial fibrillation in the International Stroke Trial. Stroke 2001; 32:2333-7.

Kwiecinski 1995 \{published and unpublished data\} Kwiecinski H, Pniewski J, Kaminska A, Szyluk B. A randomized trial of fraxiparine in acute ischaemic stroke. Cerebrovascular Diseases 1995;5:234.

Marshall 1960 \{published data only\}

* Marshall J, Shaw DA. Anticoagulant therapy in acute cerebrovascular accidents: a controlled trial. Lancet 1960;1: 995-8.

Marshall J, Shaw DA. Anticoagulant therapy in cerebrovascular disease. Proceedings of the Royal Society of Medicine. 1960:547-9.

McCarthy 1977 \{published and unpublished data\} McCarthy ST, Turner JJ, Robertson D, Hawkey CJ, Macey DJ. Low dose heparin as a prophylaxis against deep-vein thrombosis after acute stroke. Lancet 1977;ii:800-1.

McCarthy 1986 \{published and unpublished data\} McCarthy ST, Turner J. Low-dose subcutaneous heparin in the prevention of deep-vein thrombosis and pulmonary emboli following acute stroke. Age and Ageing 1986;15: 84-8.

NAT-COOP 1962 \{published data only\} * Baker RN, Broward JA, Fang HC, Fisher CM, Groch $\mathrm{SN}$, Heyman A, et al. Anticoagulant therapy in cerebral infarction. Report on co-operative study. Neurology 1962; 12:823-9.

Miller Fisher C. Anticoagulant therapy in cerebral thrombosis and cerebral embolism. A national cooperative study, interim report. Neurology 1961;11:119-31.

Pambianco 1995 \{published and unpublished data\} Desmukh M, Bisignani M, Landau P, Orchard TJ. Deep vein thrombosis in rehabilitating stroke patients. Incidence, risk factors and prophylaxis. American Journal of Physical Medicine and Rehabilitation 1991;70:313-6.

* Pambianco G, Orchard T, Landau P. Deep vein thrombosis: prevention in stroke patients during rehabilitation. Archives of Physical Medicine and Rehabilitation 1995;76:324-30.

Pince 1981 \{unpublished data only\}

Pince J. Thromboses veineuses des membres inferieurs et embolies pulmonaires au cours des accidents vasculaires cerebraux. A propos d'un essai comparitif de traitement preventif (These pour le doctorat d'etat en medecine). Toulouse: Universite Paul Sabatier, 1981.

Prins 1989 \{published and unpublished data\} * Prins MH, Gelsema R, Sing AK, van Heerde LR, den Ottolander GJ. Prophylaxis of deep venous thrombosis with a low-molecular-weight heparin (Kabi 2165/Fragmin) in stroke patients. Haemostasis 1989;19:245-50. Prins $\mathrm{MH}$, den Ottolander GJH, Gelsema R, van Woerkom TCM, Sing AK, Heller I. Deep venous thrombosis prophylaxis with a LMW heparin (KABI 2165) in stroke patients. Thrombosis and Haemostasis 1987;58:117. 


\section{Sandset 1990 \{published and unpublished data\}}

Sandset PM, Dahl T, Abildgaard U. Venous thromboembolic complications in acute thrombotic stroke. Progress report from a randomized trial. Acta Neurologia Scandinavica 1987;76:392.

* Sandset PM, Dahl T, Stiris M, Rostad B, Scheel B, Abildgaard U. A double-blind and randomized placebocontrolled trial of low molecular weight heparin once daily to prevent deep-vein thrombosis in acute ischemic stroke. Seminars in Thrombosis and Hemostasis 1990;16 Suppl: 25-33.

Tazaki 1986 \{published data only\} Tazaki Y, Kobayashi S, Togi H, Ohtomo E, Goto F, Araki $\mathrm{G}$, et al. Therapeutic effect of thrombin inhibitor MD-805 in acute phase of cerebral thrombosis - Phase II doubleblinded clinical trial (English translation). Rinsho to Kenkyu (Japanese Journal of Clinical and Experimental Medicine) 1986;63:3047-57.

Tazaki 1992 \{published data only\} Tazaki Y, Kobayashi S, Togi H, Ohtomo E, Goto F, Araki $\mathrm{G}$, et al. Clinical usefulness of thrombin inhibitor MD805 in acute phase of cerebral thrombosis - double blinded comparative study using placebo as a control (English translation). Igaku no Ayumi (Journal of Clinical and Experimental Medicine) 1992;161:887-907.

TOAST 1998 \{unpublished data only\}

Adams JHP. Trial of Org 10172 in Acute Stroke Treatment (TOAST). Stroke 1994;25:545.

* TOAST Investigators. Low molecular weight heparinoid, ORG 10172 (Danaparoid), and outcome after acute ischaemic stroke. JAMA 1998;279:1265-72.

Turpie 1987 \{published and unpublished data\}

Turpie AGG. Low molecular weight heparins: deep vein thrombosis prophylaxis in elective hip surgery and thrombotic stroke. Acta Chirurgica Scandinavica Supplementum 1988;543:85-6.

Turpie AGG, Levine MN, Hirsh J, Carter CJ, Jay RM, Powers PJ, et al. A double-blind randomized trial of Org 10172 low molecular weight heparinoid in the prevention of deep venous thrombosis in patients with thrombotic stroke. Thrombosis and Haemostasis 1987;58:123.

* Turpie AGG, Levine MN, Hirsh J, Carter CJ, Jay RM, Powers PJ, et al. Double-blind randomised trial of Org 10172 low-molecular-weight heparinoid in prevention of deep-vein thrombosis in thrombotic stroke. Lancet 1987;1: 523-6.

Vissinger 1995 \{unpublished data only\}

Vissinger H, Husted S. Trial of tinzaparin versus placebo in ischaemic stroke. Unpublished work.

\section{References to studies excluded from this review}

\section{Bradshaw 1975 \{published data only\}}

Bradshaw P, Brennan S. Trial of long-term anticoagulant therapy in the treatment of small stroke associated with a normal carotid angiogram. Journal of Neurology Neurosurgery and Psychiatry 1975;38:642-7.
Camerlingo 2005 \{published data only\}

Camerlingo M, Salvi P, Belloni G, Gamba T, Cesana BM, Mamoli A. Intravenous heparin started within the first 3 hours after onset of symptoms as a treatment for acute non lacunar hemispheric cerebral infarctions. Stroke 2005;36: 2415-20.

Carter 1961 \{published data only\}

* Carter AB. Anticoagulant treatment in progressing stroke. BMJ 1961;II:70-3.

Carter AB. Use of anticoagulants in patients with progressive cerebral infarction. Neurology 1961;11:601-9.

COU 9116 \{unpublished data only\}

Oczkowski WJ. A randomised trial of fixed low dose warfarin in the prevention of deep vein thrombosis in patients undergoing rehabilitation after stroke (Cou 9116). Unpublished protocol.

Czechanowski 1981 \{published data only\}

Czechanowski B, Heinrich F. Prevention of venous thrombosis in recent ischaemic cerebrovascular accident: double-blind study with heparin-dihydroergotamine. Deutsche Medizinische Wochenschrift 1981;106:1254-60.

Dahan 1986 \{published data only\}

Dahan R, Houlbert D, Caulin C, Cuzin E, Viltart C, Woler $\mathrm{M}$, et al. Prevention of deep vein thrombosis in elderly medical in-patients by a low molecular weight heparin: a randomized double-blind trial. Haemostasis 1986;16: 159-64.

Dan 2001 \{published data only\}

Dan G, Gonta A, Serbanescu A, Ionete C. Improvement of outcome in patients with acute ischaemic stroke treated with fragmin. Haemostasis 2001;30 Suppl 2:168-9.

\section{Dehen 1994 \{unpublished data only\}}

Dehen $\mathrm{H}$, on behalf of Laboratoire Houde. Double blind placebo controlled study of dermatan sulphate in acute middle cerebral artery infarct [Etude en double aveugle, controlee contre placebo, du dermatane sulfate (RU 54 701) dans le traitement precoce de l'infarctus sylvien]. Unpublished work.

Enger 1965 \{published data only\} Enger E, Boyesen S. Long term anticoagulant therapy in patients with cerebral infarction: a controlled clinical study. Acta Medica Scandinavica 1965;178 Suppl 438:7-61.

Eriksson 1983 \{published data only\}

Eriksson S-E, Link H. Evaluation of anticoagulants in patients with cerebral infarction with slight to moderate neurological deficit. Acta Neurologica Scandinavica 1983; 68:96-106.

Gelmers 1980 \{published data only\} Gelmers HJ. Effects of low-dose subcutaneous heparin on the occurrence of deep vein thrombosis in patients with ischemic stroke. Acta Neurologica Scandinavica 1980;61: 313-8.

Kang 2010 \{published data only\} Kang K, Kim DW, Park H-K, Yoon B-W. Optimal dosing of intravenous unfractionated heparin bolus in transient 
ischaemic attack or stroke. Clinical and Applied Thrombosis/ Haemostasis 2010;16(2):126-31.

Kario 1995 \{published data only\}

Kario K, Kodama K, Koide M, Matsuo T. Thrombin inhibition in the acute phase of ischaemic stroke using argatroban. Blood Coagulation and Fibrinolysis 1995;6: 423-7.

Kobayashi 1997 \{published data only\}

Kobayashi S, Tazaki Y. Effect of the thrombin inhibitor argatroban in acute cerebral thrombosis. Seminars In Thrombosis and Hemostasis 1997;23:531-4.

Lee 1994 \{published data only\} Lee JH, Seo DC, Kim JS, Lee MC. Therapeutic efficacy of urokinase and heparin in acute ischemic stroke. Stroke 1994;25:268.

Lee 2008 \{published data only\} Lee SH, Ahn YM, Ahn SY, Doo HK, Lee BC. Interaction between warfarin and panax ginseng in ischaemic stroke patients. Journal of Alternative and Complimentary Medicine 2008;14(6):715-21.

Luo 2013 \{published data only\} Luo W-L, He Y, Lee M, Ceng W. Safety and effects of using warfarin early in adult patients with cerebral venous and sinus thrombosis. Cerebrovascular Diseases 2013;36 Suppl 1:51.

McCarthy 1993 \{unpublished data only\} McCarthy S, McWalter R, Durkin CJ, Hallawi AH, Magnani HN, Pearson J, et al. Org 10172 for the prophylaxis of deep venous thrombosis in the legs (A protocol to establish the efficacy and safety of once or twice daily subcutaneous Org 10172 injections versus placebo in three groups of 60 non-haemorrhagic stroke victims). Unpublished protocol.

\section{McDevitt 1959 \{published data only\}}

Groch SN, McDevitt E, Wright IS. A long-term study of cerebral vascular disease. Annals of Internal Medicine 1961; 55:358-67.

* McDevitt E, Groch SN, Wright IS. A cooperative study of cerebrovascular disease. Circulation 1959;20:215-23. McDowell F, McDevitt E. Treatment of the completed stroke with long-term anticoagulant: six and one-half years experience. In: Siekert RG, Whisnant JP editor(s). Cerebral Vascular Diseases. New York: Grune \& Stratton Inc, 1965: 185-99.

McDowell F, McDevitt E, Wright IS. Anticoagulant therapy: five years' experience with the patient with an established cerebrovascular accident. Archives of Neurology 1963;8:209-14.

Meredit 2009 \{published data only\}

Meredit T, Ahmad O, Harvey I, Hughes A, Lindley R, Neeman T, et al. The Acute Cardioembolic Stroke Trial. International Journal of Stroke 2009;4 Suppl 1:20-1.

Rosin 1994 \{unpublished data only\}

Rosin A, Abramovitz Z. Preventing deep venous thrombosis following acute strokes. Unpublished protocol.
Shi 2004 \{published data only\}

Shi J, Zhang Y. The clinical observation of low molecular weight heparin calcium in treating patients with acute cerebral infarction. Pharmaceutical Care and Research 2004; 4:258-9.

Stiekema 1988 \{unpublished data only\}

Stiekema JCJ, Egberts J, Voerman J. An open, randomised, rising dose, pilot two-centre study of Org 10172 administered for the purpose of deep vein thrombosis prophylaxis in patients with a non-haemorrhagic stroke on recent onset. Organon International, 1988 (SDG Release Report 2244).

\section{Tan 1998 \{published data only\}}

Tan L, Li TS, Zhao RL. Nardoparin in treating cerebral embolism and thrombosis. Chinese Journal of New Drugs and Clinical Remedies 1998;17:325-6.

Thygesen 1964 \{published data only\}

Thygesen P, Christensen E, Dyrbye M, Eiken M, Franzen E, Gormsen J, et al. Cerebral apoplexy: a clinical, radiological, electroencephalographic and pathological study with special reference to the prognosis of cerebral infarction and the result of long-term anticoagulant therapy. Danish Medical Bulletin 1964;11:233-57.

Tomek 2011 \{published data only\} Tomek A, Matoska V, Kumstyrova T, Sramek M, Sarbochova I, Stovickova K, et al. Warfarin loading dose guided by pharmacogenetics is effective and safe in cardioembolic stroke patients. Cerebrovascular Diseases 2011;31 Suppl 2: 31.

Tsuchiya 1989 \{published data only\}

Tsuchiya T, Fujikake K, Oku K. Effects of urokinase and heparin on haemorrhagic infarction, recanalisation, recurrence - analysis of 111 cases with middle cerebral artery occlusion on a prospective controlled trial [author's translation]. Japanese Journal of Stroke 1989;11:500-10.

Tsuchiya 1990 \{published data only\} Tsuchiya T, Fujikake K, Oku K. A study on clinical effects of urokinase and heparin for acute lacunar infarcts in a prospective controlled trial. Japanese Journal of Stroke 1990; 11:177-84

VA Study 1961 \{published data only\} Baker RN. An evaluation of anticoagulant therapy in the treatment of cerebrovascular disease. Report of the Veterans Administration Cooperative Study of Atherosclerosis, Neurology Section. Neurology 1961;11:132-8.

Zhang 2005 \{published data only\} Zhang DJ, Zhu SW, Cui QX, Li YZ, Zhang HM, Xia $\mathrm{ZL}$, et al. Clinical study of low molecular weight heparin calcium and aspirin therapy on acute cerebral infarction. Clinical Pharmacology 2005;40:634-6.

Zhao 2014 \{published data only\} Zhao G. Apixaban versus Dual-antiplatelet therapy (clopidogrel and aspirin) in Acute Non-disabling Cerebrovascular Events (ADANCE). Clinicaltrials.gov (accessed June 2014). 


\section{References to ongoing studies}

\section{Nosal 2014 \{published and unpublished data\}}

Nosal V. Safety and efficacy of heparin and nadroparin in the acute phase of ischemic stroke (Heparinas). https:// clinicaltrials.gov/ct2/show/NCT01862978 (accessed June 2014).

\section{Additional references}

\section{AHA Guidelines 2012}

Jauch EC, Saver JL, Adams HP Jr, Bruno A, Connors JJ, Demaerschalk BM, et al. Guidelines for the early management of adults with ischemic stroke. Stroke 2012; 44:870-947.

\section{Altman 1996}

Altman DG, Matthews JNS. Interaction 1: heterogeneity of effects. BMJ 1996;313:486.

Andersen 2009

Andersen KK, Olsen TS, Dehlendorff C, Kammersgaard LP. Hemorrhagic and ischemic strokes compared: stroke severity, mortality, and risk factors. Stroke 2009;40(6): 2068-72.

\section{APT 1994}

Antiplatelet Trialists' Collaboration. Collaborative overview of randomised trials of antiplatelet therapy. I: Prevention of death, myocardial infarction, and stroke by prolonged antiplatelet therapy in various categories of patients. $B M J$ 1994;308:81-106.

\section{ATC 2002}

Antithrombotic Trialists' Collaboration. Collaborative meta-analysis of randomised trials of antiplatelet therapy for prevention of death, myocardial infarction, and stroke in high risk patients. BMJ 2002;324:71-86.

Bamford 1990

Bamford J, Sandercock P, Dennis M, Burn J, Warlow C. A prospective study of acute cerebrovascular disease in the community: The Oxfordshire Community Stroke Project 1981-1986. 2. Incidence, case fatality and overall outcome at one year of cerebral infarction, primary intracerebral haemorrhage and subarachnoid haemorrhage. Journal of Neurology, Neurosurgery and Psychiatry 1990;53:16-22.

\section{Bland 2003}

Bland M, Altman D. Tests for interaction. BMJ 2003;326: 219.

\section{CLOTS-3 2013}

CLOTS (Clots in Legs Or sTockings after Stroke) Trials Collaboration. Effectiveness of intermittent pneumatic compression in reduction of risk of deep vein thrombosis in patients who have had a stroke (CLOTS 3): a multicentre randomised controlled trial. Lancet 2013;382:516-24.

\section{Collins 1988}

Collins R, Scrimgeour A, Yusuf S, Peto R. Reduction in fatal pulmonary embolism and venous thrombosis by perioperative administration of subcutaneous heparin. New England Journal of Medicine 1988;318:1162-73.

\section{Coutinho 2011}

Coutinho J, de Bruijn SFTM, deVeber G, Stam J. Anticoagulation for cerebral venous sinus thrombosis. Cochrane Database of Systematic Reviews 2011, Issue 8. [DOI: $10.1002 / 14651858 . C D 002005]$

\section{Davenport 1996}

Davenport R, Dennis M, Wellwood I, Warlow C. Complications after acute stroke. Stroke 1996;27:415-20.

Egger 1997

Egger M, Davey Smith G, Schneider M, Minder C. Bias in meta-analysis detected by a simple, graphical test. $B M J$ 1997;315:629-34.

Feigin 2014

Feigin VL, Forouzanfar MH, Krishnamurthi R, Mensah GA, Connor M, Bennett DA, et al. Global and regional burden of stroke during 1990-2010: findings from the Global Burden of Disease Study 2010. Lancet 2014;383 (9913):245-54

\section{Hao 2012}

Hao Z, Liu M, Counsell C, Wardlaw JM, Lin S, Zhao X. Fibrinogen depleting agents for acute ischaemic stroke. Cochrane Database of Systematic Reviews 2012, Issue 3. [DOI: 10.1002/14651858.CD000091]

\section{Lederle 2011}

Lederle FA, Zylla D, MacDonald R, Wilt T. Venous thromboembolism prophylaxis in hospitalized medical patients and those with stroke: a background review for an American College of Physicians Clinical Practice Guideline. Annals of Internal Medicine 2011;155:602-15.

\section{Lindley 1993}

Lindley RI. Are very large trials of promising treatments for acute stroke feasible?. Newcastle Upon Tyne: University of Newcastle Upon Tyne, 1993.

\section{Lozano 2012}

Lozano R, Naghavi M, Foreman K, Lim S, Shibuya K, Aboyans V, et al. Global and regional mortality from 235 causes of death for 20 age groups in 1990 and 2010: a systematic analysis for the Global Burden of Disease Study 2010. Lancet 2012;380(9859):2095-128.

\section{Lyrer 2010}

Lyrer P, Engelter S. Antithrombotic drugs for carotid artery dissection. Cochrane Database of Systematic Reviews 2010, Issue 10. [DOI: 10.1002/14651858.CD000255]

\section{Murray 2012}

Murray CJ, Vos T, Lozano R, Naghavi M, Flaxman AD, Michaud C, et al. Disability-adjusted life years (DALYs) for 291 diseases and injuries in 21 regions, 1990-2010: a systematic analysis for the Global Burden of Disease Study 2010. Lancet 2012;380(9859):2197-223.

\section{Odgaard-Jensen 2011}

Odgaard-Jensen J, Vist GE, Timmer A, Kunz R, Akl EA, Schünemann $\mathrm{H}$, et al. Randomisation to protect against selection bias in healthcare trials. Cochrane Database of Systematic Reviews 2011, Issue Issue 4. [DOI: 10.1002/ 14651858.MR000012.pub3] 
PREVAIL 2007

Sherman DG, Albers GW, Bladin C, Fieschi C, Gabbai AA, Kase CS, et al. The efficacy and safety of enoxaparin versus unfractionated heparin for the prevention of venous thromboembolism after acute ischaemic stroke (PREVAIL Study): an open-label randomised comparison. Lancet 2007;369:1347-55.

RevMan 2014

The Nordic Cochrane Centre, The Cochrane Collaboration. Review Manager (RevMan). 5.3. Copenhagen: The Nordic Cochrane Centre, The Cochrane Collaboration, 2014.

\section{Sandercock 2008}

Sandercock PAG, Counsell C, Tseng MC. Low molecular weight heparin or heparinoids versus standard unfractionated heparin for acute ischemic stroke. Cochrane Database of Systematic Reviews 2008, Issue 3. [DOI: 10.1002/14651858.CD000119.pub3]

\section{Saxena 2001}

Saxena R, Lewis S, Berge E, Sandercock P, Koudstaal, P, the International Stroke Trial Collaborative Group. Risk of early death and recurrent stroke and effect of heparin in 3169 patients with acute ischemic stroke and atrial fibrillation in the International Stroke Trial. Stroke 2001; 32:2333-7.

\section{Wardlaw 2014}

Wardlaw JM, Murray V, Berge E, del Zoppo GJ. Thrombolysis for acute ischaemic stroke. Cochrane Database of Systematic Reviews 2014, Issue 7. [DOI: 10.1002/ 14651858.CD000213]

\section{Warlow 2008}

Warlow C, Bamford J, Dennis M, Rothwell P, Rinkel G, Sandercock P, et al. Stroke: Practical Management. 3rd Edition. Blackwells Scientific, 2008.

\section{Whiteley 2013}

Whiteley W, Adams HP, Bath PMW, Berge E, Sandset PM, Dennis M, et al. Targeted use of heparin, heparinoids, or low-molecular weight heparin to improve outcome after acute ischaemic stroke: an individual patient data metaanalysis of randomised controlled trials. Lancet Neurology 2013;12:539-45.

\section{References to other published versions of this review}

\section{Gubitz 2004}

Gubitz G, Sandercock P, Counsell C. Anticoagulants for acute ischaemic stroke. Cochrane Database of Systematic Reviews 2004, Issue 3. [DOI: 10.1002/ 14651858.CD000024.pub2]

\section{Sandercock 1993}

Sandercock PAG, van den Belt AGM, Lindley RI, Slattery J. Antithrombotic therapy in acute ischaemic stroke: an overview of the completed randomised trials. Journal of Neurology, Neurosurgery and Psychiatry 1993;56:17-25.

* Indicates the major publication for the study 


\section{CHARACTERISTICS OFSTUDIES}

\section{Characteristics of included studies [ordered by study ID]}

\section{ARGIS-1 2004}

\begin{tabular}{|c|c|c|}
\hline Methods & \multicolumn{2}{|c|}{$\begin{array}{l}\mathrm{C}=\text { randomisation not described } \\
\text { Patient, doctor and assessments blinded } \\
\text { Exclusions during the trial: none } \\
\text { Losses to FU: } 5 \text { participants }\end{array}$} \\
\hline Participants & \multicolumn{2}{|c|}{$\begin{array}{l}\text { North America } \\
171 \text { participants } \\
\text { Mean age } 65 \text { years } \\
100 \% \text { CT before entry } \\
\text { Mild to moderate ischaemic stroke NIHSS } 7 \text { to } 22 \\
\text { Less than } 12 \text { hours since onset }\end{array}$} \\
\hline Interventions & \multicolumn{2}{|c|}{$\begin{array}{l}\text { Rx: argatroban } 100 \mathrm{mcg} / \mathrm{kg} \text { bolus, followed by low-dose arm } 1 \mathrm{mcg} / \mathrm{kg} / \mathrm{min} \text { or high-dose } \\
\text { arm } 3 \mathrm{mcg} / \mathrm{kg} / \mathrm{min} \text { for } 5 \text { days versus placebo } \\
\text { Control: aspirin use in both arms }\end{array}$} \\
\hline Outcomes & \multicolumn{2}{|c|}{$\begin{array}{l}\text { Death } \\
\text { Symptomatic ICH } \\
\text { Major extracranial ICH } \\
\text { Barthel, NIHSS, MRS at } 90 \text { days }\end{array}$} \\
\hline Notes & \multicolumn{2}{|l|}{$\begin{array}{l}\text { Ex: age }>85 \\
\text { BP: }>220 / 130 \\
\text { FU: } 30 \text { days, } 90 \text { days }\end{array}$} \\
\hline \multicolumn{3}{|l|}{ Risk of bias } \\
\hline Bias & Authors' judgement & Support for judgement \\
\hline Allocation concealment (selection bias) & Unclear risk & B - Unclear \\
\hline
\end{tabular}

\section{Cazzato 1989}

$\begin{array}{ll}\text { Methods } & \text { C = random number table controlled by doctor not involved in treatment } \\ \text { Outcome assessor blind } \\ \text { Exclusions during trial: none } \\ \text { Losses to FU: none }\end{array}$


Cazzato 1989 (Continued)

Ischaemic stroke

Less than 48 hours since stroke onset

Interventions

Rx: mesoglycan (heparinoid) $50 \mathrm{mg} 8$ hourly im for 5 days, then $144 \mathrm{mg} /$ day orally for 25

days

Control: no treatment

All participants received dexamethasone iv

Duration: 30 days

\begin{tabular}{ll} 
Outcomes & Death plus cause of death \\
& Functional outcome (OHS 3, 4, 5 = dependent) \\
& PE (symptomatic plus autopsy in 9/10 deaths) \\
& Intracranial haemorrhage (symptomatic CT) \\
& Recurrent stroke \\
& Major extracranial haemorrhage \\
\hline Notes & Ex: none \\
& FU: 30 days \\
\hline
\end{tabular}

\section{Risk of bias}

\section{Bias}

Authors' judgement

Support for judgement

Allocation concealment (selection bias) Low risk

A - Adequate

\section{CESG 1983}

Methods

$\mathrm{C}=$ sealed envelopes (opaque and sequentially numbered)

Non-blind

Exclusions during trial: none

Losses to FU: none

\begin{tabular}{ll} 
Participants & North America \\
& 45 participants \\
& 42 to 83 years \\
& $58 \%$ male \\
& $100 \%$ CT before entry \\
& Cardioembolic stroke \\
& Less than 48 hours since stroke onset \\
\hline Interventions & Rx: heparin iv (continuous, APTT 1.5 to 2.5$)+/$ - coumadin \\
& Control: no treatment \\
& Duration: 10 days \\
\hline Outcomes & Death plus cause of death \\
& Intracranial haemorrhage (systematic CT on day 4 to 10$)$ \\
& Recurrent stroke \\
& Major extracranial haemorrhage
\end{tabular}


CESG 1983 (Continued)

\begin{tabular}{|c|c|c|}
\hline Notes & $\begin{array}{l}\text { Ex: BP > 180/115, bleeding risk } \\
\text { FU: } 14 \text { days }\end{array}$ & \\
\hline \multicolumn{3}{|l|}{ Risk of bias } \\
\hline Bias & Authors' judgement & Support for judgement \\
\hline Allocation concealment (selection bias) & Low risk & A - Adequate \\
\hline
\end{tabular}

Chaudhary 2002

\begin{tabular}{l|l}
\hline Methods & $\begin{array}{l}\text { C }=\text { randomisation not described } \\
\text { Assessment not blinded } \\
\text { Exclusions during trial: none } \\
\text { Losses to FU: none }\end{array}$ \\
\hline Participants & $\begin{array}{l}\text { India } \\
30 \text { participants } \\
65 \text { years } \\
100 \% \text { CT before entry } \\
\text { Acute stroke - time not otherwise defined }\end{array}$ \\
\hline Interventions & Rx: parnaparin 0.3 ml sc bid for 10 days versus placebo \\
\hline Outcomes & Death and Barthel Index at 3 months \\
\hline Notes & Ex: CT with ICH, coagulopathy \\
\hline Risk of bias & Authors judgement \\
\hline Bias & Unclear risk \\
\hline Allocation concealment (selection bias) & Support for judgement \\
\hline
\end{tabular}

Duke 1983

\begin{tabular}{ll}
\hline Methods & $\begin{array}{l}\text { C }=\text { random number list controlled by pharmacy } \\
\text { Doctor, patient, and assessor blind } \\
\text { Exclusions during trial: none } \\
\text { Losses to FU: none }\end{array}$ \\
\hline Participants & $\begin{array}{l}\text { Canada } \\
65 \text { participants } \\
\text { ? age } \\
\text { ? sex } \\
81 \% \text { CT before entry } \\
\text { 'Partial stable' ischaemic stroke }<48 \text { hours since stroke onset }\end{array}$ \\
\hline Anticoagulants for acute ischaemic stroke (Review)
\end{tabular}


Duke 1983 (Continued)

\begin{tabular}{|c|c|c|}
\hline Interventions & $\begin{array}{l}\text { Rx: heparin } 5000 \text { IU sc } 8 \text { hourly } \\
\text { Control: placebo } \\
\text { Duration: } 7 \text { days }\end{array}$ & \\
\hline Outcomes & $\begin{array}{l}\text { Death } \\
\text { DVT (systematic I-125 scan) } \\
\text { Intracranial haemorrhage (symptomatic) } \\
\text { Extracranial haemorrhage }\end{array}$ & \\
\hline Notes & $\begin{array}{l}\text { Ex: BP > } 120 \text { diastolic, bleeding risk } \\
\text { FU: } 1 \text { year }\end{array}$ & \\
\hline \multicolumn{3}{|l|}{ Risk of bias } \\
\hline Bias & Authors' judgement & Support for judgement \\
\hline Allocation concealment (selection bias) & Low risk & A - Adequate \\
\hline
\end{tabular}

Duke 1986

\begin{tabular}{|c|c|}
\hline Methods & $\begin{array}{l}\text { C = random number list controlled by pharmacy } \\
\text { Doctor, patient, and assessor blind } \\
\text { Exclusions during trial: none } \\
\text { Losses to FU: } 3 \text { participants (number in each group unknown) }\end{array}$ \\
\hline Participants & $\begin{array}{l}\text { Canada } \\
225 \text { participants } \\
\text { Mean age } 67 \text { years } \\
63 \% \text { male } \\
100 \% \text { CT before entry } \\
\text { 'Partial stable' non-cardioembolic ischaemic stroke }<48 \mathrm{hrs} \text { since stroke onset }\end{array}$ \\
\hline Interventions & $\begin{array}{l}\text { Rx: heparin iv (continuous, APTT } 50 \text { to } 70 \text { seconds) } \\
\text { Control: placebo } \\
\text { Duration: } 7 \text { days } \\
\text { Antiplatelet therapy during follow up not reported }\end{array}$ \\
\hline Outcomes & $\begin{array}{l}\text { Death but not cause of death } \\
\text { Functional outcome (measured but not reported) } \\
\text { Intracranial haemorrhage (symptomatic) }\end{array}$ \\
\hline Notes & $\begin{array}{l}\text { Ex: BP > } 110 \text { diastolic, coma } \\
\text { FU: } 1 \text { year }\end{array}$ \\
\hline \multicolumn{2}{|l|}{ Risk of bias } \\
\hline Bias & Support for judgement \\
\hline
\end{tabular}


Duke 1986

(Continued)

Allocation concealment (selection bias) Low risk

A - Adequate

Elias 1990

\begin{tabular}{|c|c|c|}
\hline Methods & \multicolumn{2}{|c|}{$\begin{array}{l}\text { C = sealed envelopes (? opaque and sequentially numbered) } \\
\text { Non-blind } \\
\text { Exclusions during trial: none } \\
\text { Losses to FU: } 2 \text { in Rx group }\end{array}$} \\
\hline Participants & \multicolumn{2}{|l|}{$\begin{array}{l}\text { Europe } \\
30 \text { participants } \\
\text { Mean age } 68 \text { years } \\
57 \% \text { male } \\
100 \% \text { CT before entry } \\
\text { Ischaemic stroke with immobility } \\
\text { Less than } 48 \text { hours since stroke onset }\end{array}$} \\
\hline Interventions & \multicolumn{2}{|c|}{$\begin{array}{l}\text { Rx: CY } 222 \text { (LMWH) } 15,000 \text { anti-Xa units sc } 24 \text { hourly } \\
\text { Control: no treatment } \\
\text { Duration: } 14 \text { days }\end{array}$} \\
\hline Outcomes & \multicolumn{2}{|c|}{$\begin{array}{l}\text { Death plus cause of death } \\
\text { DVT (systematic I-125 scan, venography 50\%) } \\
\text { Major extracranial haemorrhage }\end{array}$} \\
\hline Notes & \multicolumn{2}{|l|}{$\begin{array}{l}\text { Ex: } B P>220 / 120, \text { coma } \\
\text { FU: } 14 \text { days }\end{array}$} \\
\hline \multicolumn{3}{|l|}{ Risk of bias } \\
\hline Bias & Authors' judgement & Support for judgement \\
\hline Allocation concealment (selection bias) & Unclear risk & B - Unclear \\
\hline
\end{tabular}

FISS 1995

\begin{tabular}{ll} 
Methods & $\begin{array}{l}\text { C }=\text { sequentially numbered boxes containing identical syringes } \\
\text { Doctor, patient, and assessor blind } \\
\text { Exclusions during trial: } 4 \text { in Rx group (survival status known for all except one) } \\
\text { Losses to FU: } 2 \text { in Rx group }\end{array}$ \\
\hline Participants & Hong Kong \\
& 312 participants \\
Mean age 67 years \\
$58 \%$ male \\
$100 \%$ CT before entry \\
Ischaemic stroke with motor deficit
\end{tabular}


FISS 1995 (Continued)

Less than 48 hours since stroke onset

Interventions

Rx: nadroparin (LMWH) sc (randomised between 4100 anti-Xa units 12 hourly versus 24 hourly)

Control: placebo

Duration: 10 days

All surviving participants received aspirin $100 \mathrm{mg} /$ day after 10 days

Outcomes

Death plus cause of death

Functional outcome (dependency assessed using International Stroke Trial simple questions)

PE (symptomatic)

Intracranial haemorrhage (symptomatic and systematic CT)

Recurrent stroke

Major extracranial haemorrhage

Myocardial infarction

Notes

Ex: over 80 years, $\mathrm{BP}>180 / 120 \mathrm{mmHg}$, previous disabling stroke, bleeding risk, imminent death

FU: 6 months

Risk of bias

\begin{tabular}{lll}
\hline Bias & Authors' judgement & Support for judgement \\
\hline Allocation concealment (selection bias) & Low risk & A - Adequate \\
\hline
\end{tabular}

FISS-bis 1998

\begin{tabular}{|c|c|}
\hline Methods & $\begin{array}{l}\mathrm{C}=\text { sequentially numbered boxes } \\
\text { Doctor, patient and assessor blind } \\
\text { Exclusions during trial: unknown } \\
\text { Losses to FU: unknown }\end{array}$ \\
\hline Participants & $\begin{array}{l}\text { International } \\
766 \text { participants } \\
\text { Mean age unknown } \\
\% \text { male unknown } \\
100 \% \text { CT before entry } \\
\text { Ischaemic stroke with motor deficit }<24 \text { hours since stroke onset }\end{array}$ \\
\hline Interventions & $\begin{array}{l}\text { Rx: nadroparin (LMWH) } 86 \text { units/kg sc once daily versus } 86 \text { units/kg sc } 12 \text { hourly } \\
\text { Control: placebo } \\
\text { Duration: } 10 \text { days }\end{array}$ \\
\hline Outcomes & $\begin{array}{l}\text { Death } \\
\text { Functional Outcome (Barthel Index score }<85=\text { dependent }) \\
\text { Intracerebral haemorrhage (symptomatic CT) }\end{array}$ \\
\hline
\end{tabular}


FISS-bis 1998 (Continued)

$\begin{array}{ll}\text { Notes } & \text { Ex: mild stroke, coma } \\ & \text { FU: } 6 \text { months }\end{array}$

FU: 6 months

Risk of bias

Bias

Authors' judgement

Support for judgement

Allocation concealment (selection bias) $\quad$ Low risk $\quad$ A - Adequate

\section{IST 1997}

\begin{tabular}{|c|c|c|}
\hline Methods & \multicolumn{2}{|c|}{$\begin{array}{l}\text { C = telephone randomisation } \\
\text { Unblinded; dependency assessment mainly blinded } \\
\text { Exclusions during trial: none } \\
\text { Losses to FU: data } 99.99 \% \text { complete for } 14 \text {-day outcome and } 99.2 \% \text { complete for } 6 \text {-month } \\
\text { outcome }\end{array}$} \\
\hline Participants & \multicolumn{2}{|c|}{$\begin{array}{l}\text { International } \\
19,435 \text { participants } \\
61 \%>70 \text { years } \\
54 \% \text { male } \\
67 \% \text { CT prior to randomisation, } 29 \% \text { CT after randomisation } \\
\text { Ischaemic stroke }<48 \text { hours since stroke onset }\end{array}$} \\
\hline Interventions & \multicolumn{2}{|c|}{$\begin{array}{l}\text { Rx: sc heparin ( } 5000 \mathrm{IU} \text { or } 12,500 \mathrm{IU} 12 \text { hourly), aspirin } 300 \mathrm{mg} \text {, both, or neither (factorial } \\
\text { design) } \\
\text { Duration: } 14 \text { days or until discharge from hospital }\end{array}$} \\
\hline Outcomes & \multicolumn{2}{|c|}{$\begin{array}{l}\text { Death } \\
\text { Functional outcome (validated simple questions) } \\
\text { Recurrent stroke } \\
\text { PE } \\
\text { Intracranial haemorrhage (symptomatic CT) } \\
\text { Extracranial haemorrhage }\end{array}$} \\
\hline Notes & \multicolumn{2}{|c|}{$\begin{array}{l}\text { Ex: small likelihood of worthwhile benefit; high risk of adverse effect (e.g. hypersensitivity } \\
\text { of aspirin, recent GI bleed or peptic ulcer disease, already on long-term anticoagulation) } \\
\text { FU: } 6 \text { months }\end{array}$} \\
\hline \multicolumn{3}{|l|}{ Risk of bias } \\
\hline Bias & Authors' judgement & Support for judgement \\
\hline Allocation concealment (selection bias) & Low risk & A - Adequate \\
\hline
\end{tabular}


Kwiecinski 1995

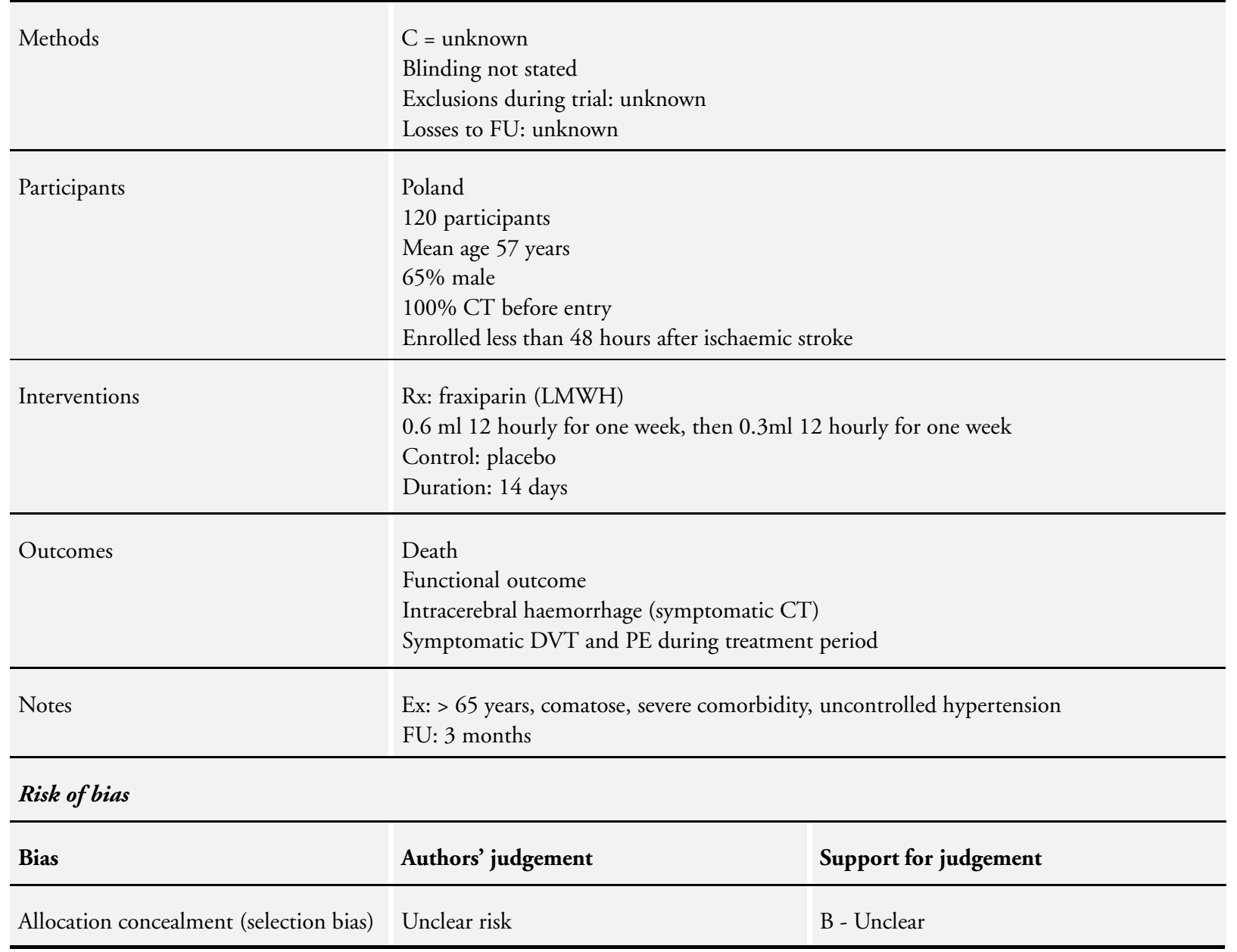

Marshall 1960

\begin{tabular}{ll} 
Methods & $\begin{array}{l}\text { C }=\text { unknown } \\
\text { Non-blind } \\
\text { Exclusions during trial: none } \\
\text { Losses to FU: none }\end{array}$ \\
\hline Participants & $\begin{array}{l}\text { United Kingdom } \\
51 \text { participants } \\
30 \text { to } 70 \text { years } \\
47 \% \text { male } \\
\text { No CT, } 100 \% \text { LP plus angiography } \\
\text { Non-cardioembolic ischaemic stroke }<72 \text { hours since stroke onset }\end{array}$ \\
\hline Interventions & $\begin{array}{l}\text { Rx: heparin iv (3 doses of } 12,500 \text { IU), then phenindione orally } 12 \text { hourly (PT } 2 \text { to } 3) \\
\text { Control: no treatment } \\
\text { Duration: } 21 \text { days } \\
\text { No antiplatelet therapy during follow up }\end{array}$ \\
\hline
\end{tabular}


Marshall 1960 (Continued)

\begin{tabular}{|c|c|c|}
\hline Outcomes & \multicolumn{2}{|c|}{$\begin{array}{l}\text { Death but not cause of death } \\
\text { Fatal intracranial haemorrhage (autopsies in } 8 / 9 \text { deaths) } \\
\text { Recurrent stroke } \\
\text { Major extracranial haemorrhage }\end{array}$} \\
\hline Notes & \multicolumn{2}{|l|}{$\begin{array}{l}\text { Ex: bleeding risk } \\
\text { FU: } 6 \text { months }\end{array}$} \\
\hline \multicolumn{3}{|l|}{ Risk of bias } \\
\hline Bias & Authors' judgement & Support for judgement \\
\hline Allocation concealment (selection bias) & Unclear risk & B - Unclear \\
\hline
\end{tabular}

\section{McCarthy 1977}

\begin{tabular}{|c|c|c|}
\hline Methods & \multicolumn{2}{|c|}{$\begin{array}{l}\text { C = sealed envelopes (? opaque and sequentially numbered) } \\
\text { DVT assessment blind } \\
\text { Exclusions during trial: none } \\
\text { Losses to FU: none }\end{array}$} \\
\hline Participants & \multicolumn{2}{|l|}{$\begin{array}{l}\text { United Kingdom } \\
32 \text { participants } \\
\text { Mean age } 78 \text { years } \\
34 \% \text { male } \\
\text { No CT, } 100 \% \text { LP before entry } \\
\text { Any stroke with no blood in CSF } \\
\text { Less than } 48 \text { hours since stroke onset }\end{array}$} \\
\hline Interventions & \multicolumn{2}{|l|}{$\begin{array}{l}\text { Rx: heparin } 5000 \text { IU sc } 8 \text { hourly } \\
\text { Control: no treatment } \\
\text { Duration: } 14 \text { days }\end{array}$} \\
\hline Outcomes & \multicolumn{2}{|l|}{$\begin{array}{l}\text { Death but not cause of death } \\
\text { DVT (systematic I-125 scan) }\end{array}$} \\
\hline Notes & \multicolumn{2}{|l|}{$\begin{array}{l}\text { Ex: BP > } 120 \text { diastolic, bleeding risk } \\
\text { FU: } 1 \text { month }\end{array}$} \\
\hline \multicolumn{3}{|l|}{ Risk of bias } \\
\hline Bias & Authors' judgement & Support for judgement \\
\hline Allocation concealment (selection bias) & Unclear risk & B - Unclear \\
\hline
\end{tabular}


McCarthy 1986

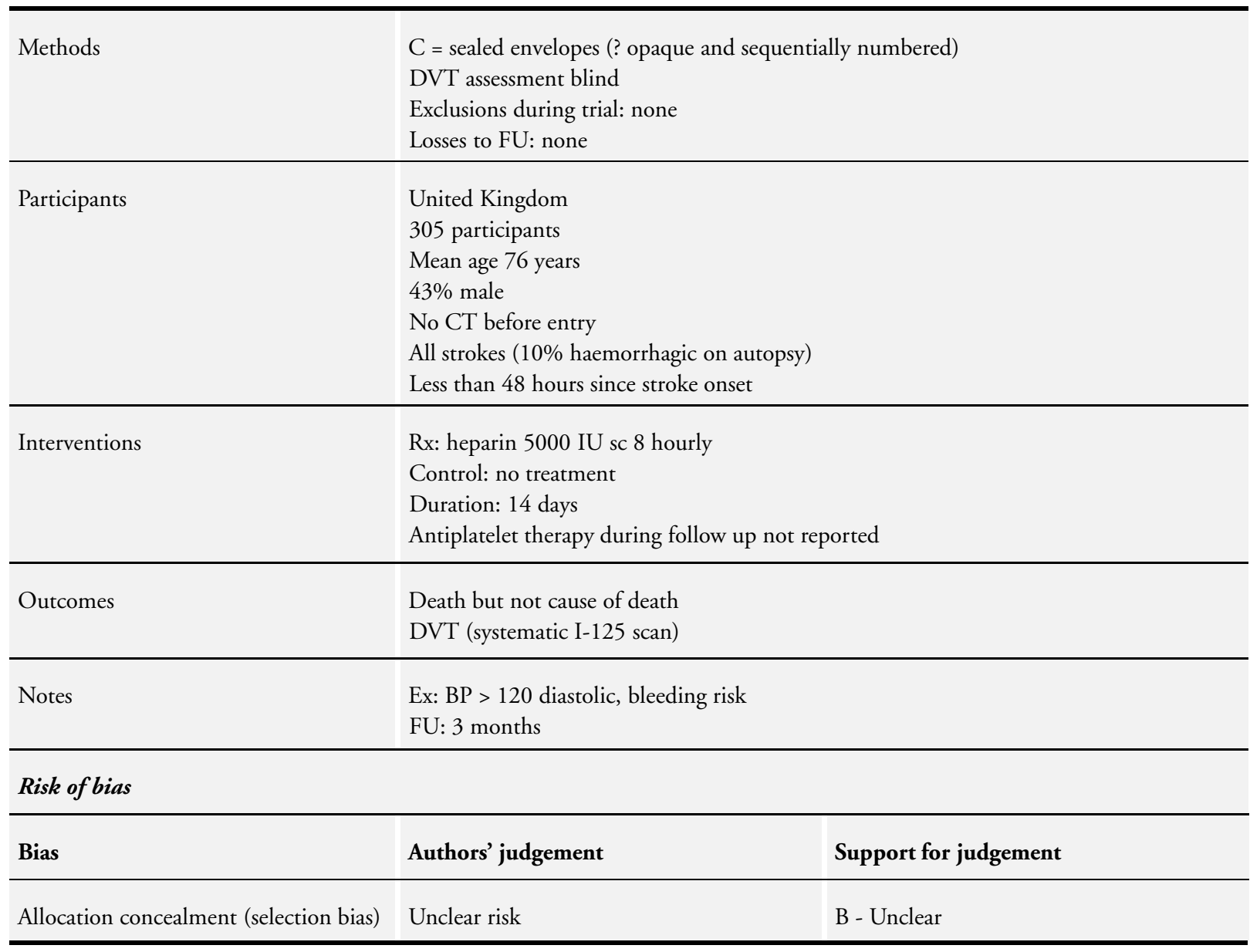

NAT-COOP 1962

\begin{tabular}{|c|c|}
\hline Methods & $\begin{array}{l}\text { C = sealed envelopes (? opaque and sequentially numbered) } \\
\text { Patient only blind } \\
\text { Exclusions during trial: none } \\
\text { Losses to FU: none }\end{array}$ \\
\hline Participants & $\begin{array}{l}\text { USA } \\
30 \text { participants } \\
26 \text { older than } 55 \text { years } \\
53 \% \text { male } \\
\text { No CT, } 100 \% \text { LP before entry } \\
\text { Cardioembolic stroke } \\
\text { Less than } 2 \text { weeks since stroke onset }\end{array}$ \\
\hline Interventions & $\begin{array}{l}\text { Rx: heparin } 50 \mathrm{mg} \text { iv } 4 \text { hourly, then dicumarol (oral anticoagulant; PT } 15 \text { to } 20 \% \text { ) } \\
\text { Control: placebo } \\
\text { Duration: } 1 \text { month }\end{array}$ \\
\hline
\end{tabular}


NAT-COOP 1962 (Continued)

\begin{tabular}{|c|c|c|}
\hline Outcomes & \multicolumn{2}{|l|}{$\begin{array}{l}\text { Death plus cause of death } \\
\text { Recurrent stroke } \\
\text { Extracranial haemorrhage }\end{array}$} \\
\hline Notes & \multicolumn{2}{|c|}{$\begin{array}{l}\text { Ex: bleeding risk } \\
\text { FU: } 1 \text { year but only complete FU for all patients up to } 1 \text { month }\end{array}$} \\
\hline \multicolumn{3}{|l|}{ Risk of bias } \\
\hline Bias & Authors' judgement & Support for judgement \\
\hline Allocation concealment (selection bias) & Unclear risk & B - Unclear \\
\hline
\end{tabular}

Pambianco 1995

\begin{tabular}{|c|c|}
\hline Methods & $\begin{array}{l}\text { C = sealed, opaque but not sequentially numbered envelopes } \\
\text { Non-blind } \\
\text { Exclusions during trial: none } \\
\text { Losses to FU: none }\end{array}$ \\
\hline Participants & $\begin{array}{l}\text { USA } \\
131 \text { participants } \\
\text { Mean age } 71 \text { years } \\
50 \% \text { male } \\
100 \% \text { CT before entry } \\
\text { Ischaemic stroke with severe leg weakness } \\
\text { Less than } 14 \text { days since stroke onset }\end{array}$ \\
\hline Interventions & $\begin{array}{l}\text { Rx: heparin } 5000 \text { IU sc } 8 \text { hourly, with dose adjustment to maintain PT } 30 \text { to } 40 \text { seconds } \\
\text { Control: no treatment } \\
\text { Duration: } 28 \text { days }\end{array}$ \\
\hline Outcomes & $\begin{array}{l}\text { Death plus cause of death } \\
\text { DVT (systematic B mode and Doppler ultrasound) } \\
\text { PE } \\
\text { Major extracranial haemorrhage }\end{array}$ \\
\hline Notes & $\begin{array}{l}\text { Ex: bleeding risk, active cancer } \\
\text { FU: } 28 \text { days }\end{array}$ \\
\hline \multicolumn{2}{|l|}{ Risk of bias } \\
\hline Bias & Support for judgement \\
\hline Allocation concealment (selection bias) & Unclear risk \\
\hline
\end{tabular}


Methods

$\mathrm{C}=$ sealed envelopes (? opaque and sequentially numbered)

Non-blind

Exclusions during trial: $\mathrm{Rx}$ 0, control 4 participants (2 with intracranial haemorrhage)

Losses to FU: none

\begin{tabular}{ll}
\hline Participants & France \\
80 participants & 30 to 92 years \\
$62 \%$ male \\
No CT, 100\% LP before entry \\
Ischaemic stroke affecting the leg \\
Less than 7 days since stroke onset $(89 \%<48$ hours $)$ \\
\hline
\end{tabular}

\begin{tabular}{ll} 
Interventions & $\begin{array}{l}\text { Rx: heparin } 5000 \text { IU sc } 8 \text { hourly } \\
\text { Control: no treatment } \\
\text { Duration: } 10 \text { days }\end{array}$ \\
\hline Outcomes & $\begin{array}{l}\text { Death but not cause of death } \\
\text { DVT (systematic I-125 scan) } \\
\text { PE } \\
\text { Major extracranial haemorrhage }\end{array}$ \\
\hline Notes & Ex: bleeding risk \\
& FU: 10 days \\
\hline
\end{tabular}

Risk of bias

\begin{tabular}{l|l|l}
\hline Bias & Authors' judgement & Support for judgement \\
\hline Allocation concealment (selection bias) & Unclear risk & B - Unclear
\end{tabular}

Prins 1989

\begin{tabular}{|c|c|}
\hline Methods & $\begin{array}{l}\mathrm{C}=\text { sequentially numbered identical syringes } \\
\text { Double-blind } \\
\text { Exclusions during trial: none } \\
\text { Losses to FU: none }\end{array}$ \\
\hline Participants & $\begin{array}{l}\text { Netherlands } \\
60 \text { participants } \\
78 \%>70 \text { years } \\
52 \% \text { male } \\
100 \% \text { CT before entry } \\
\text { Ischaemic stroke less than } 72 \text { hours since stroke onset }\end{array}$ \\
\hline Interventions & $\begin{array}{l}\text { Rx: dalteparin (LMWH, Kabi 2165) } 2500 \text { anti-Xa units sc } 12 \text { hourly } \\
\text { Control: placebo } \\
\text { Duration: } 14 \text { days }\end{array}$ \\
\hline
\end{tabular}


Prins 1989 (Continued)

\begin{tabular}{lll}
\hline Outcomes & $\begin{array}{l}\text { Death plus cause of death } \\
\text { DVT (systematic I-125 scan with venography) } \\
\end{array}$ & $\begin{array}{l}\text { PE } \\
\text { Intracranial haemorrhage (symptomatic plus systematic CT) } \\
\text { Major extracranial haemorrhage }\end{array}$ \\
\hline Notes & $\begin{array}{l}\text { Ex: coma } \\
\text { FU: } 14 \text { days }\end{array}$ \\
\hline Risk of bias & Authors' judgement & Support for judgement \\
\hline Bias & Low risk & A - Adequate \\
\hline Allocation concealment (selection bias) & & \\
\hline
\end{tabular}

\section{Sandset 1990}

\begin{tabular}{|c|c|}
\hline Methods & $\begin{array}{l}\mathrm{C}=\text { sequentially numbered identical ampoules } \\
\text { Doctor, patient and assessor blind } \\
\text { Exclusions during trial: none } \\
\text { Losses to FU: none }\end{array}$ \\
\hline Participants & $\begin{array}{l}\text { Norway } \\
103 \text { participants } \\
47 \text { to } 90 \text { years } \\
45 \% \text { male } \\
100 \% \text { CT before entry } \\
\text { Non-cardioembolic ischaemic stroke } \\
\text { Less than } 72 \text { hours since stroke onset }\end{array}$ \\
\hline Interventions & $\begin{array}{l}\text { Rx: dalteparin (LMWH, Kabi 2165) } 3000 \text { to } 5500 \text { anti-Xa U sc } 24 \text { hourly } \\
\text { Control: placebo } \\
\text { Duration: } 14 \text { days }\end{array}$ \\
\hline Outcomes & $\begin{array}{l}\text { Death plus cause of death } \\
\text { DVT (systematic venography or B mode ultrasound) } \\
\text { PE (symptomatic plus autopsy in } 5 / 6 \text { deaths) } \\
\text { Intracranial haemorrhage (systematic CT) } \\
\text { Major extracranial haemorrhage }\end{array}$ \\
\hline Notes & $\begin{array}{l}\text { Ex: BP > } 120 \text { diastolic, coma, bleeding risk } \\
\text { FU: } 28 \text { days }\end{array}$ \\
\hline \multicolumn{2}{|l|}{ Risk of bias } \\
\hline Bias & Support for judgement \\
\hline
\end{tabular}


Sandset 1990 (Continued)

\begin{tabular}{lll} 
Allocation concealment (selection bias) & Low risk & A - Adequate \\
\hline
\end{tabular}

Tazaki 1986

\begin{tabular}{|c|c|}
\hline Methods & $\begin{array}{l}\text { C = numbered or coded containers administered sequentially to enrolled participants } \\
\text { Doctor, patient and assessor blind } \\
\text { Exclusions during trial: none } \\
\text { Losses to FU: none }\end{array}$ \\
\hline Participants & $\begin{array}{l}\text { Japanese } \\
156 \text { participants } \\
68 \%>60 \text { years } \\
66 \% \text { male } \\
100 \% \text { CT before entry } \\
\text { Ischaemic stroke within } 7 \text { to } 10 \text { days of stroke onset }\end{array}$ \\
\hline Interventions & $\begin{array}{l}\text { Rx: MD805 (thrombin inhibitor) } 60 \mathrm{mg} / \text { day versus } 30 \mathrm{mg} / \text { day continuous iv for } 2 \text { days; } \\
\text { then } 20 \mathrm{mg} 12 \text { hourly iv for } 5 \text { days } \\
\text { Control: placebo } \\
\text { All patients received glycerol } 500 \mathrm{mg} / \text { day } \\
\text { Duration: } 7 \text { days }\end{array}$ \\
\hline Outcomes & $\begin{array}{l}\text { Death } \\
\text { Functional outcome (graded on ADL-type scale) }\end{array}$ \\
\hline Notes & $\begin{array}{l}\text { Ex: decreased level of consciousness, pregnancy, 'bleeding tendency', severe hepatic or renal } \\
\text { damage } \\
\text { FU: } 28 \text { days }\end{array}$ \\
\hline
\end{tabular}

Risk of bias

\begin{tabular}{lll}
\hline Bias & Authors' judgement & Support for judgement \\
\hline Allocation concealment (selection bias) & Low risk & A - Adequate \\
\hline
\end{tabular}

Tazaki 1992

\begin{tabular}{ll} 
Methods & C = numbered or coded containers administered sequentially to enrolled patients \\
& $\begin{array}{l}\text { Doctor, patient and assessor blind } \\
\text { Exclusions during trial: none } \\
\text { Losses to FU: none }\end{array}$ \\
\hline Participants & Japanese \\
& 138 participants \\
Mean age 68 years \\
$64 \%$ male \\
$100 \%$ CT before entry
\end{tabular}


Tazaki 1992 (Continued)

Ischaemic stroke within 5 to 7 days of stroke onset

\begin{tabular}{ll} 
Interventions & $\begin{array}{l}\text { Rx: MD805 (thrombin inhibitor) } 60 \mathrm{mg} / \text { days for two days (continuous iv), then MD805 } \\
20 \mathrm{mg} 12 \text { hourly for } 5 \text { days (iv) } \\
\text { Control: placebo } \\
\text { All groups received glycerol } 500 \mathrm{ml} / \text { day for } 7 \text { days } \\
\text { Duration: } 7 \text { days }\end{array}$ \\
\hline Outcomes & $\begin{array}{l}\text { Death } \\
\text { Functional outcome } \\
\text { Intracranial haemorrhage (symptomatic CT) }\end{array}$ \\
\hline
\end{tabular}

Notes

Ex: decreased level of consciousness, bleeding risk, pregnancy, age $>85$ years, significant medical disease (cardiac, hepatic, renal)

FU: 1 month

\section{Risk of bias}

Bias
Authors' judgement

Low risk

\section{Support for judgement}

A - Adequate

\section{TOAST 1998}

Methods
$\mathrm{C}=$ permuted blocks with randomly ordered sizes of 6,6 , and 4; randomisation lists pharmacy controlled

Doctor, patient and assessor blind

Exclusions during trial: none

Losses to FU: 25 participants (11 treatment, 14 control)

\begin{tabular}{|c|c|}
\hline Participants & $\begin{array}{l}\text { United States } \\
1281 \text { participants } \\
\text { Mean age } 65 \text { years } \\
61 \% \text { male } \\
100 \% \text { CT before entry } \\
\text { Ischaemic stroke }>1 \text { hour and }<24 \text { hours from symptom onset with estimat } \\
\text { Barthel Index or } 12 \text { or more }\end{array}$ \\
\hline Interventions & $\begin{array}{l}\text { Rx: danaparoid (heparinoid Org 10172) bolus followed by continuous infusio } \\
\text { blood anti-Xa levels of } 0.6 \text { to } 0.8 \\
\text { Control: placebo } \\
\text { Duration: } 7 \text { days }\end{array}$ \\
\hline Outcomes & $\begin{array}{l}\text { Functional outcome: Barthel Index }<85 \text {, NIHSS, Glasgow Outcome Scale } \\
\text { Recurrent stroke } \\
\text { Intracranial haemorrhage (symptomatic CT) } \\
\text { Extracranial haemorrhage }\end{array}$ \\
\hline
\end{tabular}

Anticoagulants for acute ischaemic stroke (Review) 
TOAST 1998 (Continued)

Ex: Age $<18$ or $>85$, women of childbearing potential, severe stroke (NIHSS score $>15)$
weight less than 125 pounds
FU: 7 days and 3 months

\section{Risk of bias}

\begin{tabular}{lll} 
Bias & Authors' judgement & Support for judgement \\
\hline Allocation concealment (selection bias) & Low risk & A - Adequate \\
\hline
\end{tabular}

Turpie 1987

\begin{tabular}{|c|c|c|}
\hline Methods & \multicolumn{2}{|c|}{$\begin{array}{l}\mathrm{C} \text { = sequentially numbered identical containers } \\
\text { Double-blind } \\
\text { Exclusions during trial: none } \\
\text { Losses to FU: none }\end{array}$} \\
\hline Participants & \multicolumn{2}{|c|}{$\begin{array}{l}\text { Canada } \\
75 \text { participants } \\
28 \text { to } 90 \text { years } \\
53 \% \text { male } \\
100 \% \text { CT before entry } \\
\text { Non-cardioembolic ischaemic stroke with immobility } \\
\text { Less than } 7 \text { days since stroke onset }\end{array}$} \\
\hline Interventions & \multicolumn{2}{|c|}{$\begin{array}{l}\text { Rx: danaparoid (heparinoid Org 10172) } 750 \text { anti-Xa units sc } 12 \text { hourly } \\
\text { Control: placebo } \\
\text { Duration: } 14 \text { days or prior discharge } \\
\text { Antiplatelet therapy during follow up not reported }\end{array}$} \\
\hline Outcomes & \multicolumn{2}{|c|}{$\begin{array}{l}\text { Death plus cause of death } \\
\text { DVT (systematic I-125 scan + plethysmography with venography) } \\
\text { PE (symptomatic) } \\
\text { Intracranial haemorrhage (symptomatic CT) } \\
\text { Extracranial haemorrhage } \\
\text { Recurrent stroke }\end{array}$} \\
\hline Notes & \multicolumn{2}{|l|}{$\begin{array}{l}\text { Ex: bleeding risk } \\
\text { FU: } 3 \text { months }\end{array}$} \\
\hline \multicolumn{3}{|l|}{ Risk of bias } \\
\hline Bias & Authors' judgement & Support for judgement \\
\hline Allocation concealment (selection bias) & Low risk & A - Adequate \\
\hline
\end{tabular}


Vissinger 1995

\begin{tabular}{|c|c|c|}
\hline Methods & \multicolumn{2}{|c|}{$\begin{array}{l}\mathrm{C}=\text { coded containers administered sequentially to enrolled participants } \\
\text { Doctor, patient and assessor blind } \\
\text { Exclusions during trial: none } \\
\text { Losses to FU: } 31 / 50 \text { participants lost to } 6 \text {-month follow up }\end{array}$} \\
\hline Participants & \multicolumn{2}{|c|}{$\begin{array}{l}\text { Denmark } \\
50 \text { participants } \\
\text { Mean age } 71.8 \text { years } \\
58 \% \text { male } \\
66 \% \text { CT before entry - haemorrhage excluded in remainder by cerebral scintigraphy } \\
\text { Non-embolic ischaemic stroke with motor deficit }<24 \text { hours since stroke onset }\end{array}$} \\
\hline Interventions & \multicolumn{2}{|c|}{$\begin{array}{l}\text { Rx: tinzaparin (LMWH) } 3500 \text { anti-Xa IU sc once daily } \\
\text { Control: placebo } \\
\text { Duration: } 14 \text { days or until full mobilisation }\end{array}$} \\
\hline Outcomes & \multicolumn{2}{|l|}{$\begin{array}{l}\text { Death } \\
\text { DVT (venography) } \\
\text { PE (symptomatic) }\end{array}$} \\
\hline Notes & \multicolumn{2}{|c|}{$\begin{array}{l}\text { Exclusion criteria: }<50 \text { years old, hypertension }(\mathrm{BP}>200 / 120 \mathrm{mmHg} \text { ), coma, aphasia, } \\
\text { bleeding risk, oral anticoagulant treatment, severe hepatic or renal disease, clinical suspicion } \\
\text { of DVT or PE } \\
\text { FU: } 12 \text { to } 14 \text { days and } 6 \text { months }\end{array}$} \\
\hline \multicolumn{3}{|l|}{ Risk of bias } \\
\hline Bias & Authors' judgement & Support for judgement \\
\hline Allocation concealment (selection bias) & Low risk & A - Adequate \\
\hline
\end{tabular}

ADL: activities of daily living

APTT: activated partial thromboplastin time

bid: twice a day

BP: blood pressure

C: concealment of allocation

CSF: cerebrospinal fluid

CT: computerised tomography

DVT: Deep venous thrombosis

Ex: exclusion criteria

FU: follow up

GI: gastrointestinal

$\mathrm{ICH}$ : intracranial haemorrhage

im: intramuscularly

iv: intravenous, intravenously

LMWH: low-molecular-weight heparin

LP: lumbar puncture

MRS: modified Rankin Scale 
NIHSS: National Institutes of Health Stroke Scale

OHS: Oxford Handicap Score

PE: pulmonary embolism

PT: prothrombin time

$\mathrm{Rx}$ : treatment

sc: subcutaneous, subcutaneously

Characteristics of excluded studies [ordered by study ID]

\begin{tabular}{|c|c|}
\hline Study & Reason for exclusion \\
\hline Bradshaw 1975 & Non-random: allocation by odd/even year of birth \\
\hline Camerlingo 2005 & Confounded by the use of low-dose unfractionated heparin in control group \\
\hline Carter 1961 & Non-random: alternate allocation \\
\hline COU 9116 & Participants randomised after 14 days of stroke onset \\
\hline Czechanowski 1981 & Confounded with dihydroergotamine \\
\hline Dahan 1986 & Not all participants were stroke patients: individual patient data for stroke patients not available \\
\hline Dan 2001 & Methods of randomisation unclear; no clinically relevant outcomes reported \\
\hline Dehen 1994 & $\begin{array}{l}\text { Control group received a low-molecular-weight heparin i.e. dermatan sulphate plus placebo versus low-molec- } \\
\text { ular-weight heparin plus placebo }\end{array}$ \\
\hline Enger 1965 & Time from stroke to treatment unclear \\
\hline Eriksson 1983 & Non-random: allocation by month of admission \\
\hline Gelmers 1980 & Non-random: alternate allocation \\
\hline Kang 2010 & No clinical outcome data \\
\hline Kario 1995 & No clinically relevant outcomes reported \\
\hline Kobayashi 1997 & No clinically relevant outcomes reported \\
\hline Lee 1994 & Confounded with urokinase \\
\hline Lee 2008 & Comparison of 2 anticoagulant regimens \\
\hline Luo 2013 & Comparison of 2 anticoagulant regimens \\
\hline
\end{tabular}

McCarthy 1993 Data not available despite repeated contact with authors 
(Continued)

\begin{tabular}{|c|c|}
\hline McDevitt 1959 & Time from stroke to treatment unclear \\
\hline Meredit 2009 & Comparison of 2 anticoagulant regimens \\
\hline Rosin 1994 & Data not available despite repeated contact with authors \\
\hline Shi 2004 & No clinically relevant outcomes reported \\
\hline Stiekema 1988 & No control group: dose-finding trial \\
\hline Tan 1998 & Not randomised; no clinically relevant outcomes reported \\
\hline Thygesen 1964 & Non-random allocation \\
\hline Tomek 2011 & Comparison of 2 anticoagulant regimens \\
\hline Tsuchiya 1989 & Confounded with urokinase \\
\hline Tsuchiya 1990 & Confounded with urokinase \\
\hline VA Study 1961 & Treatment started acutely in only $50 \%$ and unable to get individual patient data for just these participants \\
\hline Zhang 2005 & Not clearly randomised \\
\hline Zhao 2014 & Anticoagulant versus antiplatelet regimen \\
\hline
\end{tabular}

Characteristics of ongoing studies [ordered by study ID]

Nosal 2014

\begin{tabular}{ll}
\hline Trial name or title & Safety and efficacy of heparin and nadroparin in the acute phase of ischemic stroke (Heparinas) \\
\hline Methods & Double Blind (patient, caregiver, investigator, outcomes assessor) \\
\hline Participants & $\begin{array}{l}18 \text { to } 80 \text { years old } \\
\text { Estimated } 150 \text { participants } \\
\text { Slovakia }\end{array}$ \\
\hline Interventions & $\begin{array}{l}\text { Rx: heparin iv/nadroparin sc/placebo iv immediately } \\
\text { Followed by nadroparin sc at } 24 \text { hours } \\
\text { Duration of anticoagulation: } 72 \text { hours }\end{array}$ \\
\hline Outcomes & $\begin{array}{l}\text { Safety: incidence of intracranial haemorrhage } \\
\text { Efficacy: level of improvement measured by mRS, and NIHSS }\end{array}$ \\
\hline Starting date & May 2013 \\
\hline $\begin{array}{l}\text { Anticoagulants for acute ischaemic stroke (Review) } \\
\text { Copyright @ 20I5 The Cochrane Collaboration. Published by John Wiley \& Sons, Ltd. }\end{array}$
\end{tabular}


Nosal 2014 (Continued)

Contact information Vladimir Nosal, MD, PhD, vnosal@gmail.com

Notes $\quad$ ClinicalTrials.gov Identifier: NCT01862978

iv: intravenous

mRS: modified Rankin Scale

NIHSS: National Institutes of Health Stroke Scale

sc: subcutaneous 
DATA AND ANALYSES

Comparison 1. Anticoagulant versus control in acute presumed ischaemic stroke

\begin{tabular}{|c|c|c|c|c|}
\hline Outcome or subgroup title & $\begin{array}{l}\text { No. of } \\
\text { studies }\end{array}$ & $\begin{array}{c}\text { No. of } \\
\text { participants }\end{array}$ & Statistical method & Effect size \\
\hline $\begin{array}{l}1 \text { Dead or dependent at end of } \\
\text { follow up (if }>1 \text { month) }\end{array}$ & 8 & 22125 & Peto Odds Ratio (Peto, Fixed, 95\% CI) & $0.99[0.93,1.04]$ \\
\hline $\begin{array}{l}\text { 1.1 Unfractionated heparin } \\
\text { (subcutaneous) versus control }\end{array}$ & 1 & 19435 & Peto Odds Ratio (Peto, Fixed, 95\% CI) & $1.00[0.94,1.06]$ \\
\hline $\begin{array}{l}\text { 1.2 Low-molecular-weight } \\
\text { heparin versus control }\end{array}$ & 4 & 1228 & Peto Odds Ratio (Peto, Fixed, 95\% CI) & $0.82[0.64,1.04]$ \\
\hline $\begin{array}{l}1.3 \text { Heparinoid } \\
\text { (subcutaneous) versus control }\end{array}$ & 1 & 57 & Peto Odds Ratio (Peto, Fixed, 95\% CI) & $0.81[0.29,2.27]$ \\
\hline $\begin{array}{l}\text { 1.4 Heparinoid (intravenous) } \\
\text { versus control }\end{array}$ & 1 & 1276 & Peto Odds Ratio (Peto, Fixed, 95\% CI) & $0.92[0.72,1.19]$ \\
\hline $\begin{array}{l}\text { 1.5 Direct thrombin inhibitor } \\
\text { versus control (intravenous) }\end{array}$ & 1 & 129 & Peto Odds Ratio (Peto, Fixed, 95\% CI) & $1.28[0.62,2.62]$ \\
\hline $\begin{array}{l}2 \text { Death from all causes during } \\
\text { treatment period }\end{array}$ & 21 & 22562 & Peto Odds Ratio (Peto, Fixed, 95\% CI) & $0.99[0.90,1.09]$ \\
\hline $\begin{array}{l}\text { 2.1 Unfractionated heparin } \\
\text { (subcutaneous) versus control }\end{array}$ & 5 & 19743 & Peto Odds Ratio (Peto, Fixed, 95\% CI) & $0.97[0.88,1.07]$ \\
\hline $\begin{array}{l}\text { 2.2 Unfractionated heparin } \\
\text { (intravenous) versus control }\end{array}$ & 2 & 270 & Peto Odds Ratio (Peto, Fixed, 95\% CI) & $0.63[0.11,3.71]$ \\
\hline $\begin{array}{l}\text { 2.3 Low-molecular-weight } \\
\text { heparin versus control }\end{array}$ & 6 & 585 & Peto Odds Ratio (Peto, Fixed, 95\% CI) & $1.60[0.87,2.95]$ \\
\hline $\begin{array}{l}2.4 \text { Heparinoid } \\
\text { (subcutaneous) versus control }\end{array}$ & 2 & 132 & Peto Odds Ratio (Peto, Fixed, 95\% CI) & $1.03[0.32,3.37]$ \\
\hline $\begin{array}{l}2.5 \text { Heparinoid (intravenous) } \\
\text { versus control }\end{array}$ & 1 & 1281 & Peto Odds Ratio (Peto, Fixed, 95\% CI) & $1.31[0.55,3.11]$ \\
\hline $\begin{array}{l}2.6 \text { Oral vitamin } \mathrm{K} \text { antagonist } \\
\text { versus control }\end{array}$ & 2 & 81 & Peto Odds Ratio (Peto, Fixed, 95\% CI) & $1.27[0.46,3.48]$ \\
\hline $\begin{array}{l}\text { 2.7 Thrombin inhibitor versus } \\
\text { control }\end{array}$ & 3 & 470 & Peto Odds Ratio (Peto, Fixed, 95\% CI) & $2.60[0.95,7.09]$ \\
\hline $\begin{array}{l}3 \text { Death from all causes at final } \\
\text { follow up (if }>1 \text { month) }\end{array}$ & 11 & 22776 & Peto Odds Ratio (Peto, Fixed, 95\% CI) & $1.05[0.98,1.12]$ \\
\hline $\begin{array}{l}\text { 3.1 Unfractionated heparin } \\
\text { (subcutaneous) versus control }\end{array}$ & 2 & 19740 & Peto Odds Ratio (Peto, Fixed, 95\% CI) & $1.04[0.98,1.12]$ \\
\hline $\begin{array}{l}3.2 \text { Unfractionated heparin } \\
\text { (intravenous) versus control }\end{array}$ & 1 & 225 & Peto Odds Ratio (Peto, Fixed, 95\% CI) & $2.26[0.99,5.19]$ \\
\hline $\begin{array}{l}\text { 3.3 Low-molecular-weight } \\
\text { heparin versus control }\end{array}$ & 4 & 1228 & Peto Odds Ratio (Peto, Fixed, 95\% CI) & $0.99[0.74,1.32]$ \\
\hline $\begin{array}{l}3.4 \text { Heparinoid } \\
\text { (subcutaneous) versus control }\end{array}$ & 1 & 75 & Peto Odds Ratio (Peto, Fixed, 95\% CI) & $0.44[0.09,2.05]$ \\
\hline $\begin{array}{l}3.5 \text { Heparinoid (intravenous) } \\
\text { versus control }\end{array}$ & 1 & 1281 & Peto Odds Ratio (Peto, Fixed, 95\% CI) & $1.09[0.69,1.72]$ \\
\hline $\begin{array}{l}\text { 3.6 Oral vitamin } \mathrm{K} \text { antagonist } \\
\text { versus control }\end{array}$ & 1 & 51 & Peto Odds Ratio (Peto, Fixed, 95\% CI) & $1.14[0.35,3.76]$ \\
\hline
\end{tabular}

Anticoagulants for acute ischaemic stroke (Review)

Copyright @ 2015 The Cochrane Collaboration. Published by John Wiley \& Sons, Ltd. 
3.7 Direct thrombin inhibitor (intravenous) versus control

4 Deep vein thrombosis during treatment period

4.1 Unfractionated heparin (subcutaneous) versus control 4.2 Low-molecular-weight heparin versus control

4.3 Heparinoid

(subcutaneous) versus control

5 Symptomatic pulmonary

embolism during treatment

period

5.1 Unfractionated heparin

(subcutaneous) versus control

5.2 Unfractionated heparin (intravenous) versus control

5.3 Low-molecular-weight heparin versus control

5.4 Heparinoid

(subcutaneous) versus control

5.5 Heparinoid (intravenous) versus control

6 Recurrent ischaemic or unknown stroke during treatment period 6.1 Unfractionated heparin (subcutaneous) versus control 6.2 Unfractionated heparin (intravenous) versus control

6.3 Low-molecular-weight

heparin versus control

6.4 Heparinoid

(subcutaneous) versus control

6.5 Heparinoid (intravenous) versus control

6.6 Oral vitamin $\mathrm{K}$ antagonist versus control

6.7 Thrombin inhibitor versus control

7 Symptomatic intracranial haemorrhage during treatment period

7.1 Unfractionated heparin

(subcutaneous) versus control

7.2 Unfractionated heparin

(intravenous) versus control

7.3 Low-molecular-weight heparin versus control

7.4 Heparinoid

(subcutaneous) versus control
$0.21[0.15,0.29]$

$0.16[0.11,0.24]$

$0.41[0.23,0.73]$

$0.11[0.02,0.46]$

$0.60[0.44,0.81]$

$0.69[0.49,0.96]$

$0.0[0.0,0.0]$

$0.31[0.15,0.64]$

$7.66[0.15,386.16]$

$0.13[0.00,6.70]$

$0.76[0.65,0.88]$

$0.76[0.65,0.89]$

$0.11[0.01,1.85]$

$0.47[0.14,1.58]$

$4.48[0.07,286.49]$

$0.98[0.34,2.82]$

$0.65[0.11,3.90]$

$7.39[0.15,372.38]$

$2.55[1.95,3.33]$

$2.69[1.97,3.67]$

$0.0[0.0,0.0]$

$1.61[0.80,3.22]$

$4.48[0.07,286.49]$

Anticoagulants for acute ischaemic stroke (Review) 


\begin{tabular}{|c|c|c|c|c|}
\hline $\begin{array}{l}\text { 7.5 Heparinoid (intravenous) } \\
\text { versus control }\end{array}$ & 1 & 1281 & Peto Odds Ratio (Peto, Fixed, 95\% CI) & $2.91[0.98,8.69]$ \\
\hline $\begin{array}{l}\text { 7.6 Oral vitamin } \mathrm{K} \text { antagonist } \\
\text { versus control }\end{array}$ & 1 & 51 & Peto Odds Ratio (Peto, Fixed, 95\% CI) & $2.78[0.37,21.00]$ \\
\hline $\begin{array}{l}\text { 7.7 Thrombin inhibitor versus } \\
\text { control }\end{array}$ & 1 & 138 & Peto Odds Ratio (Peto, Fixed, 95\% CI) & $7.39[0.15,372.38]$ \\
\hline $\begin{array}{l}7.8 \text { Direct thrombin inhibitor } \\
\text { (intravenous) versus control }\end{array}$ & 1 & 176 & Peto Odds Ratio (Peto, Fixed, 95\% CI) & $4.60[0.70,30.35]$ \\
\hline $\begin{array}{l}\text { Any recurrent stroke or } \\
\text { symptomatic intracranial } \\
\text { haemorrhage during treatment } \\
\text { period or follow up ( }>1 \\
\text { month) }\end{array}$ & 11 & 21605 & Peto Odds Ratio (Peto, Fixed, 95\% CI) & $0.97[0.85,1.11]$ \\
\hline $\begin{array}{l}\text { 8.1 Unfractionated heparin } \\
\text { (subcutaneous) versus control }\end{array}$ & 2 & 19566 & Peto Odds Ratio (Peto, Fixed, 95\% CI) & $0.96[0.84,1.11]$ \\
\hline $\begin{array}{l}\text { 8.2 Unfractionated heparin } \\
\text { (intravenous) versus control }\end{array}$ & 1 & 45 & Peto Odds Ratio (Peto, Fixed, 95\% CI) & $0.11[0.01,1.85]$ \\
\hline $\begin{array}{l}\text { 8.3 Low-molecular-weight } \\
\text { heparin versus control }\end{array}$ & 2 & 362 & Peto Odds Ratio (Peto, Fixed, 95\% CI) & $0.39[0.12,1.26]$ \\
\hline $\begin{array}{l}8.4 \text { Heparinoid } \\
\text { (subcutaneous) versus control }\end{array}$ & 2 & 132 & Peto Odds Ratio (Peto, Fixed, 95\% CI) & $4.57[0.24,88.28]$ \\
\hline $\begin{array}{l}8.5 \text { Heparinoid (intravenous) } \\
\text { versus control }\end{array}$ & 1 & 1281 & Peto Odds Ratio (Peto, Fixed, 95\% CI) & $1.43[0.67,3.07]$ \\
\hline $\begin{array}{l}8.6 \text { Oral vitamin } \mathrm{K} \text { antagonist } \\
\text { versus control }\end{array}$ & 2 & 81 & Peto Odds Ratio (Peto, Fixed, 95\% CI) & $1.24[0.32,4.88]$ \\
\hline $\begin{array}{l}\text { 8.7 Thrombin inhibitor versus } \\
\text { stroke }\end{array}$ & 1 & 138 & Peto Odds Ratio (Peto, Fixed, 95\% CI) & $7.61[0.78,74.40]$ \\
\hline $\begin{array}{l}\text { Major extracranial haemorrhage } \\
\text { during treatment period }\end{array}$ & 18 & 22255 & Peto Odds Ratio (Peto, Fixed, 95\% CI) & $2.99[2.24,3.99]$ \\
\hline $\begin{array}{l}\text { 9.1 Unfractionated heparin } \\
\text { (subcutaneous) versus control }\end{array}$ & 4 & 19711 & Peto Odds Ratio (Peto, Fixed, 95\% CI) & $3.06[2.25,4.15]$ \\
\hline $\begin{array}{l}9.2 \text { Unfractionated heparin } \\
\text { (intravenous) versus control }\end{array}$ & 1 & 45 & Peto Odds Ratio (Peto, Fixed, 95\% CI) & $0.0[0.0,0.0]$ \\
\hline $\begin{array}{l}\text { 9.3 Low-molecular-weight } \\
\text { heparin versus control }\end{array}$ & 5 & 535 & Peto Odds Ratio (Peto, Fixed, 95\% CI) & $0.48[0.03,9.05]$ \\
\hline $\begin{array}{l}9.4 \text { Heparinoid } \\
\text { (subcutaneous) versus control }\end{array}$ & 2 & 132 & Peto Odds Ratio (Peto, Fixed, 95\% CI) & $7.66[0.15,386.16]$ \\
\hline $\begin{array}{l}9.5 \text { Heparinoid (intravenous) } \\
\text { versus control }\end{array}$ & 1 & 1281 & Peto Odds Ratio (Peto, Fixed, 95\% CI) & $3.31[1.20,9.15]$ \\
\hline $\begin{array}{l}9.6 \text { Oral vitamin } \mathrm{K} \text { antagonist } \\
\text { versus control }\end{array}$ & 2 & 81 & Peto Odds Ratio (Peto, Fixed, 95\% CI) & $0.14[0.00,6.82]$ \\
\hline $\begin{array}{l}\text { 9.7 Thrombin inhibitor versus } \\
\text { control }\end{array}$ & 2 & 294 & Peto Odds Ratio (Peto, Fixed, 95\% CI) & $0.0[0.0,0.0]$ \\
\hline $\begin{array}{l}9.8 \text { Direct thrombin inhibitor } \\
\text { (intravenous) versus control }\end{array}$ & 1 & 176 & Peto Odds Ratio (Peto, Fixed, 95\% CI) & $0.0[0.0,0.0]$ \\
\hline $\begin{array}{l}0 \text { Subgroup analysis by } \\
\text { anticoagulant dose: effect on } \\
\text { death or dependency }\end{array}$ & 8 & 22127 & Peto Odds Ratio (Peto, Fixed, 95\% CI) & $0.99[0.93,1.04]$ \\
\hline $\begin{array}{l}\text { 10.1 Adjusted full-dose } \\
\text { intravenous anticoagulant }\end{array}$ & 2 & 1409 & Peto Odds Ratio (Peto, Fixed, 95\% CI) & $0.95[0.75,1.20]$ \\
\hline
\end{tabular}


10.2 Medium fixed-dose anticoagulant

10.3 Low fixed-dose anticoagulant

Analysis I.I. Comparison I Anticoagulant versus control in acute presumed ischaemic stroke, Outcome I Dead or dependent at end of follow up (if > I month).

Review: Anticoagulants for acute ischaemic stroke

Comparison: I Anticoagulant versus control in acute presumed ischaemic stroke

Outcome: I Dead or dependent at end of follow up (if $>$ I month)

Study or subgroup $\quad$ Treatment Control Peto Peto

n/N n/N Peto,Fixed,95\% Cl Peto,Fixed,95\% Cl

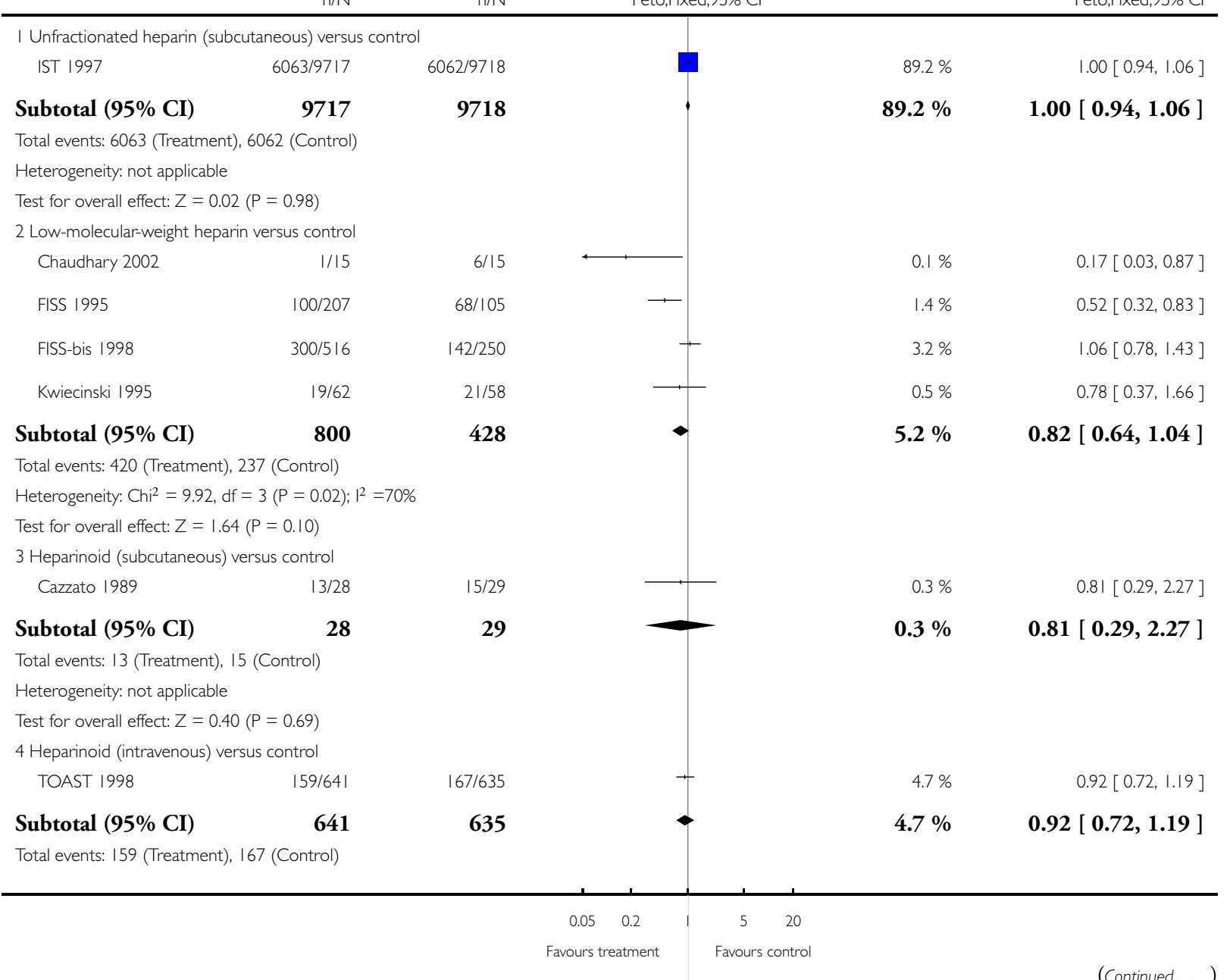




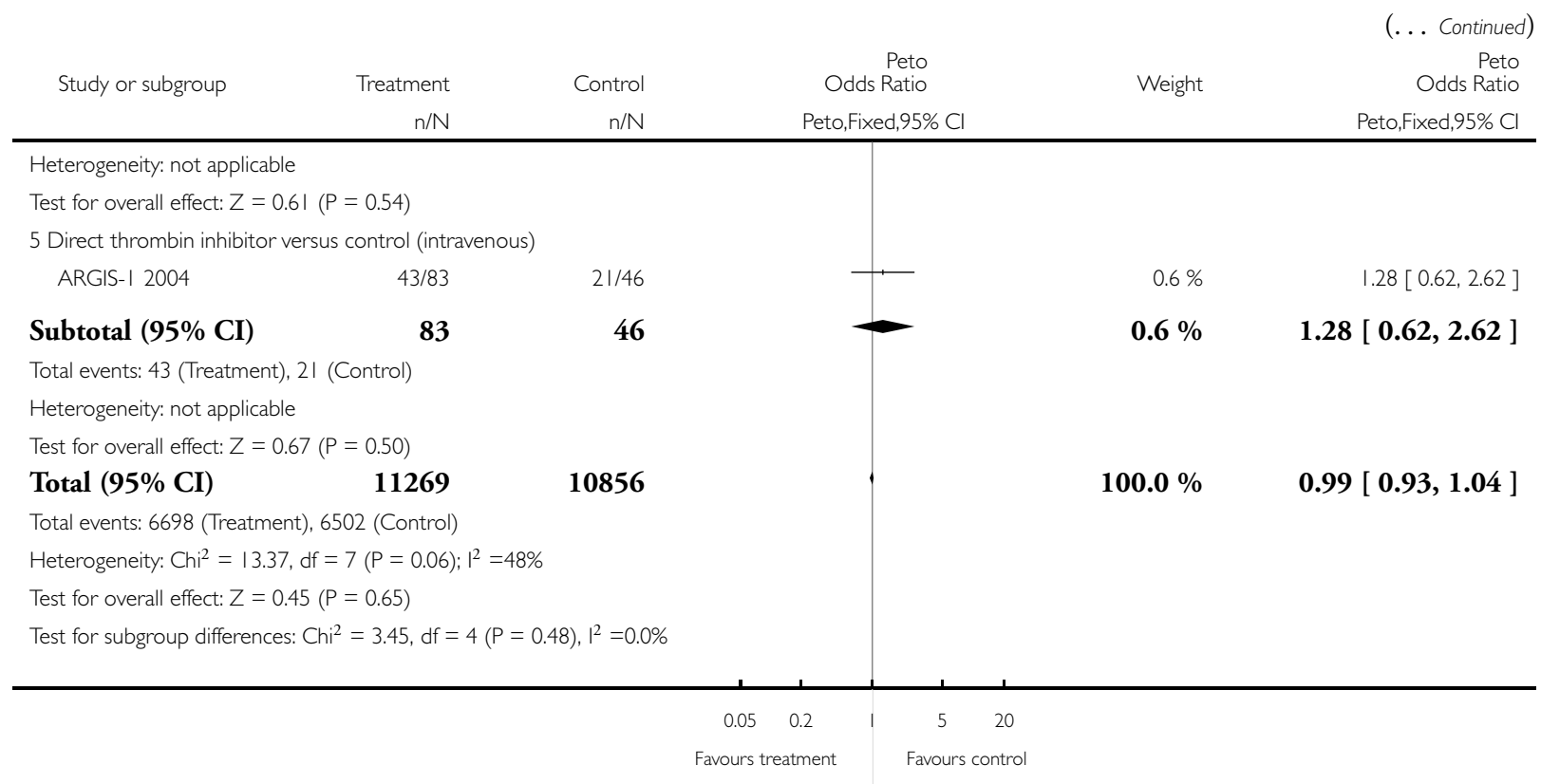




\section{Analysis I.2. Comparison I Anticoagulant versus control in acute presumed ischaemic stroke, Outcome 2 Death from all causes during treatment period.}

Review: Anticoagulants for acute ischaemic stroke

Comparison: I Anticoagulant versus control in acute presumed ischaemic stroke

Outcome: 2 Death from all causes during treatment period

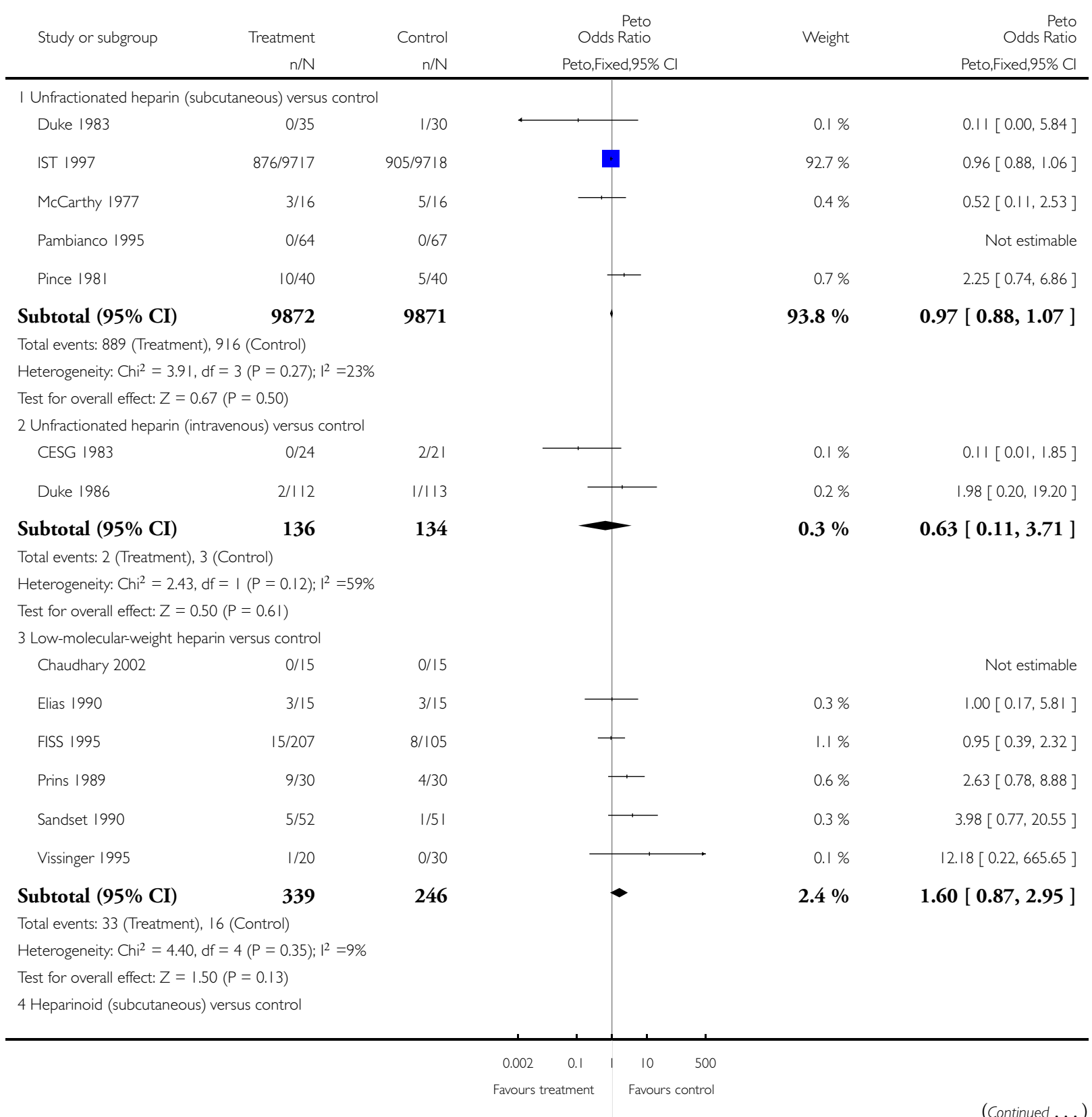




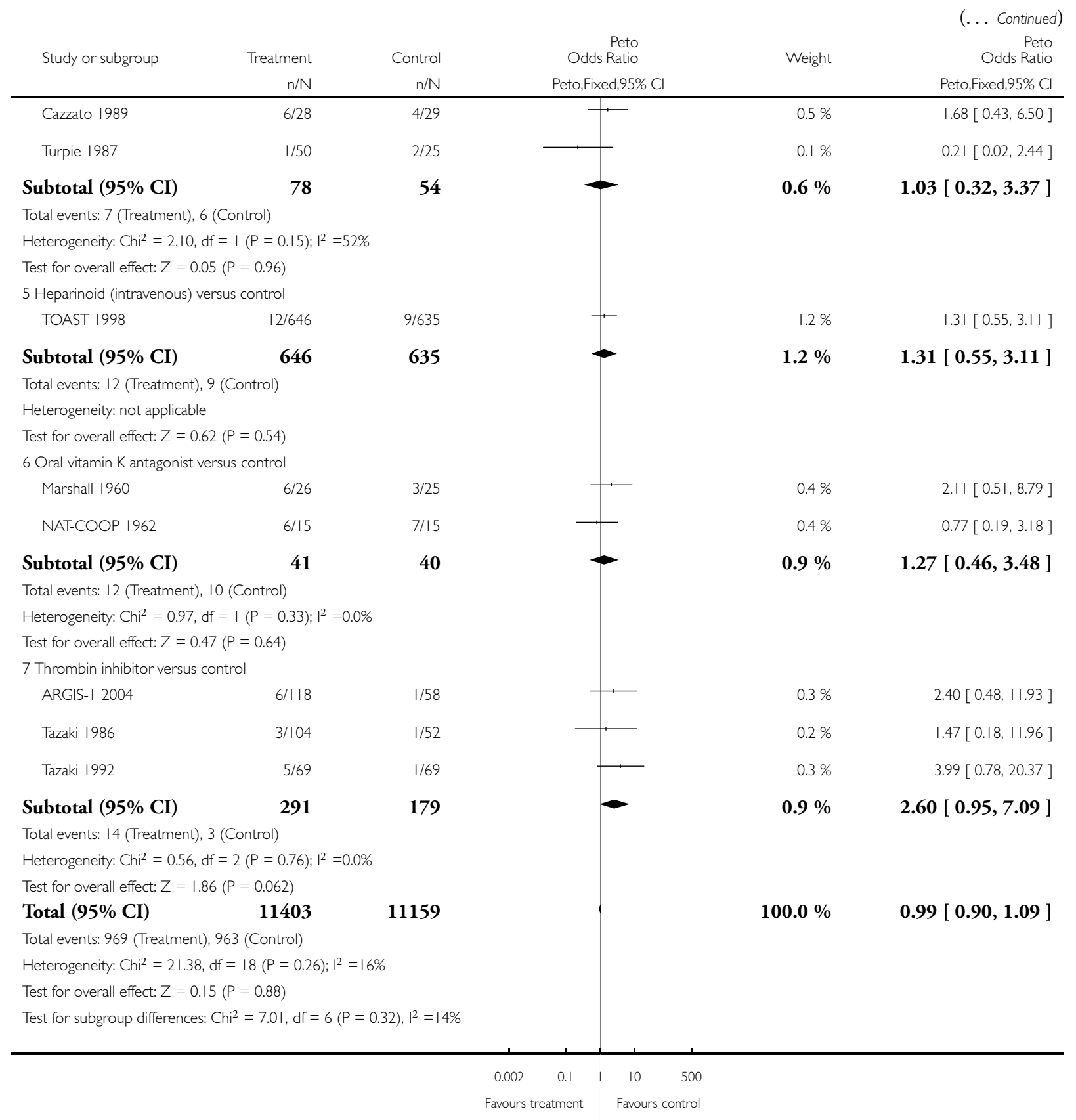




\section{Analysis I.3. Comparison I Anticoagulant versus control in acute presumed ischaemic stroke, Outcome 3 Death from all causes at final follow up (if $>$ I month).}

Review: Anticoagulants for acute ischaemic stroke

Comparison: I Anticoagulant versus control in acute presumed ischaemic stroke

Outcome: 3 Death from all causes at final follow up (if > I month)

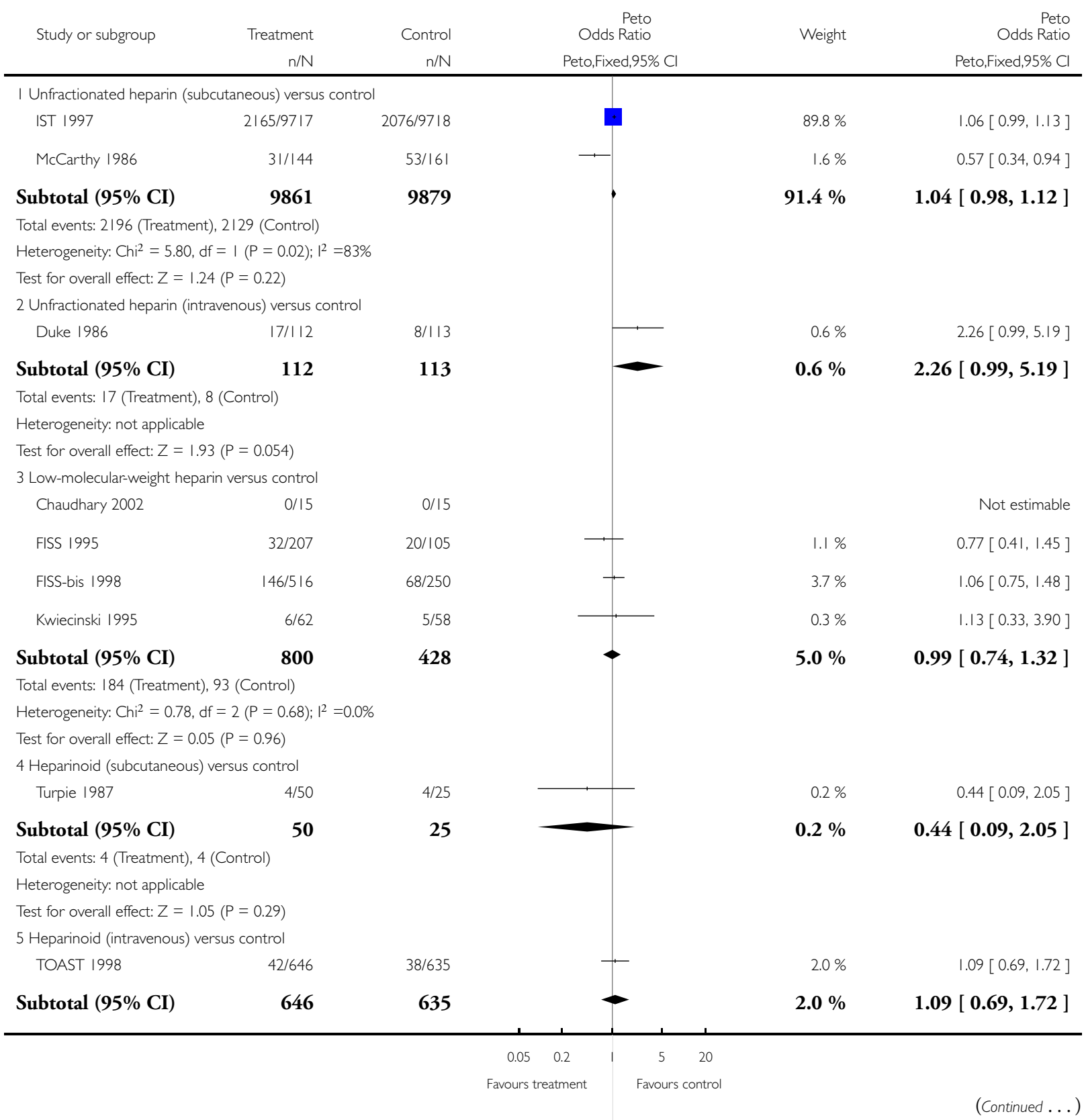




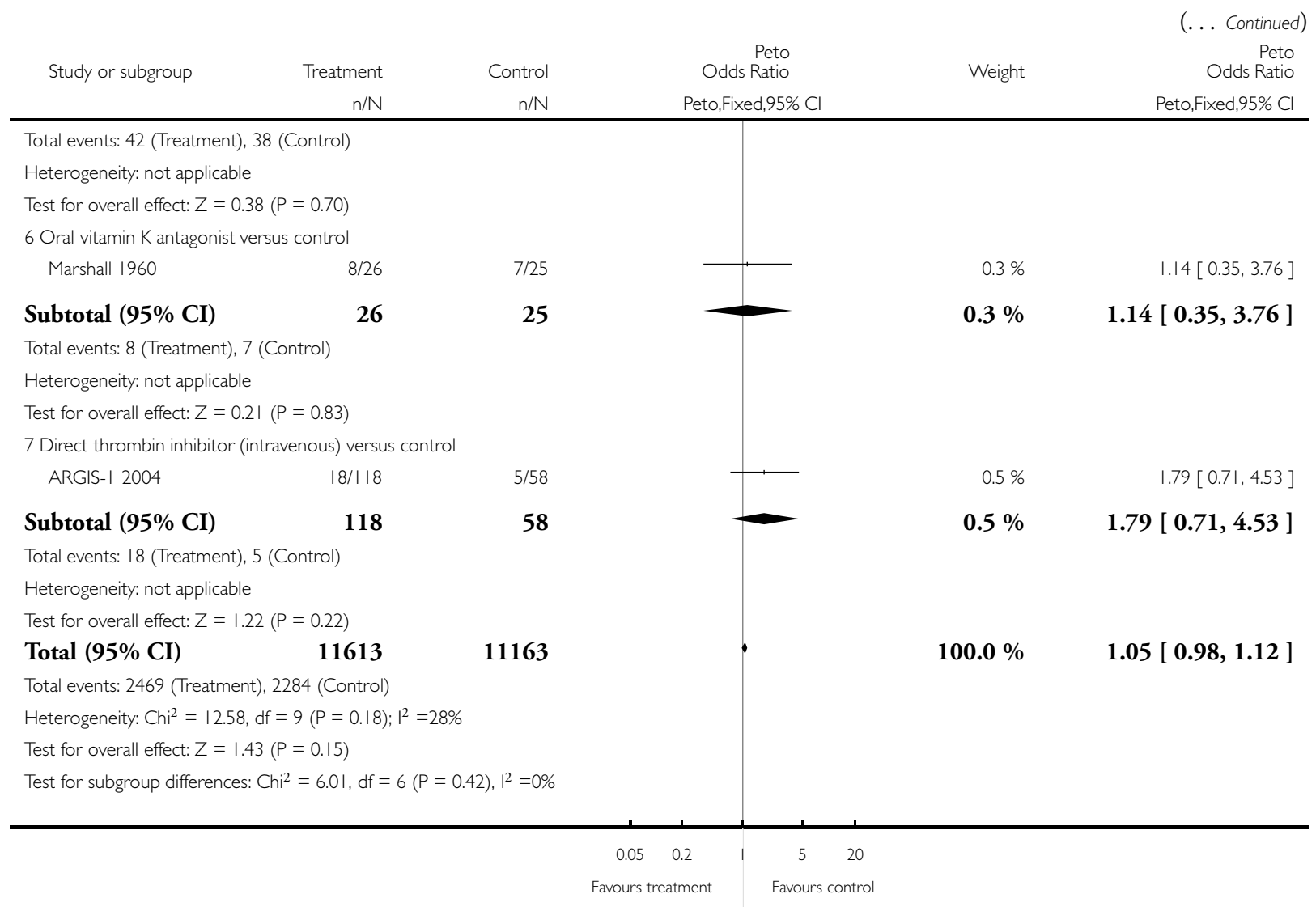




\section{Analysis I.4. Comparison I Anticoagulant versus control in acute presumed ischaemic stroke, Outcome 4 Deep vein thrombosis during treatment period.}

Review: Anticoagulants for acute ischaemic stroke

Comparison: I Anticoagulant versus control in acute presumed ischaemic stroke

Outcome: 4 Deep vein thrombosis during treatment period

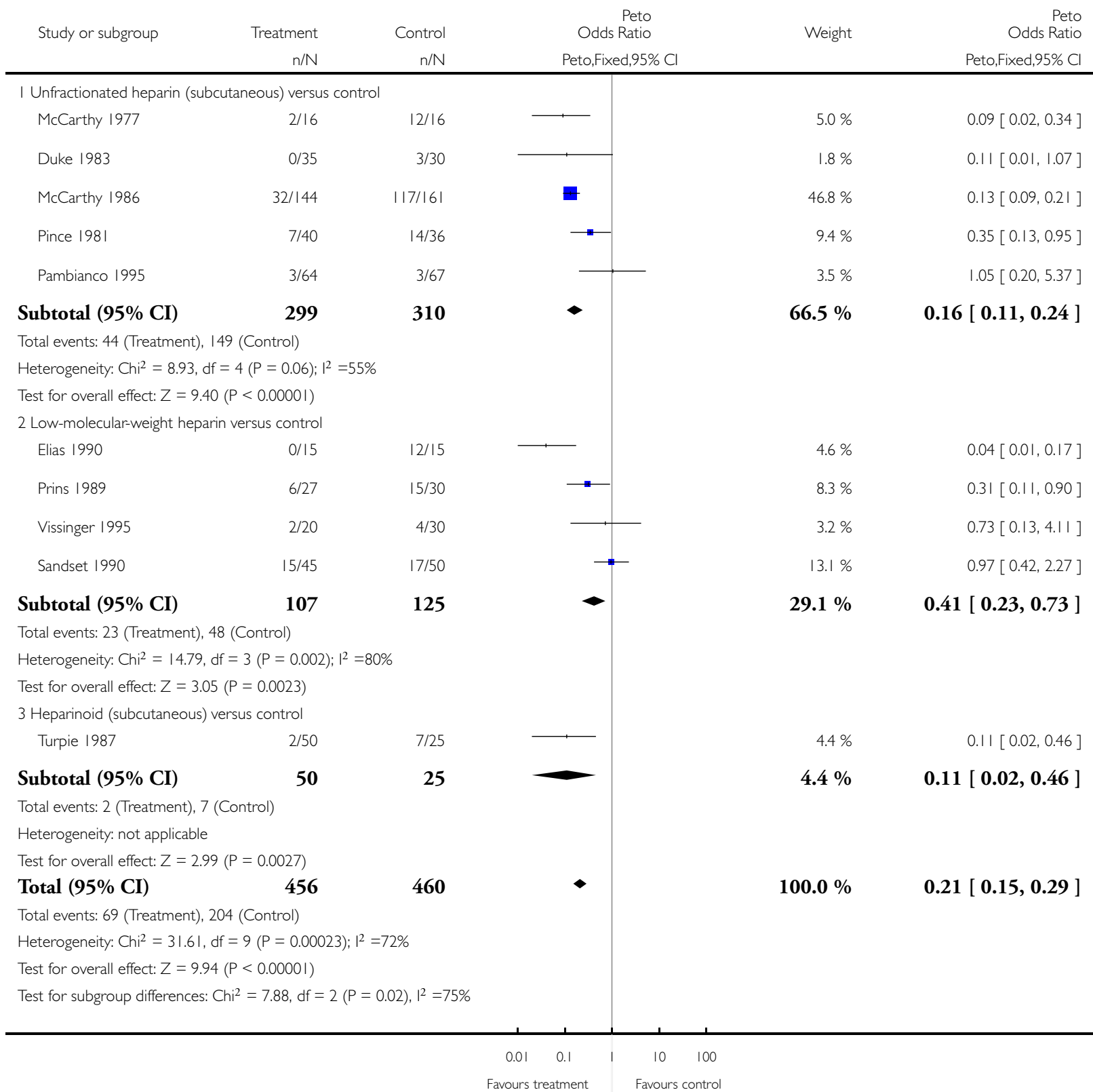


Analysis I.5. Comparison I Anticoagulant versus control in acute presumed ischaemic stroke, Outcome 5 Symptomatic pulmonary embolism during treatment period.

Review: Anticoagulants for acute ischaemic stroke

Comparison: I Anticoagulant versus control in acute presumed ischaemic stroke

Outcome: 5 Symptomatic pulmonary embolism during treatment period

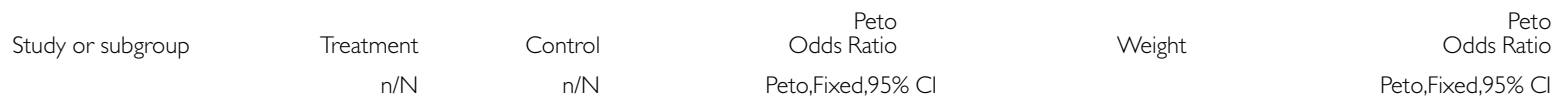

I Unfractionated heparin (subcutaneous) versus control

$\begin{array}{lll}\text { IST } 1997 & 53 / 9716 & 81 / 9718\end{array}$

$\begin{array}{lll}\text { Pambianco } 1995 & 2 / 64 & \text { |/67 }\end{array}$

$\begin{array}{lll}\text { Pince 198| } & \text { |/40 }\end{array}$

Subtotal (95\% CI) $\quad 9820 \quad 9825$

Total events: 56 (Treatment), 82 (Control)

Heterogeneity: $\mathrm{Chi}^{2}=2.37, \mathrm{df}=2(P=0.31) ; \mathrm{I}^{2}=16 \%$

Test for overall effect: $Z=2.21(P=0.027)$

2 Unfractionated heparin (intravenous) versus control

CESG 1983

$0 / 24$

$0 / 21$

Subtotal $(95 \% \mathrm{CI})$

24

21

Total events: 0 (Treatment), 0 (Control)

Heterogeneity: not applicable

Test for overall effect: not applicable

3 Low-molecular-weight heparin versus control

\begin{tabular}{|c|c|c|c|c|c|c|c|}
\hline Subtotal (9)\% C1) & 24 & 21 & & & & & Not estimable \\
\hline Total events: 0 (Treatmen & & & & & & & \\
\hline Heterogeneity: not applica & & & & & & & \\
\hline Test for overall effect: not & & & & & & & \\
\hline 3 Low-molecular-weight h & s contro & & & & & & \\
\hline Elias 1990 & $0 / 15$ & $1 / 15$ & & & & $0.6 \%$ & $0.14[0.00,6.82]$ \\
\hline FISS 1995 & 0/207 & $0 / 105$ & & & & & Not estimable \\
\hline FISS-bis 1998 & $9 / 516$ & $14 / 250$ & & $\rightarrow-$ & & $11.7 \%$ & $0.27[0.11,0.65]$ \\
\hline Kwiecinski 1995 & $0 / 62$ & $2 / 58$ & & & - & $1.2 \%$ & $0.12[0.01,2.01]$ \\
\hline Prins 1989 & $1 / 30$ & $2 / 30$ & & & & $1.7 \%$ & $0.50[0.05,5.02]$ \\
\hline Sandset 1990 & $2 / 52$ & $2 / 51$ & & & - & $2.3 \%$ & $0.98[0.13,7.17]$ \\
\hline Vissinger 1995 & $0 / 20$ & $0 / 30$ & & & & & Not estimable \\
\hline Subtotal (95\% CI) & 902 & 539 & & $<$ & & $17.5 \%$ & $0.31[0.15,0.64]$ \\
\hline Total events: 12 (Treatmer & (rol) & & & & & & \\
\hline Heterogeneity: $\mathrm{Chi}^{2}=2.1$ & $=0.71)$; & & & & & & \\
\hline Test for overall effect: $Z=$ & $.0016)$ & & & & & & \\
\hline 4 Heparinoid (subcutanec & ontrol & & & & & & \\
\hline Cazzato 1989 & $1 / 28$ & $0 / 29$ & & & & $0.6 \%$ & $7.66[0.15,386.16]$ \\
\hline Turpie 1987 & $0 / 50$ & $0 / 25$ & & & & & Not estimable \\
\hline & & & 0.002 & 0.1 & $10 \quad 500$ & & \\
\hline & & & Favours & tment & Favours control & & (Continued... \\
\hline
\end{tabular}

$\begin{array}{lll}\text { FISS } 1995 & 0 / 207 & 0 / 105\end{array}$

$\begin{array}{lll}\text { FISS-bis } 1998 & 9 / 516 & \text { 14/250 }\end{array}$

$\begin{array}{lll}\text { Kwiecinski } 1995 & 0 / 62 & \text { 2/58 }\end{array}$

$\begin{array}{lll}\text { Prins } 1989 & \text { I/30 }\end{array}$

Sandset $1990 \quad 2 / 52 \quad 2 / 51$

Vissinger 1995

$0 / 20 \quad 0 / 30$

Subtotal $(95 \% \mathrm{CI})$

902

539

Total events: 12 (Treatment), 2 I (Control)

Heterogeneity: $\mathrm{Chi}^{2}=2.15, \mathrm{df}=4(P=0.7 \mathrm{I}) ; \mathrm{I}^{2}=0.0 \%$

Test for overall effect: $Z=3.15(P=0.0016)$

4 Heparinoid (subcutaneous) versus control

Cazzato 1989

Turpie 1987

$0 / 50$

$0 / 25$

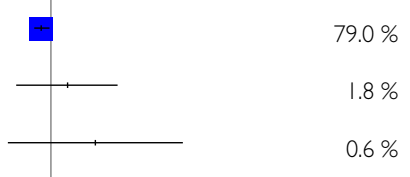

$81.4 \%$

Not estimable

Not estimable

15

250

\begin{tabular}{|c|c|c|c|c|c|c|c|}
\hline Subtotal (9)\% C1) & 24 & 21 & & & & & Not estimable \\
\hline Total events: 0 (Treatmen & & & & & & & \\
\hline Heterogeneity: not applica & & & & & & & \\
\hline Test for overall effect: not & & & & & & & \\
\hline 3 Low-molecular-weight h & s contro & & & & & & \\
\hline Elias 1990 & $0 / 15$ & $1 / 15$ & & & & $0.6 \%$ & $0.14[0.00,6.82]$ \\
\hline FISS 1995 & 0/207 & $0 / 105$ & & & & & Not estimable \\
\hline FISS-bis 1998 & $9 / 516$ & $14 / 250$ & & $\rightarrow-$ & & $11.7 \%$ & $0.27[0.11,0.65]$ \\
\hline Kwiecinski 1995 & $0 / 62$ & $2 / 58$ & & & - & $1.2 \%$ & $0.12[0.01,2.01]$ \\
\hline Prins 1989 & $1 / 30$ & $2 / 30$ & & & & $1.7 \%$ & $0.50[0.05,5.02]$ \\
\hline Sandset 1990 & $2 / 52$ & $2 / 51$ & & & - & $2.3 \%$ & $0.98[0.13,7.17]$ \\
\hline Vissinger 1995 & $0 / 20$ & $0 / 30$ & & & & & Not estimable \\
\hline Subtotal (95\% CI) & 902 & 539 & & $<$ & & $17.5 \%$ & $0.31[0.15,0.64]$ \\
\hline Total events: 12 (Treatmer & (rol) & & & & & & \\
\hline Heterogeneity: $\mathrm{Chi}^{2}=2.1$ & $=0.71)$; & & & & & & \\
\hline Test for overall effect: $Z=$ & $.0016)$ & & & & & & \\
\hline 4 Heparinoid (subcutanec & ontrol & & & & & & \\
\hline Cazzato 1989 & $1 / 28$ & $0 / 29$ & & & & $0.6 \%$ & $7.66[0.15,386.16]$ \\
\hline Turpie 1987 & $0 / 50$ & $0 / 25$ & & & & & Not estimable \\
\hline & & & 0.002 & 0.1 & $10 \quad 500$ & & \\
\hline & & & Favours & tment & Favours control & & (Continued... \\
\hline
\end{tabular}

$0 / 30$

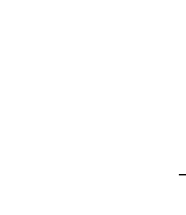

Anticoagulants for acute ischaemic stroke (Review) 


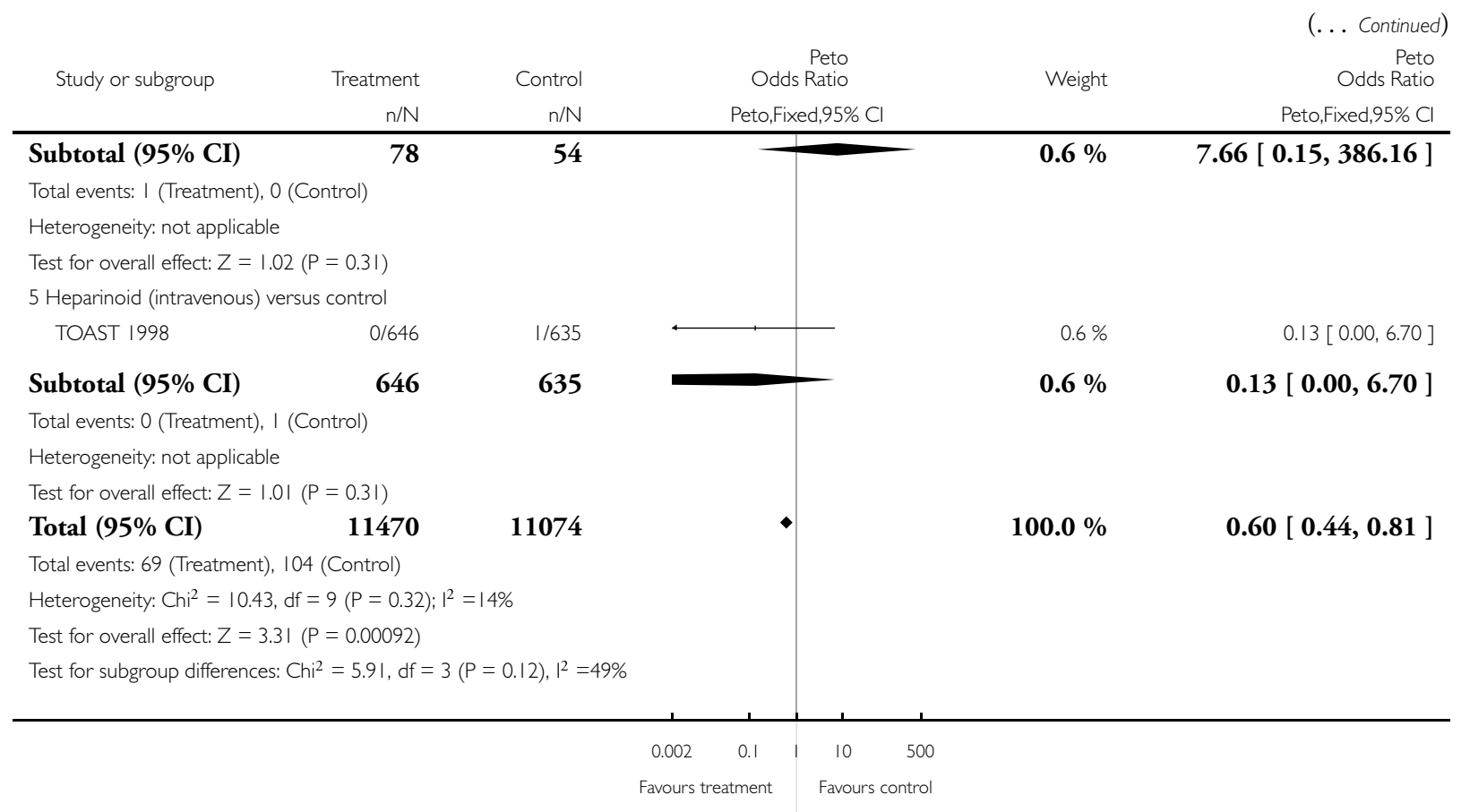


Analysis I.6. Comparison I Anticoagulant versus control in acute presumed ischaemic stroke, Outcome 6 Recurrent ischaemic or unknown stroke during treatment period.

Review: Anticoagulants for acute ischaemic stroke

Comparison: I Anticoagulant versus control in acute presumed ischaemic stroke

Outcome: 6 Recurrent ischaemic or unknown stroke during treatment period

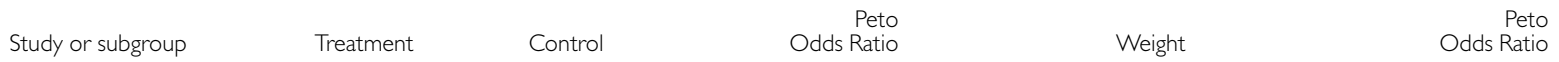

$n / N \quad n / N \quad$ Peto,Fixed,95\% Cl Peto,Fixed,95\% Cl

I Unfractionated heparin (subcutaneous) versus control

IST $1997 \quad 283 / 9717 \quad 370 / 9718$

$\begin{array}{lll}\text { Pambianco } 1995 & 0 / 64 & 0 / 67\end{array}$

Subtotal (95\% CI) $\quad 9781 \quad 9785$

Total events: 283 (Treatment), 370 (Control)

Heterogeneity: not applicable

Test for overall effect: $Z=3.46(P=0.00054)$

2 Unfractionated heparin (intravenous) versus control CESG 1983

Subtotal $(95 \% \mathrm{CI})$

24

21

$0.3 \%$

$0.11[0.01,1.85]$

Total events: 0 (Treatment), 2 (Control)

Heterogeneity: not applicable

Test for overall effect: $Z=1.53(P=0.13)$

3 Low-molecular-weight heparin versus control

FISS 1995

$6 / 207$

Vissinger 1995

$6 / 105$

227

Subtotal (95\% CI)

135

Total events: 6 (Treatment), 6 (Control)

Heterogeneity: not applicable

Test for overall effect: $Z=1.22(P=0.22)$

4 Heparinoid (subcutaneous) versus control

Cazzato 1989

Turpie 1987

Subtotal (95\% CI)

78

$$
0 / 30
$$

$+$

$95.1 \%$

$0.76[0.65,0.89]$

Not estimable

$95.1 \%$

$0.76[0.65,0.89]$

$0.3 \%$

$0.11[0.01,1.85$ ]

Total events: I (Treatment), 0 (Control)

Heterogeneity: not applicable

Test for overall effect: $Z=0.7 \mid(P=0.48)$

5 Heparinoid (intravenous) versus control

TOAST 1998

$7 / 646$

646

Subtotal (95\% CI)

Total events: 7 (Treatment), 7 (Control)

635
$2.1 \%$

$0.98[0.34,2.82]$

$2.1 \%$

$0.98[0.34,2.82$ ]

(Continued ....) 


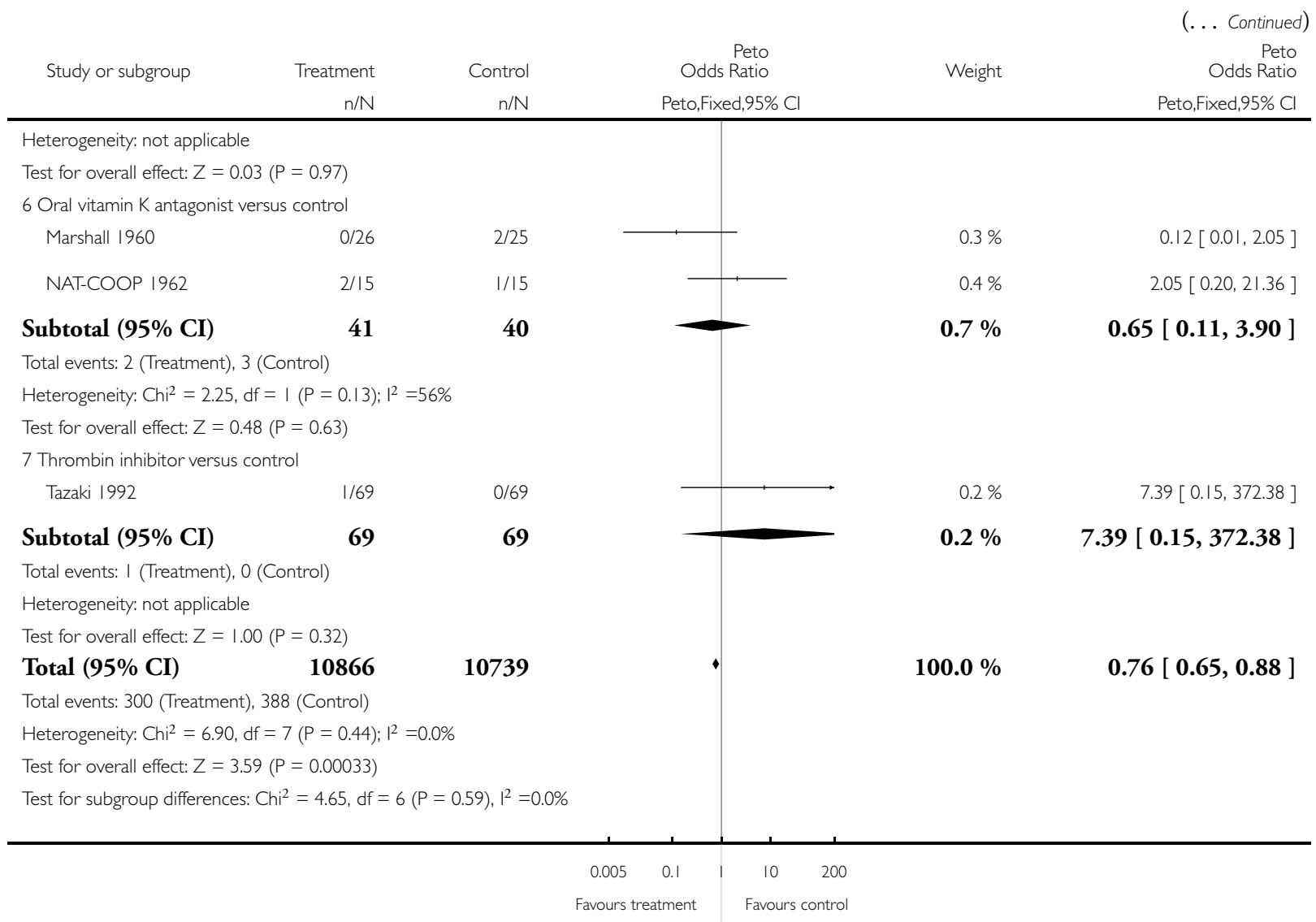


Analysis I.7. Comparison I Anticoagulant versus control in acute presumed ischaemic stroke, Outcome 7 Symptomatic intracranial haemorrhage during treatment period.

Review: Anticoagulants for acute ischaemic stroke

Comparison: I Anticoagulant versus control in acute presumed ischaemic stroke

Outcome: 7 Symptomatic intracranial haemorrhage during treatment period

\begin{tabular}{|c|c|c|c|c|c|}
\hline \multirow[t]{2}{*}{ Study or subgroup } & Treatment & Control & $\begin{array}{r}\text { Peto } \\
\text { Odds Ratio }\end{array}$ & \multirow[t]{2}{*}{ Weight } & \multirow{2}{*}{$\begin{array}{r}\text { Peto } \\
\text { Odds Ratio } \\
\text { Peto Fixed } 95 \% \text { Cl }\end{array}$} \\
\hline & $n / N$ & $n / N$ & Peto,Fixed,95\% Cl & & \\
\hline \multicolumn{6}{|c|}{ I Unfractionated heparin (subcutaneous) versus control } \\
\hline Duke 1983 & $0 / 35$ & 0/30 & & & Not estimable \\
\hline IST 1997 & $120 / 9717$ & $4|/ 97| 8$ & $\boldsymbol{B}$ & $74.5 \%$ & $2.69[1.97,3.67]$ \\
\hline Pambianco 1995 & $0 / 64$ & 0/67 & & & Not estimable \\
\hline Subtotal $(95 \% \mathrm{CI})$ & 9816 & 9815 & • & $74.5 \%$ & $2.69[1.97,3.67]$ \\
\hline \multicolumn{6}{|c|}{ Total events: 120 (Treatment), 4I (Control) } \\
\hline \multicolumn{6}{|c|}{ Heterogeneity: not applicable } \\
\hline \multicolumn{6}{|c|}{ Test for overall effect: $Z=6.25(P<0.0000$ I $)$} \\
\hline \multicolumn{6}{|c|}{2 Unfractionated heparin (intravenous) versus control } \\
\hline CESG 1983 & $0 / 24$ & $0 / 21$ & & & Not estimable \\
\hline Duke 1986 & $0 / 112$ & $0 / 113$ & & & Not estimable \\
\hline Subtotal $(95 \% \mathrm{CI})$ & 136 & 134 & & & Not estimable \\
\hline \multicolumn{6}{|c|}{ Total events: 0 (Treatment), 0 (Control) } \\
\hline \multicolumn{6}{|c|}{ Heterogeneity: not applicable } \\
\hline \multicolumn{6}{|c|}{ Test for overall effect: not applicable } \\
\hline \multicolumn{6}{|c|}{3 Low-molecular-weight heparin versus control } \\
\hline Chaudhary 2002 & $0 / 15$ & $0 / 15$ & & & Not estimable \\
\hline FISS 1995 & 0/207 & $1 / 105$ & - & $0.4 \%$ & $0.05[0.00,3.24]$ \\
\hline FISS-bis 1998 & $25 / 516$ & $7 / 250$ & - & $12.6 \%$ & $1.67[0.78,3.54]$ \\
\hline Prins 1989 & $1 / 30$ & 0/30 & & $0.5 \%$ & $7.39[0.15,372.38]$ \\
\hline Sandset 1990 & 2/52 & $|/ 5|$ & T- & $1.4 \%$ & $1.94[0.20,19.03]$ \\
\hline Vissinger 1995 & $0 / 20$ & 0/30 & & & Not estimable \\
\hline Subtotal $(95 \% \mathrm{CI})$ & 840 & 481 & - & $14.9 \%$ & $1.61[0.80,3.22]$ \\
\hline \multicolumn{6}{|c|}{ Total events: 28 (Treatment), 9 (Control) } \\
\hline \multicolumn{6}{|c|}{ Heterogeneity: $\mathrm{Ch}^{2}=3.27, \mathrm{df}=3(\mathrm{P}=0.35) ; \mathrm{I}^{2}=8 \%$} \\
\hline \multicolumn{6}{|c|}{ Test for overall effect: $Z=1.33(P=0.18)$} \\
\hline \multicolumn{6}{|c|}{4 Heparinoid (subcutaneous) versus control } \\
\hline Turpie 1987 & 1/50 & 0/25 & & $0.4 \%$ & $4.48[0.07,286.49]$ \\
\hline Subtotal $(95 \% \mathrm{CI})$ & 50 & 25 & & $0.4 \%$ & $4.48[0.07,286.49]$ \\
\hline
\end{tabular}




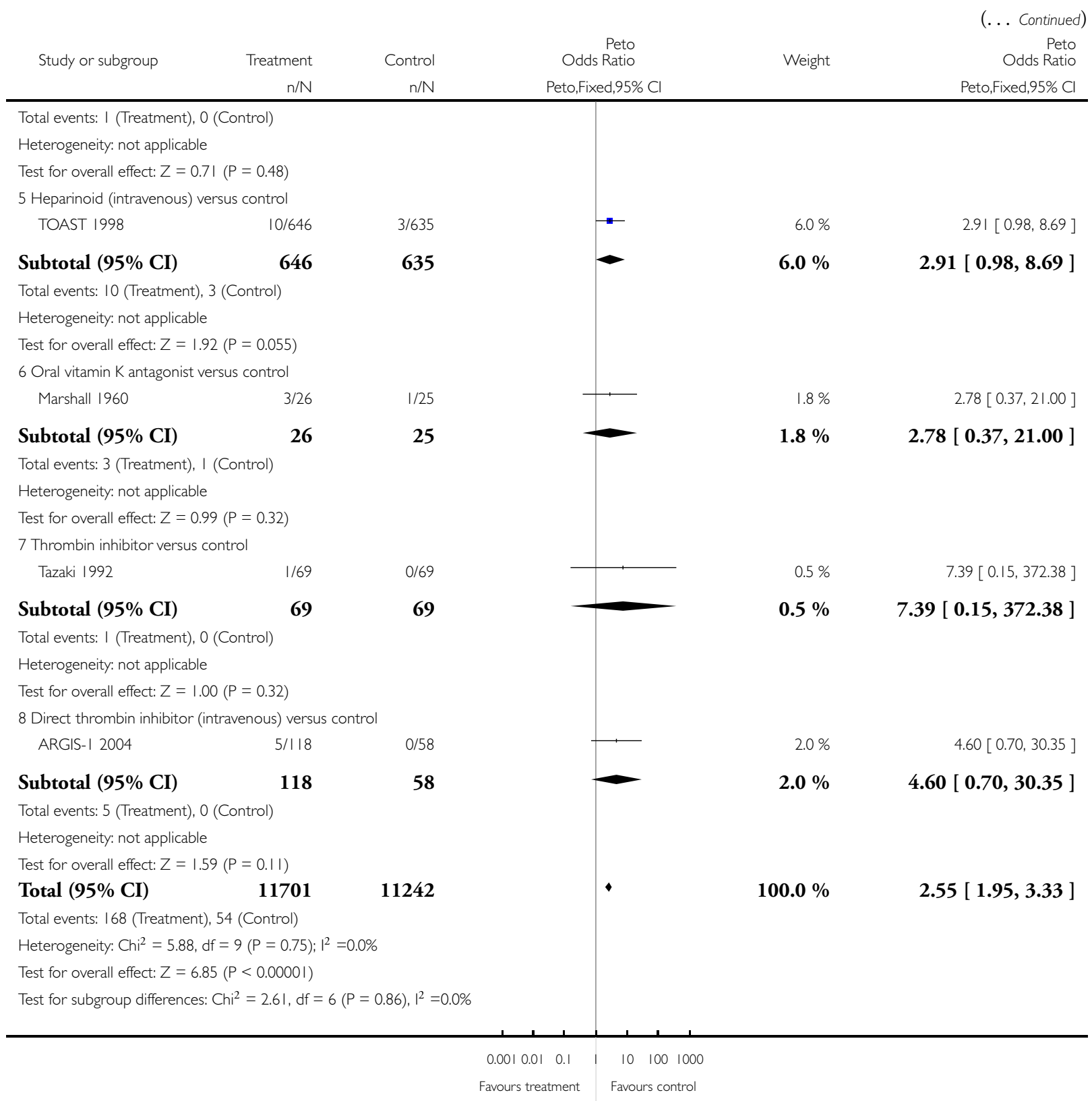


Analysis I.8. Comparison I Anticoagulant versus control in acute presumed ischaemic stroke, Outcome 8 Any recurrent stroke or symptomatic intracranial haemorrhage during treatment period or follow up ( $>$ I month).

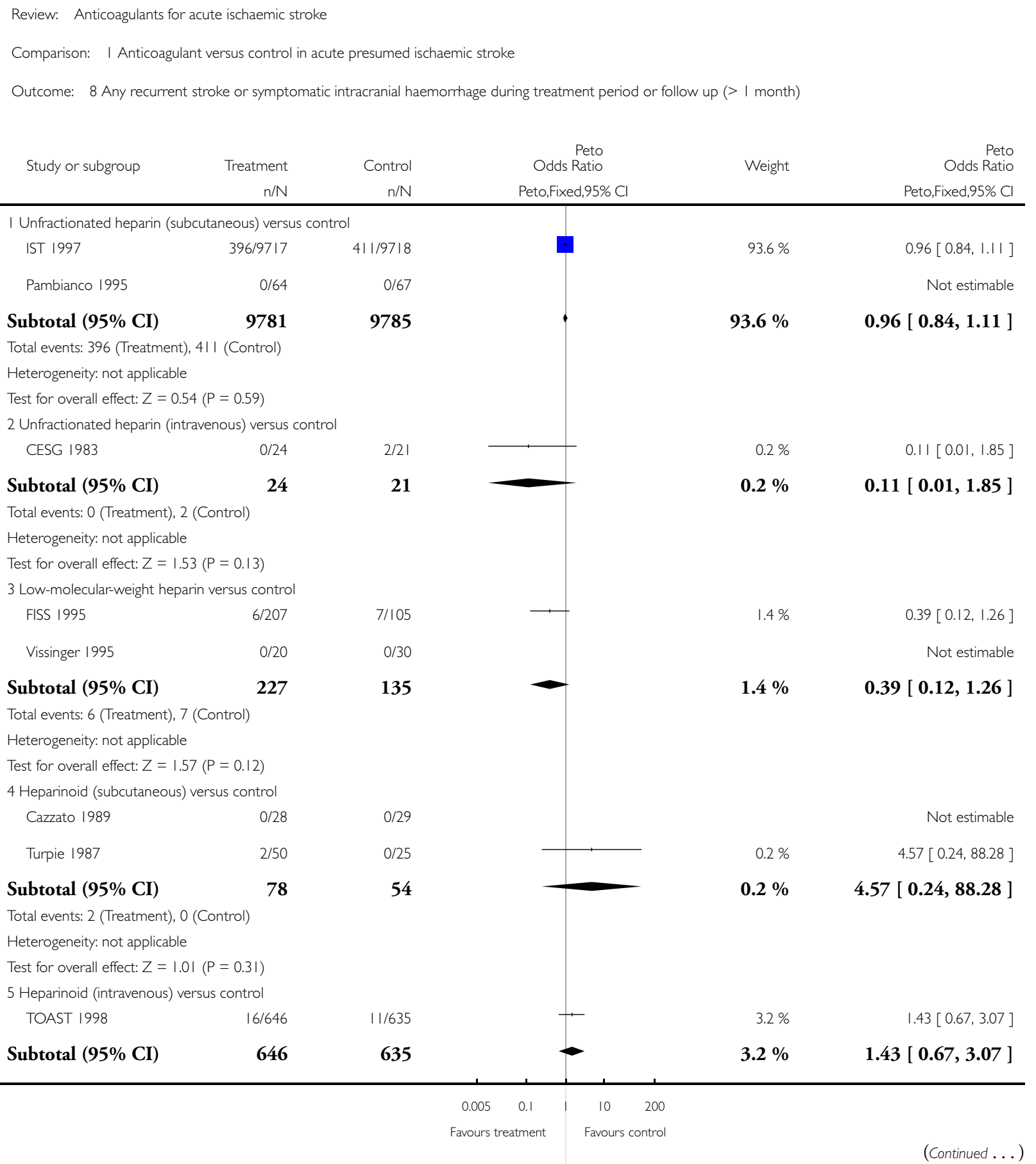




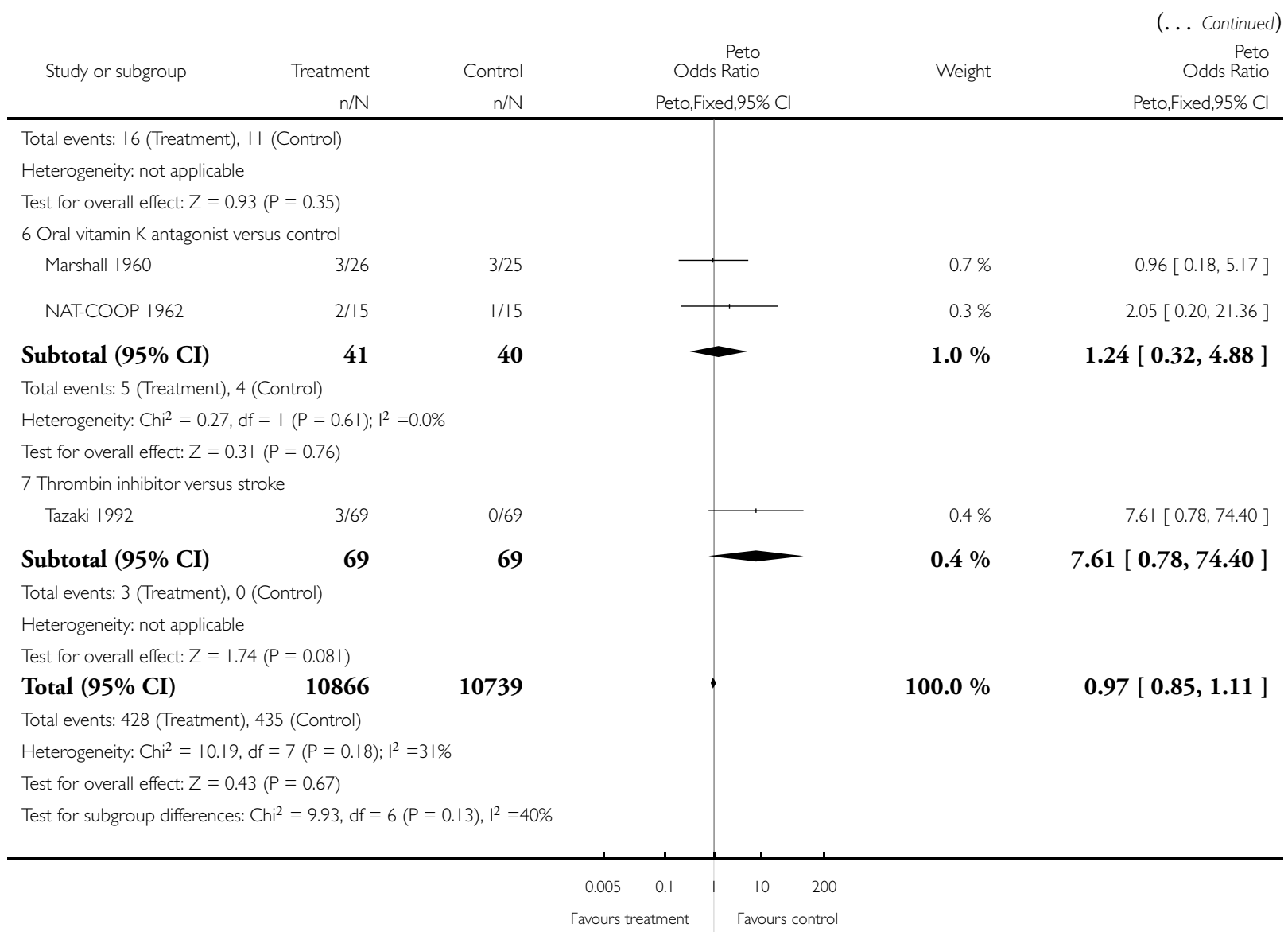


Analysis I.9. Comparison I Anticoagulant versus control in acute presumed ischaemic stroke, Outcome 9 Major extracranial haemorrhage during treatment period.

Review: Anticoagulants for acute ischaemic stroke

Comparison: I Anticoagulant versus control in acute presumed ischaemic stroke

Outcome: 9 Major extracranial haemorrhage during treatment period

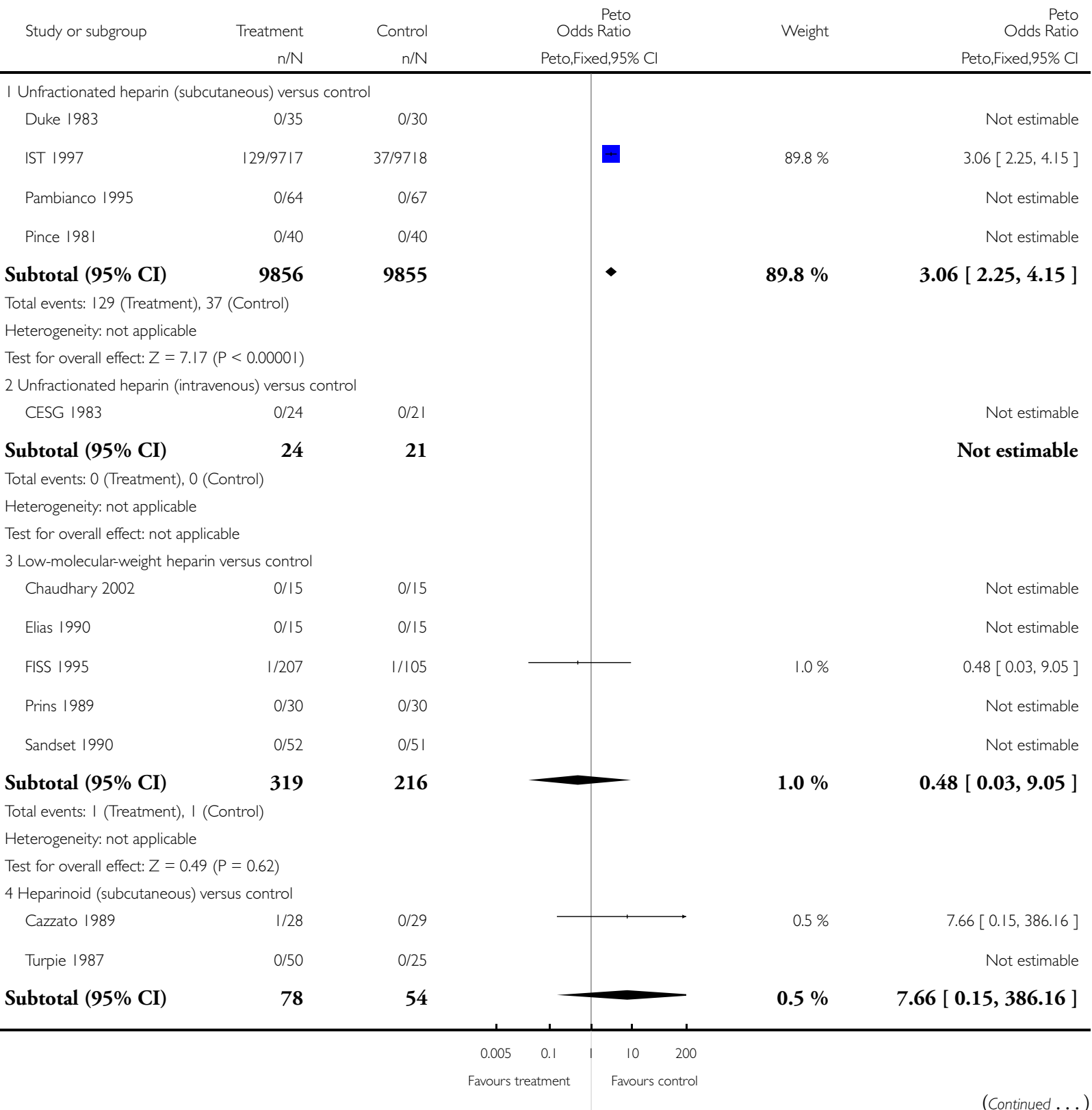




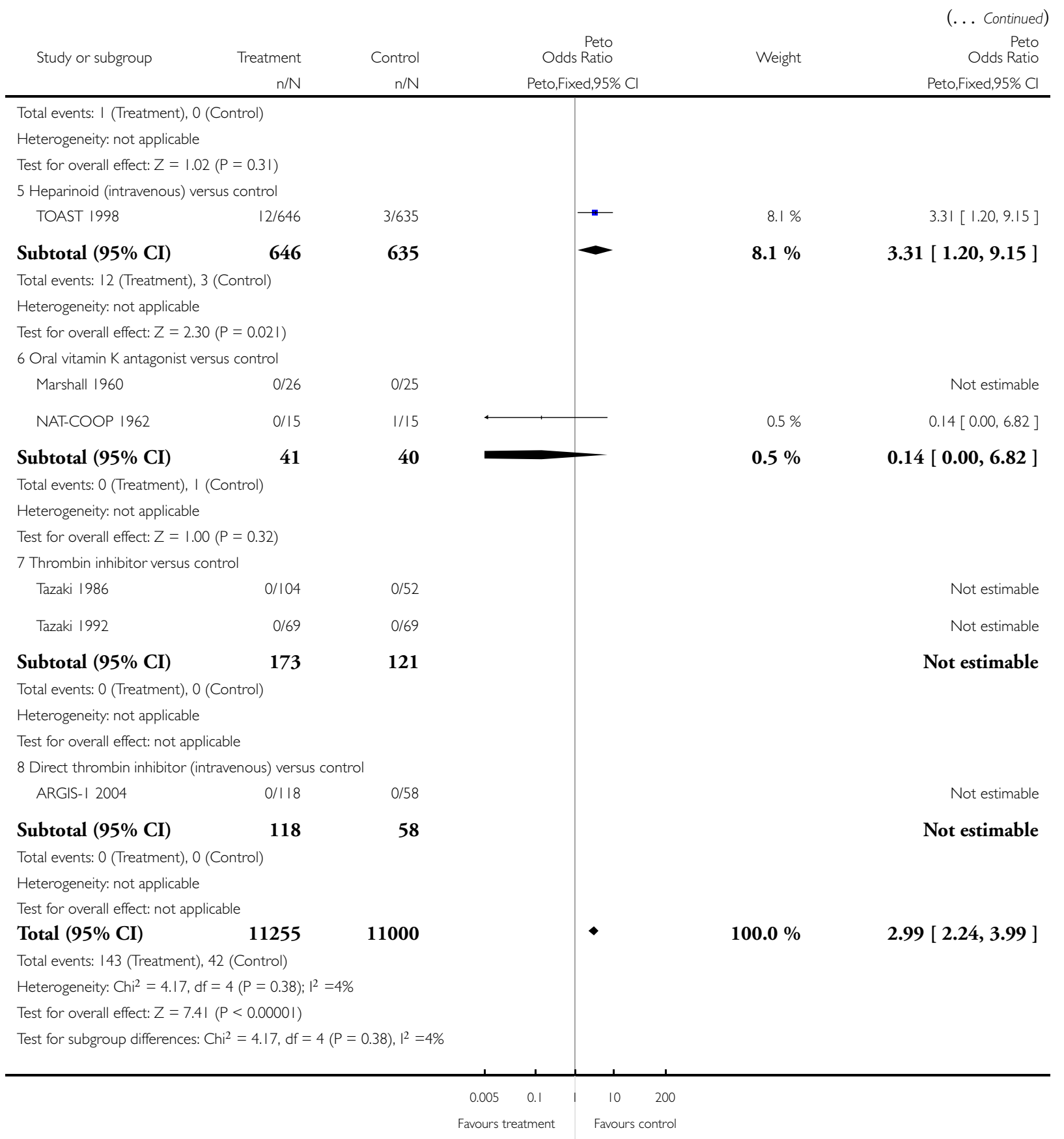


Analysis I.10. Comparison I Anticoagulant versus control in acute presumed ischaemic stroke, Outcome 10 Subgroup analysis by anticoagulant dose: effect on death or dependency.

Review: Anticoagulants for acute ischaemic stroke

Comparison: I Anticoagulant versus control in acute presumed ischaemic stroke

Outcome: 10 Subgroup analysis by anticoagulant dose: effect on death or dependency

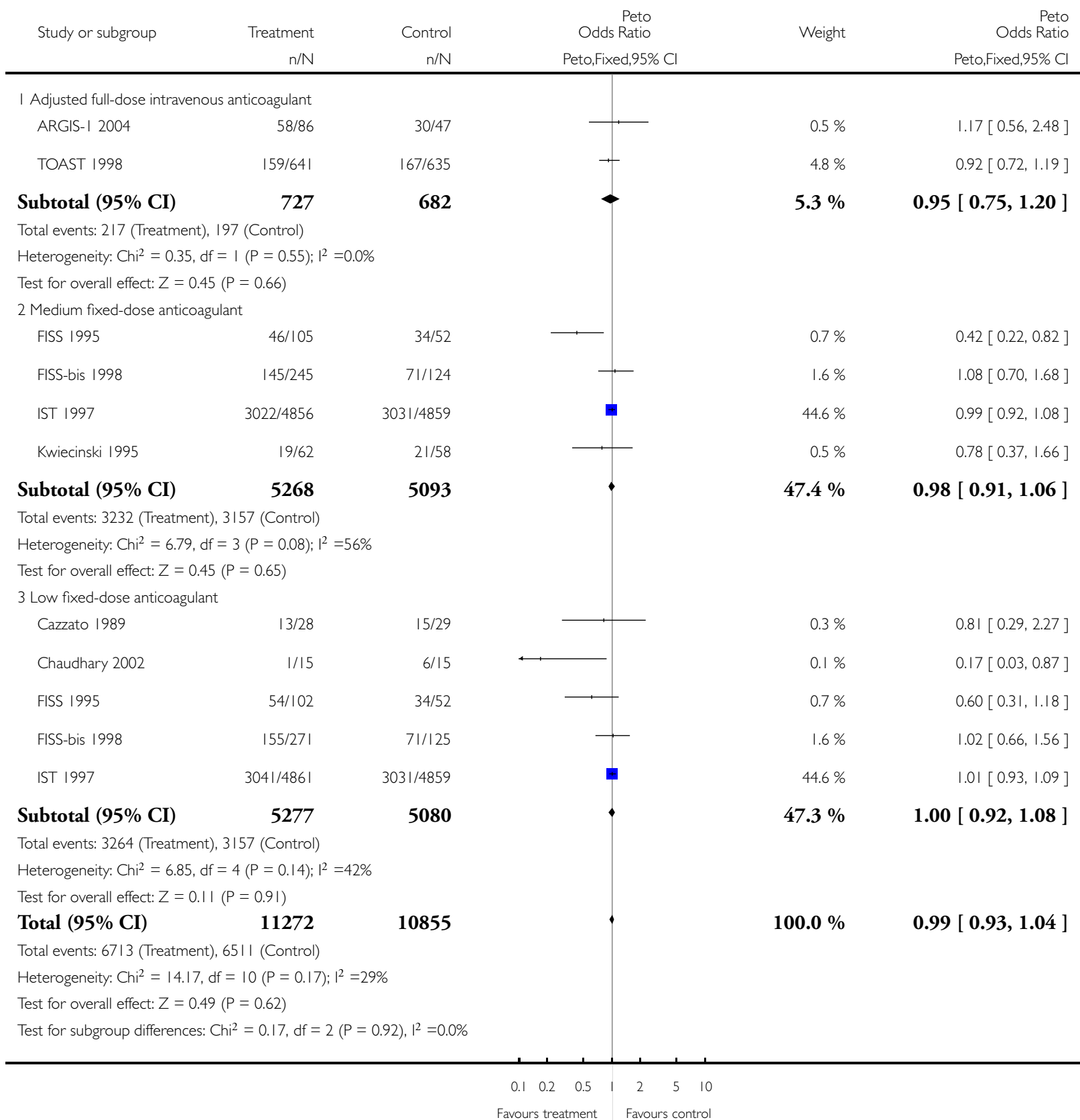

Anticoagulants for acute ischaemic stroke (Review)

Copyright @ 2015 The Cochrane Collaboration. Published by John Wiley \& Sons, Ltd. 


\section{A P P E N D I C E S}

\section{Appendix I. Cochrane Library Databases (CENTRAL, CDSR, DARE, HTA)}

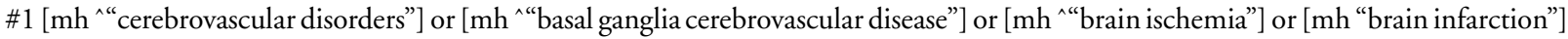
or [mh “"hypoxia-ischemia, brain”] or [mh “"carotid artery diseases”] or [mh “"carotid artery thrombosis"] or [mh “"carotid artery, internal, dissection”] or [mh “ intracranial arterial diseases”] or [mh ^"cerebral arterial diseases”] or [mh “"infarction, anterior cerebral artery”] or [mh “"infarction, middle cerebral artery”] or [mh “"infarction, posterior cerebral artery”] or [mh "intracranial embolism and thrombosis"] or [mh stroke] or [mh “"vertebral artery dissection”]

\#2 isch*mi* near/5 (stroke* or apoplex* or cerebral next vasc* or cerebrovasc* or cva):ti,ab

\#3 (brain or cerebr* or cerebell* or vertebrobasil* or hemispher* or intracran* or intracerebral or infratentorial or supratentorial or middle next cerebr* or mca* or "anterior circulation" or "basilar artery" or "vertebral artery") near/5 (isch*mi* or infarct* or thrombo* or emboli* or occlus* or hypoxi*):ti,ab

\#4 \#1 or \#2 or \#3

$\# 5$ [mh anticoagulants]

\#6 [mh "Blood coagulation factors"/AI,DE] or [mh "Blood coagulation"/AI,DE]

\#7 (anticoagul* or antithromb*):ti,ab

\#8 [mh ^Warfarin] or [mh ^4-hydroxycoumarins] or [mh âcenocoumarol] or [mh ^coumarins] or [mh ^dicumarol] or [mh ^"ethyl biscoumacetate"] or [mh ^phenindione] or [mh ^phenprocoumon]

\#9 [mh "Vitamin K"/AI]

\#10 (warfarin* or coumadin* or coumarin* or cumarin* or phenprocoum* or phenprocum* or dicoumar* or dicumar* or acenocoumar* or acenocumar* or fluindione or phenindione or clorindione or diphenadione or "ethyl biscoumacetate"):ti,ab

\#11 (Vitamin next K next antagonist* or VKA or VKAs or “antivitamin K”):ti,ab

\#12 [mh antithrombins] or [mh “"hirudin therapy"] or [mh ^thrombin/AI]

\#13 ((direct* near/5 thrombin near/5 inhib*) or DTI or DTIs):ti,ab

\#14 (argatroban or MD805 or "MD-805" or dabigatran or ximelagatran or melagatran or efegatran or flovagatran or inogatran or napsagatran or bivalirudin or lepirudin or hirudin* or desirudin or desulfatohirudin or hirugen or hirulog or AZD0837 or bothrojaracin or odiparcil):ti,ab

$\# 15$ [mh “"factor Xa”/AI]

\#16 (("factor Xa" or "factor 10a" or fXa or "autoprothrombin c" or thrombokinase) near/5 inhib*):ti,ab

\#17 (activated near/5 ("factor X" or "factor 10") near/5 inhib*):ti,ab

\#18 xabans:ti,ab

\#19 (antistasin or apixaban or betrixaban or "du 176b" or eribaxaban or fondaparinux or idraparinux or otamixaban or razaxaban or rivaroxaban or yagin or "ym 150" or ym150 or LY517717 or darexaban or edoxaban or SSR126517E or fidexaban or idrabiotaparinux or letaxaban or tanogitran or taxexaban):ti,ab

\#20 [mh ^heparin] or [mh "heparin, low-molecular-weight"] or [mh ^heparinoids]

\#21 (heparin* or lmwh* or enoxaparin* or glycosaminoglycan* or nadroparin* or mesoglycan* or tedelparin* or certoparin or tinzaparin or parnaparin or dalteparin or reviparin or fraxiparin* or danaparoid or lomoparan or "org 10172" or mesoglycan or pentosan next polysul* or sp54 or "sp-54" or cy222 or "cy-222" or cy216 or "cy-216" or dermatan next sul* or heparan next sul*):ti,ab $\# 22$ or \#5-\#21\}

$\# 23 \# 4$ and \#22

\#24 atrial fibrillation:ti

\#25 \#23 not \#24

Anticoagulants for acute ischaemic stroke (Review) 


\section{Appendix 2. MEDLINE (Ovid)}

1. cerebrovascular disorders/ or basal ganglia cerebrovascular disease/ or brain ischemia/ or exp brain infarction/ or hypoxia-ischemia, brain/ or carotid artery diseases/ or carotid artery thrombosis/ or carotid artery, internal, dissection/ or intracranial arterial diseases/ or cerebral arterial diseases/ or infarction, anterior cerebral artery/ or infarction, middle cerebral artery/ or infarction, posterior cerebral artery/ or exp "intracranial embolism and thrombosis"/ or exp stroke/ or vertebral artery dissection/

2. (isch?emi\$ adj5 (stroke\$ or apoplex\$ or cerebral vasc\$ or cerebrovasc $\$$ or cva)).tw.

3. ((brain or cerebr $\$$ or cerebell $\$$ or vertebrobasil $\$$ or hemispher $\$$ or intracran $\$$ or intracerebral or infratentorial or supratentorial or middle cerebr $\$$ or mca $\$$ or anterior circulation or basilar artery or vertebral artery) adj5 (isch?emi $\$$ or infarct $\$$ or thrombo $\$$ or emboli $\$$ or occlus\$ or hypoxi\$)).tw.

4. 1 or 2 or 3

5. exp anticoagulants/

6. exp Blood coagulation factors/ai, de or exp Blood coagulation/ai, de

7. (anticoagul\$ or antithromb\$).tw.

8. Warfarin/ or 4-hydroxycoumarins/ or acenocoumarol/ or coumarins/ or dicumarol/ or ethyl biscoumacetate/ or phenindione/ or phenprocoumon/

9. $\exp$ Vitamin K/ai

10. (warfarin $\$$ or coumadin $\$$ or coumarin $\$$ or cumarin $\$$ or phenprocoum $\$$ or phenprocum $\$$ or dicoumar $\$$ or dicumar $\$$ or acenocoumar\$ or acenocumar\$ or fluindione or phenindione or clorindione or diphenadione or ethyl biscoumacetate).tw, nm.

11. (Vitamin K antagonist\$ or VKA or VKAs or antivitamin K).tw.

12. exp antithrombins/ or hirudin therapy/ or thrombin/ai

13. ((direct $\$$ adj5 thrombin adj5 inhib\$) or DTI\$1).tw.

14. (argatroban or MD805 or MD-805 or dabigatran or ximelagatran or melagatran or efegatran or flovagatran or inogatran or napsagatran or bivalirudin or lepirudin or hirudin\$ or desirudin or desulfatohirudin or hirugen or hirulog or AZD0837 or bothrojaracin or odiparcil).tw,nm.

15. factor Xa/ai

16. ((factor Xa or factor 10a or XXa or autoprothrombin c or thrombokinase) adj5 inhib\$).tw.

17. (activated adj5 (factor X or factor 10) adj5 inhib\$).tw.

18. xabans.tw.

19. (antistasin or apixaban or betrixaban or du $176 \mathrm{~b}$ or eribaxaban or fondaparinux or idraparinux or otamixaban or razaxaban or rivaroxaban or yagin or ym 150 or ym150 or LY517717 or darexaban or edoxaban or SSR126517E or fidexaban or idrabiotaparinux or letaxaban or tanogitran or taxexaban).tw,nm.

20. heparin/ or exp heparin, low-molecular-weight/ or heparinoids/

21. (heparin $\$$ or $\operatorname{lmwh} \$$ or enoxaparin $\$$ or glycosaminoglycan $\$$ or nadroparin $\$$ or mesoglycan $\$$ or tedelparin $\$$ or certoparin or tinzaparin or parnaparin or dalteparin or reviparin or fraxiparin $\$$ or danaparoid or lomoparan or org 10172 or mesoglycan or pentosan polysul\$ or sp54 or sp-54 or cy 222 or cy-222 or cy 216 or cy- 216 or dermatan sul $\$$ or heparan sul\$).tw,nm.

22. or $/ 5-21$

23. Randomized Controlled Trials as Topic/

24. random allocation/

25. Controlled Clinical Trials as Topic/

26. control groups/

27. clinical trials as topic/ or clinical trials, phase i as topic/ or clinical trials, phase ii as topic/ or clinical trials, phase iii as topic/ or clinical trials, phase iv as topic/

28. double-blind method/

29. single-blind method/

30. Placebos/

31. placebo effect/

32. Research Design/

33. randomized controlled trial.pt.

34. controlled clinical trial.pt.

35. (clinical trial or clinical trial phase i or clinical trial phase ii or clinical trial phase iii or clinical trial phase iv).pt.

36. (random $\$$ or RCT or RCTs).tw.

37. (controlled adj5 (trial\$ or stud\$)).tw.

Anticoagulants for acute ischaemic stroke (Review) 
38. (clinical\$ adj5 trial\$).tw.

39. ((control or treatment or experiment\$ or intervention) adj5 (group\$ or subject\$ or patient\$)).tw.

40. (quasi-random $\$$ or quasi random $\$$ or pseudo-random $\$$ or pseudo random\$).tw.

41. ((control or experiment $\$$ or conservative) adj5 (treatment or therapy or procedure or manage $\$)$ ).tw.

42. ((singl\$ or doubl\$ or tripl\$ or trebl\$) adj5 (blind\$ or mask\$)).tw.

43. (placebo\$ or sham).tw.

44. trial.ti.

45. (assign $\$$ or allocat $\$)$.tw.

46. controls.tw.

47. or/23-46

48. 4 and 22 and 47

49. exp animals/ not humans.sh.

50. 48 not 49

51. atrial fibrillation.ti.

52.50 not 51

\section{Appendix 3. EMBASE (Ovid)}

1. brain infarction/ or brain stem infarction/ or cerebellum infarction/ or exp brain ischemia/ or carotid artery disease/ or exp carotid artery obstruction/ or cerebral artery disease/ or exp cerebrovascular accident/ or exp occlusive cerebrovascular disease/ or stroke patient/

2. (isch?emi $\$$ adj 5 (stroke\$ or apoplex\$ or cerebral vasc\$ or cerebrovasc $\$$ or cva)).tw.

3. ((brain or cerebr $\$$ or cerebell $\$$ or vertebrobasil $\$$ or hemispher $\$$ or intracran $\$$ or intracerebral or infratentorial or supratentorial or middle cerebr $\$$ or mca $\$$ or anterior circulation or basilar artery or vertebral artery) adj5 (isch?emi $\$$ or infarct $\$$ or thrombo $\$$ or emboli $\$$ or occlus\$ or hypoxi\$)).tw.

4. 1 or 2 or 3

5. exp anticoagulant agent/

6. anticoagul\$.tw.

7. antithromb\$.tw.

8. coumarin derivative/ or 4 hydroxycoumarin/ or 4 hydroxycoumarin derivative/ or acenocoumarol/ or coumarin/ or dicoumarol/ or ethyl biscoumacetate/ or phenprocoumon/ or warfarin/ or phenindione/

9. antivitamin $\mathrm{k} /$

10. (warfarin $\$$ or coumadin $\$$ or coumarin $\$$ or cumarin $\$$ or phenprocoum $\$$ or phenprocum $\$$ or dicoumar $\$$ or dicumar $\$$ or acenocoumar $\$$ or acenocumar $\$$ or fluindione or phenindione or clorindione or diphenadione or ethyl biscoumacetate).tw.

11. (Vitamin K antagonist\$ or VKA or VKAs or antivitamin K).tw.

12. exp thrombin inhibitor/

13. ((direct\$ adj5 thrombin adj5 inhib\$) or DTI\$1).tw.

14. (argatroban or MD805 or MD-805 or dabigatran or ximelagatran or melagatran or efegatran or flovagatran or inogatran or napsagatran or bivalirudin or lepirudin or hirudin\$ or desirudin or desulfatohirudin or hirugen or hirulog or AZD0837 or bothrojaracin or odiparcil).tw.

15. blood clotting factor 10a inhibitor/

16. ((factor Xa or factor 10a or XXa or autoprothrombin c or thrombokinase) adj5 inhib\$).tw.

17. (activated adj5 (factor X or factor 10) adj5 inhib\$).tw.

18. xabans.tw.

19. (antistasin or apixaban or betrixaban or du $176 \mathrm{~b}$ or eribaxaban or fondaparinux or idraparinux or otamixaban or razaxaban or rivaroxaban or yagin or ym 150 or ym150 or LY517717 or darexaban or edoxaban or SSR126517E or fidexaban or idrabiotaparinux or letaxaban or tanogitran or taxexaban).tw.

20. heparin derivative/ or heparin/ or heparinoid/ or exp low molecular weight heparin/

21. (heparin \$ or lmwh\$ or enoxaparin \$ or glycosaminoglycan \$ or nadroparin \$ or mesoglycan\$ or tedelparin $\$$ or certoparin or tinzaparin or parnaparin or dalteparin or reviparin or fraxiparin $\$$ or danaparoid or lomoparan or org 10172 or mesoglycan or pentosan polysul\$ or sp54 or sp-54 or cy 222 or cy-222 or cy216 or cy-216 or dermatan sul\$ or heparan sul\$).tw.

22. or/5-21

23. Randomized Controlled Trial/

Anticoagulants for acute ischaemic stroke (Review)

Copyright @ 2015 The Cochrane Collaboration. Published by John Wiley \& Sons, Ltd. 
24. Randomization/

25. Controlled Study/

26. control group/

27. clinical trial/ or phase 1 clinical trial/ or phase 2 clinical trial/ or phase 3 clinical trial/ or phase 4 clinical trial/ or controlled clinical trial/

28. Double Blind Procedure/

29. Single Blind Procedure/ or triple blind procedure/

30. placebo/

31. (random\$ or RCT or RCTs).tw.

32. (controlled adj5 (trial\$ or stud\$)).tw.

33. (clinical $\$$ adj5 trial\$).tw.

34. ((control or treatment or experiment\$ or intervention) adj5 (group\$ or subject\$ or patient\$)).tw.

35. (quasi-random $\$$ or quasi random $\$$ or pseudo-random $\$$ or pseudo random $\$$ ).tw.

36. ((control or experiment $\$$ or conservative) adj5 (treatment or therapy or procedure or manage $\$)$ ).tw.

37. ( (singl\$ or doubl\$ or tripl\$ or trebl\$) adj5 (blind $\$$ or mask $\$)$ ).tw.

38. placebo\$.tw.

39. trial.ti.

40. (assign $\$$ or allocat $\$) . t w$.

41. controls.tw.

42. or/23-41

43. 4 and 22 and 42

44. (exp animals/ or exp invertebrate/ or animal experiment/ or animal model/ or animal tissue/ or animal cell/ or nonhuman/) not (human/ or normal human/ or human cell/)

45. 43 not 44

46. (atrial fibrillation or myocardial or coronary or cardiac or heart or renal or subarachnoid or arteritis or hypertens $\$$ or aortic or cancer or pregnan $\$$ or dementia or diabetes or sickle cell or aneurysm\$ or cardiopulmonary or migrain \$).ti.

47. 45 not 46

\section{Appendix 4. Ongoing trials registries search}

ClinicalTrials.gov

"stroke" AND "anticoagulants"

"stroke" AND "heparin"

Internet Stroke Center Stroke Trials Registry

"stroke" AND "anticoagulants"

"stroke" AND "heparin"

ISRCTN Registry

"stroke" AND "anticoagulants"

"stroke” AND "heparin" 


\section{F E E D B A C K}

\section{Conclusions too weak, 25 June 2007}

\section{Summary}

This review of anticoagulant trials, including over 22,000 patients with acute ischemic stroke, found no net benefit with the use of any anticoagulant. Consequently, the implications for practice and implications for research are too timid. The implication for practice should say that anticoagulants should be contraindicated in patients with acute ischemic stroke. The implications for research should say that further trials of anticoagulants in acute ischemic stroke would be unethical.

\section{Reply}

This comment was submitted before the 2008 update was performed. The wording of the Authors' conclusions section has been modified to be more in keeping with this comment.

Note: the response to this feedback was delayed by a number of unavoidable administrative factors.

\section{Contributors}

Commenter: David A Cundiff MD

Reply: Peter Sandercock

\section{WHAT'S NEW}

Last assessed as up-to-date: 10 November 2014.

\begin{tabular}{|c|c|}
\hline Date & Event \\
\hline
\end{tabular}

18 September 2014 New search has been performed

We have searched the literature for new relevant studies to June 2014. We identified one small new ongoing study, but did not identify any new studies for inclusion. We have reformatted and updated the text throughout

18 September 2014 New citation required but conclusions have not The conclusions are unchanged changed 


\section{H I S T O R Y}

Protocol first published: Issue 1, 1995

Review first published: Issue 1, 1995

\begin{tabular}{|c|c|c|}
\hline Date & Event & Description \\
\hline 9 January 2009 & Feedback has been incorporated & $\begin{array}{l}\text { Feedback on the previous version of this review had } \\
\text { not been incorporated. This omission has now been } \\
\text { rectified in this small revision to the } 2008 \text { update }\end{array}$ \\
\hline 7 November 2008 & Amended & $\begin{array}{l}\text { Duplicate text in 'Updated' event of } 11 \text { January } 2008 \\
\text { has been deleted }\end{array}$ \\
\hline 17 March 2008 & Amended & Converted to new review format. \\
\hline 11 January 2008 & $\begin{array}{l}\text { New citation required but conclusions have not } \\
\text { changed }\end{array}$ & $\begin{array}{l}\text { New co-author: Ayeesha Kamal has replaced Gordon } \\
\text { Gubitz. }\end{array}$ \\
\hline 11 January 2008 & New search has been performed & $\begin{array}{l}\text { The searches have been updated to October } 2007 \text {. Two } \\
\text { trials (ARGIS-1 2004; Chaudhary 2002), with } 201 \text { par- } \\
\text { ticipants, were included in this update, bringing the } \\
\text { total number of trials to } 24 \text { involving } 23,547 \text { partic- } \\
\text { ipants. The text has been extensively revised and up- } \\
\text { dated }\end{array}$ \\
\hline
\end{tabular}

\section{CONTRIBUTIONSOFAUTHORS}

Peter Sandercock designed the original 1993 review of anticoagulant versus control, double-checked the data and supervised the analysis and writing of this report. Edward Kane did the new literature searches and helped reformat and rewrite this update.

Ayeesha Kamal did the new literature searches, extracted the new data , performed the analysis and helped rewrite the text of the 2008 update.

Carl Counsell prepared the first version of the review and helped with the analysis and text of subsequent updates.

\section{DECLARATIONSOF INTEREST}

Dr Sandercock was the principal investigator of the International Stroke Trial and Dr Counsell was also on the Steering Committee of this trial (IST 1997). Edward Kane has no conflicts of interest to declare. 


\section{SOURCES OF SUPPORT}

\section{Internal sources}

- University of Edinburgh, UK.

\section{External sources}

- Wellcome Trust, UK.

- Medical Research Council, UK.

\section{INDEX TERMS}

\section{Medical Subject Headings (MeSH)}

Anticoagulants [adverse effects; ${ }^{*}$ therapeutic use]; Brain Ischemia [*drug therapy; prevention \& control]; Randomized Controlled Trials as Topic; Risk; Stroke [*drug therapy; prevention \& control]

\section{MeSH check words}

Humans 